Detecção de cenas em segmentos semanticamente complexos

Bruno Lorenço Lopes 

SERVIÇO DE PÓS-GRADUAÇÃO DO ICMC-USP

Data de Depósito:

Assinatura:

\title{
Detecção de cenas em segmentos semanticamente complexos
}

\author{
Bruno Lorenço Lopes
}

Orientador: Prof. Dr. Rudinei Goularte

Dissertação apresentada ao Instituto de Ciências Matemáticas e de Computação - ICMC-USP, como parte dos requisitos para obtenção do título de Mestre em Ciências - Ciências de Computação e Matemática Computacional. VERSÃO REVISADA

USP - São Carlos

Junho de 2014 
Ficha catalográfica elaborada pela Biblioteca Prof. Achille Bassi e Seção Técnica de Informática, ICMC/USP, com os dados fornecidos pelo(a) autor(a)

L864d $\begin{aligned} & \text { Lorenço Lopes, Bruno } \\ & \text { Deteç̧ão de cenas em segmentos semanticamente } \\ & \text { complexos / Bruno Lorenço Lopes; orientador Rudinei } \\ & \text { Goularte. -- São Carlos, 2014. } \\ & \text { 91 p. } \\ & \text { Dissertação (Mestrado - Programa de Pós-Graduação } \\ & \text { em Ciências de Computação e Matemática } \\ & \text { Computacional) -- Instituto de Ciências Matemáticas } \\ & \text { e de Computação, Universidade de São Paulo, 2014. } \\ & \text { 1. multimídia. 2. deteç̧ão de cenas. 3. } \\ & \text { descritores visuais. 4. descritores sonoros. 5. Bag } \\ & \text { of Visual Words. I. Goularte, Rudinei, orient. II. } \\ & \text { Título. }\end{aligned}$


Dedico esse trabalho a meus pais e à minha noiva, que sempre me apoiaram e ajudaram em todos os momentos. 



\section{Agradecimentos}

Agradeço em primeiro lugar a Deus, por ter me iluminado durante todo o desenvolvimento do trabalho, dando a paciência e a inspiração necessária para sua realização.

Agradeço também, a meu orientador, pelos infindáveis conselhos e por sua orientação sempre tão pertinente.

Agradeço aos professores das matérias realizadas no mestrado, que certamente contribuíram beneficamente para a realização dessa pesquisa.

Agradeço aos colegas e amigos do laboratório de pesquisa, que sempre me apoiaram e me deram forças nos momentos de desânimo.

Agradeço ao CNPq pelo auxílio financeiro, processo $n^{\circ}$ 134245/2011-3.

Agradeço à FAPESP pelo auxílio financeiro, processo $n^{\circ}$ 2011/05238-0, Fundação de Amparo à Pesquisa do Estado de São Paulo (FAPESP). "As opiniões, hipóteses e conclusões ou recomendações expressas neste material são de responsabilidade do(s) autor(es) e não necessariamente refletem a visão da FAPESP”. 


iversas áreas da Computação (Personalização e Adaptação de Conteúdo, Recuperação de Informação, entre outras) se beneficiam da segmentação de vídeo em unidades menores de informação. A literatura apresenta diversos métodos e técnicas cujo objetivo é identificar essas unidades. Uma limitação é que tais técnicas não tratam o problema da detecção de cenas em segmentos semanticamente complexos, definidos como trechos de vídeo que apresentam mais de um assunto ou tema, e cuja semântica latente dificilmente pode ser determinada utilizando-se somente uma única mídia. Esses segmentos são muito relevantes, pois estão presentes em diversos domínios de vídeo, tais como filmes, noticiários e mesmo comerciais.

A presente Dissertação de Mestrado propõe uma técnica de segmentação de vídeo capaz de identificar cenas em segmentos semanticamente complexos. Para isso utiliza a semântica latente alcançada com o uso de Bag of Visual Words para agrupar os segmentos de um vídeo. O agrupamento é baseado em multimodalidade, analisando-se características visuais e sonoras de cada vídeo e combinando-se os resultados por meio da estratégia fusão tardia. O presente trabalho demonstra a viabilidade técnica em reconhecer cenas em segmentos semanticamente complexos.

Palavras-chave: multimídia, detecção de cenas, descritores visuais, descritores sonoros, Bag of Visual Words 


tation, Information Retrieval, among other) benefit from video segmentation in smaller information units. The literature reports lots of techniques and methods, whose goal is to identify these units. One of these techniques' limitations is that they don't handle scene detection in semantically complex segments, which are defined as video snippets that present more than one subject or theme, whose latent semantics can hardly be determined using only one media. Those segments are very relevant, since they are present in multiple video domains as movies, news and even television commercials.

This Master's dissertation proposes a video scene segmentation technique able to detect scenes in semantically complex segments. In order to achieve this goal it uses latent semantics extracted by the Bag of Visual Words to group a video segments. This grouping process is based on multimodality, through the visual and aural features analysis, and their results combination using late fusion strategy. This works demonstrates technical feasibility in recognizing scenes in semantically complex segments.

Keywords: multimedia, scene detection, visual descriptors, audio descriptors, Bag of Visual Words 

Resumo

$\begin{array}{lll}\text { Abstract } & \text { iii }\end{array}$

Sumário $\quad$ v

$\begin{array}{ll}\text { Lista de Figuras } & \text { vii }\end{array}$

$\begin{array}{ll}\text { Lista de Tabelas } & \text { ix }\end{array}$

Lista de Siglas $\quad$ xi

1 Introdução 1

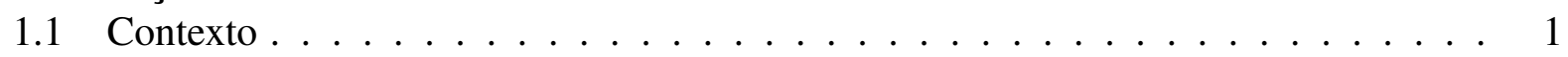

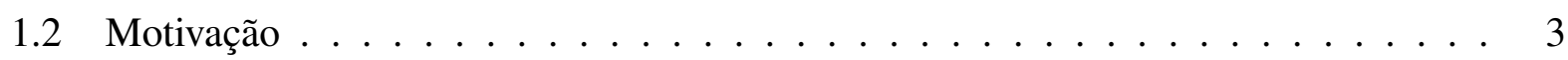

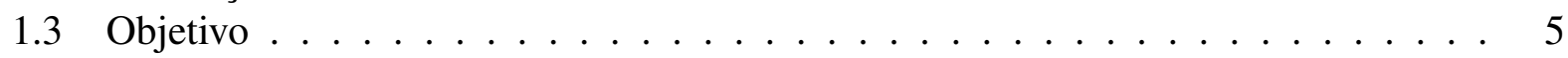

1.4 Organização do Texto . . . . . . . . . . . . . . . . . . . 5

2 Revisão Bibliográfica $\quad 7$

2.1 Estrutura de Vídeo . . . . . . . . . . . . . . . . . . . . . . . . . . 8

2.2 Segmentação de Vídeo em Cenas . . . . . . . . . . . . . . . . . . . . . . . . 10

2.3 Descritores de Características . . . . . . . . . . . . . . . . . . . . 17

2.3.3 Definição de Descritores de Características . . . . . . . . . . . . . . . 17

2.3.3 Extratores e Descritores de Características Visuais . . . . . . . . . . . 18

2.3.3 Extratores e Descritores de Características Sonoras . . . . . . . . . . . . 21

2.4 Bag of Visual Words . . . . . . . . . . . . . . . . . . . . . . 23

2.5 Multimodalidade . . . . . . . . . . . . . . . . 26

2.5.5 Definições e Conceitos de Multimodalidade . . . . . . . . . . . . . . 26

2.5.5 Fusão de Características . . . . . . . . . . . . . . . . . 27

2.5.5.5 Fusão Prévia . . . . . . . . . . . . . . . . . 28

2.5.5.5 Fusão Tardia . . . . . . . . . . . . . . . . . . 28

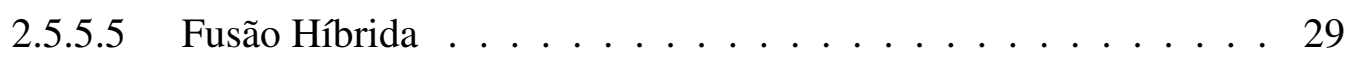

2.6 Avaliação . . . . . . . . . . . . . . . . . . . . 30

2.6.6 Medidas de Avaliação . . . . . . . . . . . . . . . . . . . 30

2.6.6 Medidas de Similaridade . . . . . . . . . . . . . . . . . 32

2.7 Considerações Finais . . . . . . . . . . . . . . . . . . 33 
3 Segmentação em Cenas Baseada em Bag of Visual Words Multimodal 35

3.1 Segmentação em Cenas com Descritores Visuais . . . . . . . . . . . . . . . . 35

3.1 Detecção de Quadros-Chave . . . . . . . . . . . . . . . . . . . . . . . . . 36

3.1 .1 Detecção de Cortes de Cenas . . . . . . . . . . . . . . . . . . . . 39

3.2 Segmentação em Cenas com Descritores Sonoros . . . . . . . . . . . . . . . . 43

3.2.2 Ajustes para os Descritores de Áudio . . . . . . . . . . . . . . . . . . . . 44

3.2.2 Técnica de Detecção de Cenas Adaptada para Descritores de Áudio . . . . 45

3.3 Técnica de Segmentação em Cenas com Fusão Tardia . . . . . . . . . . . . . . . 46

4 Experimentos e Resultados 49

4.1 Formação das Bases de Segmentação em Tomadas e Cenas . . . . . . . . . . . . . 49

4.2 Configurações do Ambiente de Testes . . . . . . . . . . . . . . . . . . . 51

4.3 Definição dos Descritor Visual e da Distância . . . . . . . . . . . . . . . . . 52

4.4 Análise Visual . . . . . . . . . . . . . . . . . . . . . . . 54

4.5 Definição do Descritor de Áudio . . . . . . . . . . . . . . . . . . . . . 56

4.6 Análise da Técnica Multimodal Desenvolvida . . . . . . . . . . . . . . . 58

4.7 Comparação da Técnica Multimodal com Técnicas da Literatura . . . . . . . . . . 61

5 Conclusões $\quad \mathbf{6 5}$

5.1 Resultados . . . . . . . . . . . . . . . . . . . 66

5.2 Dificuldades Encontradas . . . . . . . . . . . . . . . . . . 67

5.3 Trabalhos Futuros . . . . . . . . . . . . . . . . . . 67

$\begin{array}{lr}\text { Referências } & 69\end{array}$ 


\section{Lista de Figuras}

2.1 Unidades de informação que compõem um vídeo. Baseado em: (Ngo et al., 2001) . 8

2.2 Cenas do filme De Volta para o Futuro com mudança de assunto sem alterações visuais. . . . . . . . . . . . . . . . . . . 15

2.3 Cena do filme Piratas do Caribe sem mudança de assunto e com alterações visuais. 16

2.4 Etapas para o cálculo dos MFCCs. . . . . . . . . . . . . . . . 23

2.5 Passos da técnica Bag of Visual Words. . . . . . . . . . . . . . . . . . . 25

2.6 Estratégia de fusão prévia. . . . . . . . . . . . . . . . . . . . . . 29

2.7 Estratégia de fusão tardia. . . . . . . . . . . . . . . . . . . . . . . . . . 29

2.8 Estratégia de fusão híbrida. . . . . . . . . . . . . . . . . . 30

3.1 Método para detecção de quadros-chave de uma tomada. . . . . . . . . . . . . . . 37

3.2 Extração de vetores de características visuais dos quadros-chave de uma tomada. . 40

3.3 Geração do vocabulário de palavras visuais. . . . . . . . . . . . . . . . . . . . 40

3.4 Quadros-chave de tomadas de cena do filme 60 Segundos. . . . . . . . . . . . . . 42

3.5 Grau de influência das tomadas vizinhas em uma determinada tomada. . . . . . . . . 42

3.6 Variação da distância entre tomadas subsequentes e determinação de cortes de cenas. 43

3.7 Quadros-chaves de tomadas de cena do filme Uma Mente Brilhante. . . . . . . . . 44

3.8 Aplicação de descritores sonoros sobre subconjuntos de amostras de áudio. . . . . 45

3.9 Variação da distância entre tomadas subsequentes e determinação de cortes de cenas. 46

3.10 Segmento semanticamente complexo no filme Uma Mente Brilhante. . . . . . . . . 48

4.1 Cena do filme A Era do Gelo segmentada incorretamente pela técnica TV3. . . . . 57

4.2 Cenas do filme Uma Mente Brilhante detectadas corretamente pela parte sonora. . . 60 



\section{Lista de Tabelas}

4.1 Filmes que compõem a BFSSC, com sua duração, número de tomadas e cenas. . 50

4.2 Resultados da técnica visual com descritores SIFT e SURF, e Distância Euclideana. 52

4.3 Resultados da técnica visual com descritores SIFT e SURF, e Distância $\chi^{2}$. . . . . 53

4.4 Resultados da técnica visual com descritores SIFT e SURF, e Intersecção de His-

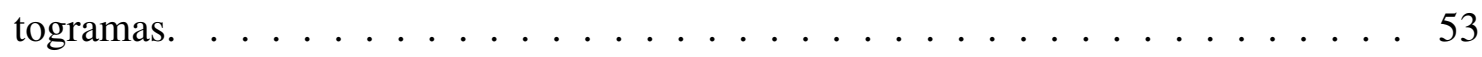

4.5 Resultados das técnicas de vídeo aplicadas aos filmes "Uma Mente Brilhante", "60 Segundos" e "Era do Gelo". . . . . . . . . . . . . . . . . . . . . . . . 55

4.6 $F_{1}$ das técnicas de vídeo em seus respectivos trabalhos e aplicadas na BFSSC. . . . 55

4.7 Resultados da técnica sonora com descritores LPCC e MFCC, e Distância Euclideana. . . . . . . . . . . . . . . . . . . 58

4.8 Resultados das técnicas de áudio, vídeo e multimodal aplicadas aos vídeos da BFSSC . . . . . . . . . . . . . . . . . . . . 59

4.9 Variação da técnica multimodal em relação as partes sonora e visual nos filmes da BFSSC, para as medidas precisão, abrangência e $F_{1}$. . . . . . . . . . . . 62

4.10 Comparação de técnicas multimodais. . . . . . . . . . . . . . 62 

BoVW - Bag of Visual Words

BSC - Backward Shot Coherence

BFSSC - Base de Filmes com Segmentos Semanticamente Complexos

CSV - Comma-Separated Values

HSV - Hue, Saturation, and Value

LPC - Linear Prediction Coefficients

LPCC - Linear Prediction Cepstral Coefficients

MFCC - Mel-Frequency Cepstrum Coefficients

MPEG - Moving Picture Experts Group

MSER - Maximally Stable Extremal Regions

RGB - Red, Green and Blue

SIFT - Scale Invariant Feature Transform

SOM - Self-Organising Map

SURF - Speeded Up Robust Features

SVM - Support Vector Machines

WAVE - WAVEform Audio File Format

ZCR - Zero Crossing Rate 


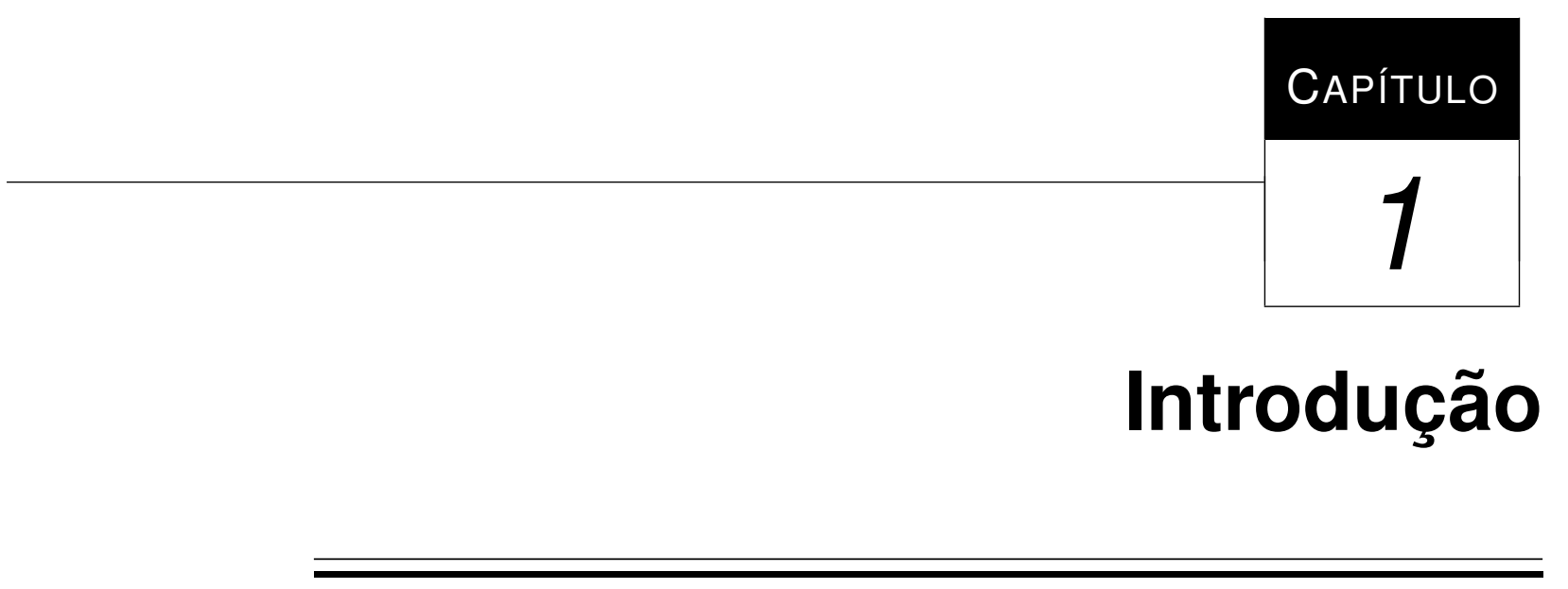

Este capítulo visa contextualizar a importância da segmentação em cenas e discutir os problemas existentes na realização dessa tarefa em segmentos semanticamente complexos. Além disso, pretende-se apresentar as motivações e os objetivos do presente trabalho, enfatizando sua importância e suas contribuições. Esse capítulo encontra-se assim organizado: A seção 1.1 apresenta o conceito de segmentação de vídeo, e como ele se relaciona com as demais áreas do conhecimento. A seção 1.2 apresenta de modo sucinto o estado da arte da área, indicando algumas lacunas que motivaram a realização do presente trabalho. Já a seção 1.3 define o objetivo do presente trabalho. Por fim, a seção 1.4 apresenta a estrutura do texto.

\subsection{Contexto}

A popularização de dispositivos capazes de capturar imagens digitalmente, tais como câmeras fotográficas, smartphones e webcams propiciam um aumento significativo na geração de conteúdos digitais. Sites como Youtube ${ }^{1}$ e Flickr ${ }^{2}$, entre outros, voltados para a distribuição de conteúdo digital (vídeos, imagens, áudio, e outros tipos) ganharam notoriedade devido ao fato do conteúdo gerado e disponibilizado poder ser acessado no momento desejado pelo usuário, bem como pela capacidade deste escolher qual conteúdo deseja acessar. Esses fatos ajudam a explicar a grande variedade e disponibilidade de conteúdo digital existente atualmente.

Com esse aumento expressivo no volume de dados, o usuário passou a encontrar maior dificuldade em localizar itens relevantes e de seu interesse, em meio à todo esse conteúdo gerado. Esse

\footnotetext{
${ }^{1}$ http://wwww.youtube.com

${ }^{2}$ http://wwww.flickr.com
} 
problema, denominado sobrecarga de informação (Toffler, 1970), associado à busca constante por interatividade em aplicações multimídia e à recente diversidade de dispositivos e meios de acesso a conteúdo (como PCs, celulares, televisão, etc.) tem estimulado pesquisas recentes (Anand et al., 2013; Kabary et al., 2013; Schabetsberger e Schedl, 2013) por alternativas que visam possibilitar ao usuário acesso transparente (ou seja, independente do dispositivo que este utiliza) e facilitado ao conteúdo multimídia.

Este problema está presente em uma das linhas de pesquisa do grupo Sistema Web e Multimídia Interativos, do ICMC-USP, mais precisamente na área denominada Personalização e Adaptação de Conteúdo (P\&A). A adaptação tem como objetivo disponibilizar meios de acessar conteúdo multimídia a partir de diferentes condições de dispositivos, rede e ambiente computacional enquanto a personalização, tida como um caso particular da adaptação, estuda meios de customizar e/ou filtrar os dados segundo as preferências, interesses e necessidades de um usuário específico (Magalhães e Pereira, 2004).

A personalização, que nos últimos anos tem sido o enfoque dos pesquisadores, por sua vez, envolve diferentes serviços que podem ser categorizados em seleção de conteúdo, sistemas de recomendação e sistemas de sumarização (Adomavicius e Tuzhilin, 2005; Chasanis et al., 2008; Albanese et al., 2013). A seleção de conteúdo engloba os serviços que oferecem busca de itens multimídia a partir de critérios interativamente definidos pelos usuários. Na recomendação, itens de interesse são automaticamente oferecidos ao usuário a partir de um perfil de preferências ou do histórico de acesso a conteúdo do mesmo. Já a sumarização busca produzir uma versão do conteúdo reduzida e semanticamente significativa para o usuário, como por exemplo, um noticiário contendo apenas notícias sobre educação (Adomavicius e Tuzhilin, 2005).

É importante perceber que esses três diferentes sistemas de personalização, cada um a sua maneira, visam simplificar a identificação de conteúdo relevante para o usuário, e por isso, apresentam uma necessidade em comum: o conhecimento dos dados presentes no conteúdo. Essa informação pode ser expressa em metadados, ou seja, informações presentes no conteúdo que descrevem o próprio conteúdo. Os metadados podem ser de baixo nível semântico, descrevendo características da mídia em si (histogramas de cor, tipo de compressão, formato de arquivo, etc.), ou de alto nível semântico, descrevendo características conceituais sobre o conteúdo (presença e/ou identificação de pessoas, localidade, assunto, etc.) (Snoek et al., 2005). Existem técnicas automáticas bem conhecidas (Lam e Lee, 1998; Ishtiaq et al., 2009) para extrair metadados de baixo nível semântico diretamente do conteúdo.

Já no caso dos metadados de alto nível semântico, muitas das técnicas disponíveis envolvem o auxílio de especialistas para interpretar e descrever características conceituais. Isso ocorre devido a um problema bem conhecido da área, a lacuna semântica, caracterizado pelo pouco relacionamento entre os metadados obtidos diretamente do conteúdo e a interpretação do usuário para esse mesmo conteúdo (Smeulders et al., 2000).

Informações semânticas têm potencial para promover uma melhoria nos serviços de personalização, uma vez que podem formar um elo entre a representação computacional de um conteúdo e 
a interpretação dos dados por um determinado usuário, diminuindo, por sua vez, a lacuna semântica (Smeulders et al., 2000). Devido a esse fato, esforços relatados na literatura (Xu et al., 2009; Hauptmann et al., 2007) têm sido feitos no sentido de desenvolver meios de extrair informações semânticas do conteúdo do modo automático.

No contexto de vídeos digitais, a extração automática dessas informações é importante, dado que o crescimento acelerado das bases de vídeo acelerou também a necessidade de modos mais eficientes de classificar, indexar e recuperar esses vídeos. Deve-se notar que a execução manual dessas tarefas em grandes bases de vídeo pode se tornar impraticável devido à necessidade de um grande número de especialistas, além, é claro, do tempo extenso necessário para a realização dessa atividade. Não obstante, outro problema que surge na realização manual dessas tarefas é a subjetividade, já que especialistas diferentes podem descrever um mesmo item de modos diferentes. Uma etapa importante, que normalmente antecede a extração de informações de vídeos, é a sua segmentação, cujo objetivo é identificar unidades menores de informação, computacionalmente mais fáceis de tratar: quadros, tomadas e cenas.

\subsection{Motivação}

A segmentação de vídeo pode ser realizada em três níveis (seção 2.2): quadros, tomadas e cenas. A segmentação em quadros é um problema bem conhecido e de fácil solução. A segmentação em tomadas apresenta várias soluções na literatura: histogramas (Lam e Lee, 1998), transformadas (Ishtiaq et al., 2009) e multimodalidade (Liu e He, 2009; Coimbra, 2011). O estado da arte para esse problema apresenta soluções com precisões elevadas (Sidiropoulos et al., 2011). A segmentação em tomadas, no entanto, pode gerar um alto número de fragmentos, o que pode dificultar a navegação pelo conteúdo, além de muitas vezes a descrição em nível de tomadas não ser significativa para a percepção de um evento (Mohanta e Saha, 2009).

Outro problema é que muitas técnicas e métodos propostos são específicas para determinados domínios, o que dificulta ou mesmo impossibilita sua aplicação em outros domínios. Por isso, a segmentação em unidades semanticamente compreensíveis aos humanos é interessante, e leva à segmentação em cenas. Diferente das segmentações em quadros e em tomadas, a segmentação em cenas ainda é um problema pouco investigado e desafiador devido ao fato de cena ser um conceito semanticamente mais rico, além de outros fatores, tais como (Wang et al., 2006): a dependência da definição adotada para cena; a não-sincronização entre áudio e vídeo; a subjetividade na definição do conceito de cena; carência de bases para testes (Hu et al., 2011; Money e Agius, 2008).

Trabalhos recentes usam diversas mídias visando extrair o máximo possível de dados do fluxo de vídeo que possam servir de subsídios para a geração de informação semântica. No caso de segmentação de cenas de filmes, gênero adotado neste trabalho, a literatura reporta trabalhos que exploram: a) informações visuais (Liu et al., 2013; Tapu e Zaharia, 2012); b) análise do áudio associado que indique mudança de assunto/locutor (Rao et al., 2014); c) utilização de legendas 
(Scaiano et al., 2010); d) combinação de mídias como vídeo e áudio (Chen et al., 2012), áudio e texto (Tsiartas et al., 2011) e vídeo e texto (Cour et al., 2008). Tais trabalhos provam que cada uma das mídias pode fornecer informações para a segmentação em cenas, e que a abordagem multimodal, que utiliza mais de uma mídia do vídeo, obtém melhores resultados do que abordagens que utilizam dados provenientes de uma única mídia. Por outro lado, um fator importante é o conceito de cena utilizado. Os trabalhos relacionados, utilizam a seguinte definição para cena: "um conjunto de tomadas subsequentes semanticamente relacionadas" (Rui et al., 1999; Lehane e Murphy, 2001; Zhai e Shah, 2006). A subjetividade presente na "relação semântica" que se busca estabelecer leva a diferentes interpretações, culminando no fato de que tais trabalhos não apresentam soluções para segmentar cenas em segmentos de vídeos, aqui denominados, semanticamente complexos. Esses segmentos podem ser definidos como trechos de vídeo que apresentam um ou mais assuntos ou temas, e cuja semântica latente dificilmente pode ser determinada utilizando-se somente uma única mídia. Um exemplo é um trecho de vídeo que apresente uma perseguição em um filme. As tomadas presentes nesse trecho podem ser visualmente bem diferentes, no entanto, todas apresentam o mesmo tema, que é a perseguição. Compondo, portanto, uma única cena. Outro exemplo é uma conversa entre dois personagens em um mesmo ambiente. Apesar das tomadas poderem ser muito semelhantes visualmente, o assunto tratado pelos personagens pode variar, o que caracteriza uma mudança de cena nesse segmento. Esse entendimento de cena está mais próximo do usuário, que tende a mentalmente organizar as informações por assuntos ou eventos (Yeung e Yeo, 1997; Hanjalic et al., 1999b; Durak, 2004; Chen et al., 2008).

Dentre as técnicas automáticas atuais de segmentação de vídeo em cenas, destacam-se àquelas que fazem uso de características visuais (Mohanta et al., 2010; Liu et al., 2013; Trojahn e Goularte, 2013). Isso ocorre pois a parte visual é capaz de capturar boa parte da semântica latente. De modo especial, entre as técnicas visuais, recentemente tem havido um crescente interesse na utilização de descritores locais de características (Huang e Chen, 2009; Liang et al., 2009; Kumar et al., 2011). Esses descritores possuem alto poder discriminativo, sendo adequados para identificar a ocorrência de um objeto (como o âncora em um segmento). No entanto, não resolvem o problema dos segmentos semanticamente complexos (Lopes e Goularte, 2013), uma vez que os descritores locais não possuem o poder de generalização necessário para diferenciar categorias com diferentes semânticas (Valle e Cord, 2009). Situação semelhante (discriminação x generalização) vem sendo enfrentada na área de Recuperação de Informação Baseada em Conteúdo (Content-Based Information Retrieval - CBIR) com o uso de técnicas Bag of Visual Words, obtendo bons resultados em categorização semântica latente de imagens (Sivic e Zisserman, 2006; Batista et al., 2009; Lazebnik et al., 2006; Ionescu et al., 2013). Essa técnica consiste em extrair descritores visuais das imagens, para a formação de um vocabulário, que é utilizado para determinar imagens semanticamente relacionadas, de modo latente. A semântica é dita latente, pois se busca descobrir a relação entre as imagens, ao invés de buscar o significado individual de cada imagem. Sendo assim, a semântica latente emerge do relacionamento entre as imagens da base. 
Porém, a aplicação direta de Bag of Visual Words na detecção de cenas em segmentos semanticamente complexos não é suficiente porque, uma vez que a técnica trata apenas da mídia visual, a mesma não seria capaz de reconhecer segmentos vizinhos visualmente diferentes, que tratam do mesmo assunto, como pertencentes à mesma cena (Lopes e Goularte, 2013). De modo análogo, duas tomadas visualmente semelhantes, mas que, contudo, apresentem assuntos ou temas distintos, seriam agrupadas erroneamente em uma única cena, ao invés de serem divididas em duas cenas.

Assim, a possível solução aqui proposta, até onde se sabe, ainda não reportada na literatura, é expandir a técnica Bag of Visual Words para trabalhar com multimodalidade. A multimodalidade consiste na utilização de dois ou mais modos presentes no vídeo em conjunto para a realização de uma determinada tarefa, no caso a segmentação do vídeo em cenas. Com o uso de multimodalidade, é possível aproveitar características latentes vindas de outras mídias presentes no filme (como áudio, legendas, closed caption, etc.).

Como resultado foi possível segmentar cenas de um modo mais próximo da perspectiva do usuário, onde as transições ocorrem de acordo com a mudança do assunto em vez de ocorrerem somente devido a mudanças na mídia analisada, como no exemplo da aparição do âncora. Isso implica que a técnica desenvolvida foi capaz de detectar corretamente cenas em segmentos semanticamente complexos. Assim, espera-se também poder contribuir com a área de P\&A, aplicando os resultados da segmentação obtida com a técnica proposta para facilitar a execução de serviços de seleção de conteúdo e de recomendação, bem como com outras áreas que possam fazer uso de cenas.

\subsection{Objetivo}

O objetivo deste trabalho é desenvolver uma técnica multimodal, capaz de segmentar vídeos em cenas agrupando tomadas semanticamente relacionadas. A relação semântica é obtida de modo latente por meio de dicionários de palavras visuais (Bag of Visual Words) e sonoras (Bag of Audio Words).

Esse objetivo possui contribuições em dois aspectos principais: primeiro por abordar o problema dos segmentos semanticamente complexos, ignorado pelas técnicas existentes; segundo, por utilizar multimodalidade como um modo de capturar a semântica latente presente nas tomadas, facilitando o seu agrupamento em cenas.

\subsection{Organização do Texto}

Os próximos capítulos desta dissertação estão assim organizados:

- O Capítulo 2 apresenta os conceitos necessários para a compreensão deste trabalho, tais como descritores de características, medidas de avaliação e de dissimilaridade. A técnica 
Bag of Visual Words e suas características são discutidas, por serem a base do presente trabalho. Também é feita uma síntese da literatura, apresentando a evolução das técnicas de segmentação de vídeo em cenas;

- O Capítulo 3 descreve em detalhes a técnica multimodal proposta;

- O Capítulo 4 apresenta os experimentos realizados e seus respectivos resultados, além de detalhes sobre a formação da base de vídeo utilizada neste trabalho;

- O Capítulo 5 discute os avanços promovidos pela técnica proposta. Também são abordadas as limitações da técnica, assim como possíveis trabalhos futuros. 


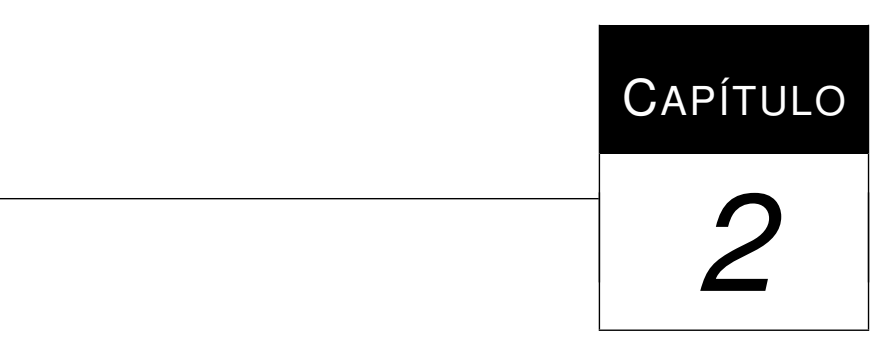

Revisão Bibliográfica

Este capítulo visa apresentar o estado da arte em de Segmentação de Vídeo, área na qual está inserido o presente trabalho bem como demonstrar alguns conceitos fundamentais para a compreensão do mesmo. A organização deste capítulo encontra-se estruturada desse modo:

A composição de um vídeo é discutida na seção 2.1 , sendo que a definição e importância de cada segmento constituinte do vídeo é apresentada. Trabalhos que refletem o estado da arte na área de Segmentação de Vídeos em Cenas são discutidos na seção 2.2. Nessa seção são apresentadas as lacunas existentes nos métodos e técnicas propostos. A seção 2.3 aborda o conceito de descritores de características, e apresenta sua definição. A seção 2.3.3 apresenta os descritores visuais globais e locais, de modo especial, os descritores SIFT (Scale-Invariant Feature Transform)(Lowe, 1999, 2004) e SURF (Speeded Up Robust Features)(Bay et al., 2006, 2008). Já na seção 2.3.3 são apresentados os descritores sonoros, em específico, os descritores MFCC e LPCC.

A seção 2.4 revisa a técnica Bag of Visual Words, que é o conceito fundamental desse trabalho, sendo discutidos os passos necessários para sua execução, e sua relação com os demais conceitos presentes nessa revisão.

A seção 2.5 trata da multimodalidade, que é a combinação de diferentes modos. Na seção 2.5.5 é apresentado o conceito de multimodalidade, explorado pela técnica desenvolvida. A seção 2.5.5 aborda as estratégias de fusão de características: fusão prévia, (seção 2.5.5.5), fusão tardia (seção 2.5.5.5) e fusão híbrida (seção 2.5.5.5).

Para a mensurar a eficiência da técnica proposta, algumas medidas de avaliação serão utilizadas, e são discutidas na seção 2.6. Além disso, elas permitem a comparação da técnica proposta com outros trabalhos presentes na literatura. Também são apresentadas na seção 2.6 algumas medidas de dissimilaridade, as quais são utilizadas pela técnica Bag of Visual Words para a formação 
do dicionário visual e da geração dos histogramas, serão apresentadas, possibilitando seu uso no método proposto.

As considerações finais (seção 2.7) apresentam uma síntese dos assuntos discutidos, bem como uma análise crítica sobre os principais temas.

\subsection{Estrutura de Vídeo}

Como dito anteriormente, a segmentação de vídeos em unidades menores de informação facilita a extração de informações presentes em um vídeo. Sendo assim, é importante conhecer a estrutura de um vídeo, a qual é exibida na Figura 2.1.

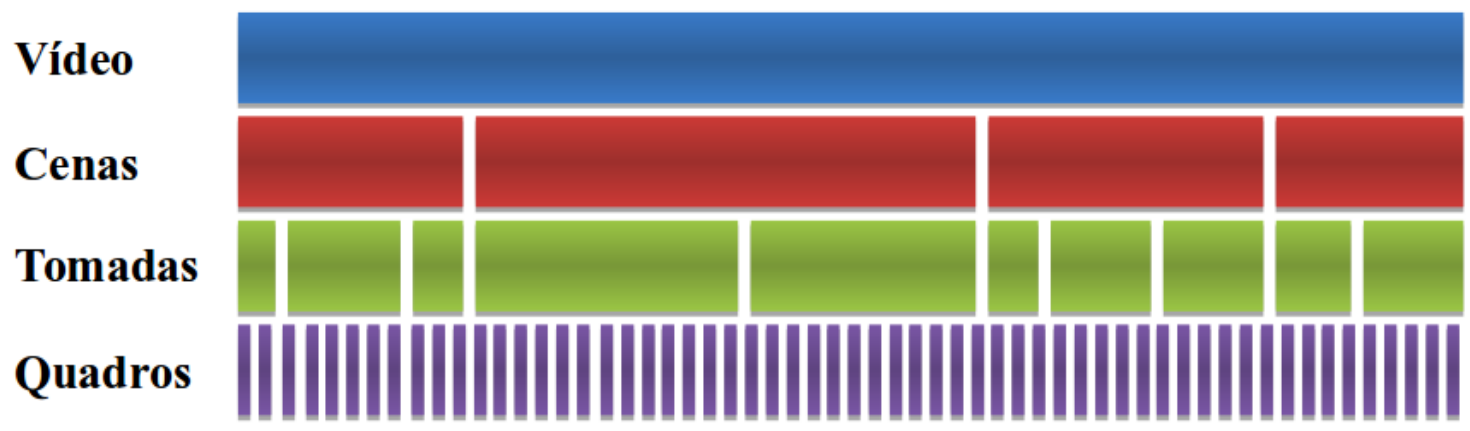

Figura 2.1: Unidades de informação que compõem um vídeo. Baseado em: (Ngo et al., 2001)

Na Figura 2.1 são apresentadas três camadas que constituem um determinado vídeo (Ngo et al., 2001). A camada com maior nível semântico, e portanto mais significativa para o usuário é a cena. Este é o tema central desse trabalho. A cena é definida de maneiras distintas na literatura, por ser um conceito subjetivo. Velivelli et al. (2003). Velivelli et al. (2003), por exemplo, definem a cena como uma coleção de tomadas que são temporalmente unificadas ou que ocorrem em uma mesma localidade. No entanto, segundo Choi e Lee (2010), a definição correntemente aceita para cena é: um conjunto de tomadas que retrata uma única ideia, tema ou conceito, sem limitações de tempo ou espaço. Ou seja, uma cena é definida como um conjunto de tomadas semanticamente relacionadas, que apresentam um mesmo tema ou assunto.

Segundo Chianese et al. (2008), a tomada é definida como uma série de quadros consecutivos obtidos continuamente por uma única câmera e que representam uma ação contínua no tempo e espaço. Os quadros, por sua vez, são todas as imagens que compõem o vídeo. Quando exibidas em uma determinada frequencia transmitem a sensação de movimento do vídeo. Essa camada apresenta baixo nível semântico

Além dessas camadas, pode-se dividir o vídeo em segmentos. Segmentos são conjuntos com um número arbitrário de quadros do vídeo (Dang et al., 2012). Neste trabalho, apresentamos a definição de segmentos denominados semanticamente complexos. Esses segmentos são trechos de 
vídeo que apresentam mais de um assunto ou tema, e cuja semântica latente dificilmente pode ser determinada utilizando-se somente uma única mídia. Esses segmentos são de grande importância pois ocorrem em diversos domínios de vídeo, como filmes, programas de entrevista e telejornais.

O reconhecimento de segmentos semanticamente complexos é um tema que não tem sido abordado na literatura. Um dos motivos para isso é a dificuldade natural de estabelecer a relação semântica entre as tomadas nesses caso. Além disso, muitas técnicas utilizam somente uma mídia, o que torna a tarefa de identificar esses segmentos ainda mais difícil. No entanto, o determinação correta desses segmentos permite a definição de cenas mais próximas do entendimento do usuário, cujo corte entre elas é determinado pela mudança na semântica entre elas.

Como o vídeo é composto de outras mídias, pode-se definir uma camada composta por amostras de áudio. Assim como os quadros do vídeo, essa camada apresenta baixo nível semântico.

Segundo Sundaram e Chang (2000), a segmentação do vídeo em unidades menores de informação, tais como as camadas apresentadas nessa Seção, permite a navegação não-linear por um vídeo e é considerada o primeiro passo para o entendimento semântico de um vídeo inteiro, pois permite a aplicação de técnicas de extração de características, e a combinação dos resultados na expectativa de obter informação semântica (Chaisorn et al., 2003; Chen e Li, 2010; Ogawa et al., 2008; Liu et al., 2009; Yu et al., 2007; Wang et al., 2008).

A divisão de vídeos em segmentos de quadros visualmente semelhantes é importante, pois se pode considerar o problema de segmentação de vídeo em um problema de dissimilaridade entre imagens, no caso em específico, entre os quadros, ou seja, visa segmentar o vídeo em conjuntos de quadros semelhantes visualmente. Esses segmentos não são necessariamente tomadas, porém podem ser utilizados para encontrá-las. A identificação de quadros semelhantes exige a definição de uma medida de dissimilaridade, a qual será utilizada para a comparação entre um par de quadros subseqüentes. Um corte ocorre quando a diferença entre o par de imagens for maior que um limiar definido arbitrariamente, o que causa dependência dos resultados em relação à escolha desse limiar (Guimarães et al., 2001).

Outra possibilidade é a transformação de um vídeo em uma imagem $2 \mathrm{D}$, chamada ritmo visual. Uma vez obtido o ritmo visual, é possível aplicar a extração de padrões relacionados às transições. Desse modo, o problema é transformado em um problema de segmentação de imagem (Guimarães et al., 2001). Essa abordagem é utilizada, por exemplo, em Chung (1999) e Ngo et al. (1999).

A segmentação em tomadas, por sua vez, visa detectar tomadas, conforme o conceito mencionado anteriormente, e portanto, está diretamente relacionada ao modo como um vídeo é produzido (Mittalkod e Srinivasan, 2011), sendo considerada a tarefa mais básica de segmentação temporal de vídeo.

É importante observar, que, diferentemente da segmentação em quadros semelhantes visualmente, na qual somente a similaridade visual entre os quadros é importante, a segmentação em tomadas deve ser capaz de detectar um conjunto de quadros captados continuamente por uma única câmera, independente da similaridade visual entre eles. Com isso, a segmentação em toma- 
das deve lidar com situações como a diferença na transição entre as tomadas, que pode ser abrupta ou gradual. No primeiro caso, o conteúdo de dois quadros consecutivos apresenta uma mudança súbita, devido ao desligamento ou reinício da câmera. Já na transições graduais, a mudança se estende por vários quadros, e pode ser de três categorias distintas: dissolução, Fade In e Fade Out e Wipes.

$\mathrm{Na}$ dissolução, a imagem da próxima tomada vai sendo sobreposta a da tomada atual gradativamente, durante vários quadros, até sobrepor totalmente a imagem atual (Kundu e Mondal, 2012). Transições Fade In e Fade Out ocorrem quando uma imagem escura vai sendo clareada até desaparecer, ou o oposto. Pode ser vista como um caso especial da dissolução, pois ocorre uma sobreposição de quadros escuros a claros, ou vice-versa. Wipes ocorrem quando uma imagem sofre algum tipo de movimentação, sendo por exemplo "empurrada" ou "dobrada", sendo substituída por outra. Segundo Fabro e Böszörmenyi (2013), esse é um problema já resolvido, uma vez que diversas técnicas propostas apresentam resultados expressivos quanto a sua precisão nessa tarefa (Truong e Venkatesh, 2007).

Entre as abordagens encontradas na literatura para realizar a segmentação vídeo em tomadas, encontram-se a utilização de características (Thakar e Hadia, 2013; Baber et al., 2011), diferenças entre quadros (Chiu et al., 2008) e busca binária adaptativa (Jiang et al., 2012).

Entretanto, a segmentação em tomadas pode não ser significativa para a percepção de um evento (Mohanta e Saha, 2009). Isso ocorre pois um observador humano tende a lembrar de diversos eventos após assistir um filme (Yeung e Yeo, 1997; Hanjalic et al., 1999b; Chen et al., 2008; Durak, 2004), e normalmente os eventos são representados por meio de cenas (Chen et al., 2008).

A detecção de tomadas é um passo importante para a segmentação de cenas. Isso ocorre, pois em geral, as mudanças de cena ocorrem em uma mudança de tomada (Mittalkod e Srinivasan, 2011), e também porque uma cena pode ser considerada é um conjunto de tomadas semanticamente relacionadas. Além disso, segundo Kim et al. (2003), o desempenho das técnicas de segmentação em tomadas invariavelmente afetam as tarefas subsequentes, como por exemplo a segmentação em cenas.

Como foi visto, a segmentação em cenas é muito importante por ser um conceito mais próximo do entendimento do usuário. Sendo assim, esse assunto será tratado no próxima seção.

\subsection{Segmentação de Vídeo em Cenas}

O problema da detecção automática de cenas em vídeo é bem mais complexo do que o problema de detecção automática de tomadas, uma vez que uma cena exprime uma relação semântica entre os quadros que a compõe, acrescentando subjetividade à tarefa. Além disso, por ser um conceito mais próximo dos usuários, em relação à tomada, uma cena apresenta maior relevância para a indexação, recuperação e personalização de conteúdo. A detecção de cenas é uma área relativa- 
mente nova, que tem sido muito pesquisada devido à sua relevância. A seguir serão apresentadas algumas técnicas que visam segmentar vídeos em cenas.

As primeiras técnicas que serão apresentadas fazem uso somente da parte visual do vídeo para realizar a segmentação do vídeo. Segundo Fabro e Böszörmenyi (2013), técnicas que dependem somente de características visuais normalmente são específicas para um determinado domínio ou propósito, podendo alcançar altas taxas de precisão. No entanto, devido ao problema da lacuna semântica, ou seja, devido à falta de correspondência entre as características visuais de baixo nível com a semântica compreendida pelo usuário, essas técnicas tendem a apresentar baixas no seu desempenho quando aplicadas a outras bases ou domínios.

Yeung et al. (1998) propuseram a representação gráfica de um vídeo através de um grafo de transição de cena (do inglês, Scene Transition Graph). Nesse modelo, cada nó do grafo é a representação de uma tomada, e as arestas são as transições entre as cenas. Utilizando uma restrição de similaridade, esse grafo é dividido em subgrafos, cada qual representando uma cena. Hanjalic et al. (1999a) utiliza uma abordagem semelhante, para vídeos MPEG, identificando story units. O trabalho considerou o domínio de filmes.

Rasheed e Shah (2003) propõem um método de detecção em cenas em vídeos codificados em MPEG-1, que consiste em inicialmente segmentar um vídeo em tomadas, considerando os cortes de câmera. Cada tomada é então representada por um ou mais quadros-chave, de acordo com a quantidade de atividade presente nela. Também é verificado seu comprimento (quantidade de quadros) e são identificados conteúdos que se movem. Uma medida de similaridade chamada Backward Shot Coherence (BSC) é calculada para identificar tomadas que são candidatas a fazerem parte de uma mesma cena. Por fim, a duração e o conteúdo de cada cena são comparados, e se houver cenas onde eles sejam razoavelmente parecidos, essas cenas são agrupadas, dando origem a uma cena maior. O domínio explorado nesse trabalho foram filmes de Hollywood (Top Gun, A Beautiful Mind, entre outros) e programas de entrevista.

Zhai e Shah (2005b) trata a detecção de cenas como um problema de ponto de mudança, ou seja, ocorre uma mudança de cena sempre que o conceito central muda. A técnica Markov Chain Monte Carlo (MCMC) foi adaptada para detectar a mudança de cenas em dois domínios diferentes: vídeos caseiros e filmes. Parâmetros referentes ao processo de segmentação como o número de cenas e a localização das fronteiras das cenas são alterados iterativamente e são usadas várias cadeias de Markov independentes com o objetivo de evitar detecções erradas de uma única cadeia. No domínio de vídeos caseiros, a precisão obtida foi $84,0 \%$ e a abrangência foi $91,3 \%$. Já nos filmes os valores da precisão variaram entre 79,0\% e 96,0\% e os valores da abrangência variaram entre $79,0 \%$ e $82,8 \%$. Portanto, pode-se dizer que esse método teve resultados bons, tanto para filmes caseiros quanto para filmes.

Sakarya e Telatar (2007) propõem um método de detecção de fronteiras de cenas baseado em partições de grafos. Para isso, um sinal unidimensional é construído para cada característica de semelhança entre tomadas. Posteriormente o sinal é filtrado eliminando informações desnecessárias. O algoritmo K-Means é utilizado para obter candidatos de fronteiras de cenas. Por último, uma 
fase para eliminação de falsos positivos é executada. Nesse trabalho, foram utilizados 3 filmes e 1 programa de televisão. A medida selecionada foi a $F 1$, com resultados variando de $65 \%$ e $87 \%$. A Fl apresenta valores próximos de 1 quando tanto a abrangência quanto a precisão são boas, sendo assim, percebe-se que esse método apresentou um desempenho que variou entre regular (65\%) e satisfatório (87\%). Dois filmes e uma série de televisão foram utilizados nos testes.

Chaisorn et al. (2002) demonstram que a estrutura dos telejornais é dividida entre uma abertura, composta de um resumo das principais notícias, e a parte principal, onde uma série de notícias é organizada de acordo com o interesse geográfico (nacional ou internacional) e categorias, tais como política, finanças, esportes, entretenimento. Além disso, antes de uma reportagem, o âncora do jornal faz uma breve introdução ao assunto que será abordado. Portanto, em geral, cada cena é iniciada com essa aparição do âncora. Os autores propõem um método para segmentação de cenas em telejornais em dois níveis, sendo o primeiro utilizado para classificar identificar as tomadas em 13 categorias pré-definidas, com o uso de uma árvore de decisão, e o segundo, para a identificação de cenas, por meio dos Modelos Ocultos de Markov (do inglês, Hidden Markov Models), um método estocástico.

Como se pode perceber pelos trabalhos apresentados até aqui, alguns métodos são específicos para determinados domínios de vídeos, por exemplo, filmes e noticiários e tentam explorar particularidades desses domínios.

Uma outra linha de pesquisa que tem apresentado bastante sucesso na segmentação de vídeos em cenas é o uso de multimodalidade. Esse conceito será discutido em maiores detalhes na seção 2.5, mas de modo resumido, a multimodalidade ocorre com a utilização de duas ou mais mídias com o objetivo de completar uma tarefa. Segundo Fabro e Böszörmenyi (2013), o uso de mais de uma mídia, em especial áudio e vídeo, devem ser escolhidos em detrimento da utilização somente da parte visual na tarefa de segmentação de vídeo.

Chen et al. (2012) propõem uma abordagem para a sumarização de vídeo que inicialmente agrupa tomadas em segmentos de vídeo relacionados semanticamente denominados sub-histórias (do inglês, sub-stories). Os autores exploram a similaridade de cor e áudio entre as tomadas, além de observar a atração temporal entre as tomadas. As características de áudio utilizadas são obtidas com o descritor sonoro MFCC. E após a formação das sub-histórias, uma visualização multinível é formada para representá-las, com objetos, personagens e locais de interesse.

Sidiropoulos et al. (2011) propõem um método para a detecção de vídeos em cenas que utiliza características visuais e sonoras. De modo específico, são utilizados vetores HSV (Hue, Saturation, and Value), vetores constituídos de respostas de detectores de conceitos visuais, características de áudio como histograma de falantes e vetores constituídos de respostas de detectores de conceitos sonoros. Um grafo de transição de cenas é utilizado para realizar a segmentação. A definição de cena utilizada não foi explicitada, mas é mencionada a relação semântica entre as tomadas.

Tsiartas et al. (2011) definem um método para a análise de vídeos multilinguais, que visa encontrar segmentos de fala equivalentes nas diversas línguas, utilizando as legendas (mídia textual) 
e o áudio. Apesar desses segmentos falados não serem exatamente cenas, segundo o conceito de cena utilizado neste trabalho, esses segmentos apresentam uma certa relação semântica pois estão ligados a fala de um ou mais personagens. A característica de áudio utilizada são os descritores MFCC.

Em Delezoide (2005), uma segmentação hierárquica de vídeos é proposta. Modelos Ocultos de Markov são utilizados para dividir o áudio em clips, os quais são classificados em quatro diferentes categorias: fala, música, som ambiente e silêncio. Os segmentos de fala são subdivididos de acordo com o falante. Já a parte visual é segmentada em tomadas, que são representadas por quadroschave. Uma matriz de similaridade é utilizada para identificar as fronteiras dos segmentos, que são posteriormente agrupados com o algoritmo K-Means. O conceito de cena utilizado é baseado na composição cromática das tomadas, nas condições de iluminação e no som ambiente.

Outro trabalho importante que faz uso de multimodalidade é apresentado por Coimbra (2011), no qual é empregada uma técnica multimodal que considera características visuais, sonoras e de closed-caption. Essa técnica faz uso de técnicas de segmentação de vídeo visuais (wavelets, histograma local e histograma global), sonoras (detecção de silêncio e análise de RMS), e de closedcaption (análise do closed-caption) para segmentar vídeos. Essa técnica utiliza um ranking de transições detectadas associado a pesos pré-definidos para cada característica, os quais são definidos com base na precisão e abrangência das técnicas utilizadas para extraí-las. Sendo assim, cada transição encontrada recebe um peso maior caso a técnica que a identificou tenha precisão e abrangência maiores, e um peso menor caso contrário. Os resultados da técnica multimodal desenvolvida foram melhores do que os resultados apresentados pelas técnicas individualmente.

Outra linha que tem obtido bastante sucesso na segmentação de vídeos é a utilização de vocabulários visuais, formados com Bag of Visual Words. Algumas técnicas serão apresentadas a seguir.

Klaser et al. (2010b) propõem um método centrado em humanos para detecção e localização de ações humanas em vídeos. Essa localização é realizada tanto temporalmente, quanto espacialmente (em cada quadro). Para isso utilizam uma técnica para detectar atores humanos em cada um dos quadros. A seguir, essas detecções são relacionadas por um rastreador de propósito geral chamado KLT, dando origem a trilhas. Dada uma determinada ação, é realizada uma busca nessas trilhas para identificar os quadros que contém essa ação, e a localização da ação em cada quadro. Apesar de haver uma relação semântica entre os quadros, esse método só consegue identificar relação semântica entre quadros parecidos, pelo fato de utilizar as trilhas. Além disso, uma ação não necessariamente determina uma cena. Um aperto de mão ou um beijo, por exemplo, podem ser apenas uma pequena parte de uma cena.

Numa linha diferente, Klaser et al. (2010a) propõem um método para a detecção de ações em vídeos utilizando a técnica Bag of Visual Words (seção 2.4) em união com técnicas de localização de pessoas. Nesse trabalho, são utilizados detectores de pessoas e detectores da parte superior do corpo para criar caixas que são limitantes para os atores presentes na imagem e sua vizinhança mais próxima. São definidos “corredores” espaço-temporais, que são um conjunto dessas caixas 
limitantes referentes a um determinado ator no tempo. Apenas as características contidas pelas caixas limitantes são utilizadas. Os vocabulários foram gerados utilizando 4000 características amostradas de maneira aleatória, o que segundo os autores é um modo mais rápido do que utilizar o K-Means para gerar o vocabulário, e apresenta um desempenho comparável. Foram utilizadas três bases de dados: KTH (Schuldt et al., 2004), UCF(Rodriguez et al., 2008), e Hollywood(Laptev et al., 2008), contendo respectivamente ações normais do dia-a-dia, de esporte, e ações comuns em filmes. Os resultados apresentados foram superiores aos de trabalhos similares. No entanto, esse trabalho difere da presente proposta, uma vez que consiste em detectar ações previamente estabelecidas em um vídeo, e não em identificar cenas em segmentos semanticamente complexos.

Kumar et al. (2011) também apresentam um algoritmo baseado em Bag of Visual Words. As representações das tomadas obtidas com essa técnica são utilizadas em um modelo de grafo bipartido, que é responsável por computar a similaridade semântica entre elas. A similaridade é então utilizada para realizar a segmentação em cenas. O domínio utilizado são filmes de Hollywood.

Os trabalhos e os resultados analisados em sua maioria consideram apenas o aspecto visual. Essa característica inviabiliza a detecção de cenas onde há uma mudança no assunto, sem que, contudo, exista uma mudança no visual das tomadas. É possível perceber também a recorrência na utilização de tomadas como base para a segmentação de cenas.

Outra técnica utilizada com certa frequência é o treinamento do algoritmo proposto em uma base de vídeos, para permitir a identificação de categorias de cenas pré-definidas, ou ações. De certa forma, essa técnica limita o funcionamento do algoritmo, uma vez que um vídeo que não apresente as características semelhantes aos vídeos da base pode apresentar resultados piores.

Também é possível perceber que diversos conceitos de cenas são empregados, e as bases utilizadas em cada trabalho variam consideravelmente, o que dificulta uma comparação direta entre os técnicas propostas. Além disso, alguns trabalhos segmentam apenas partes dos vídeos, sem uma definição clara do critério utilizado para a seleção desses trechos.

É possível perceber que os métodos apresentados são restritos a domínios específicos, e com definições restritivas do que é uma cena, o que dificulta sua aplicação de modo generalizado. No presente trabalho, uma cena é definida como um conjunto de tomadas semanticamente relacionadas, sendo que apresentam um mesmo tema ou assunto. É importante observar que não há imposições sobre como deve ser a definida a semântica entre as tomadas que compõem a cena. A única restrição é que apresentem um mesmo tema ou assunto, ou seja, algo bem mais próximo do entendimento do usuário do que os trabalhos apresentados neste capítulo.

Por ter uma definição muito restritiva, essas técnicas não tratam adequadamente o problema da segmentação em cenas em segmentos semanticamente complexos. Esses segmentos são definidos como um conjunto de tomadas, no qual mais de um assunto é abordado, podendo existir ou não, semelhanças nos aspectos visuais ou sonoros (interlocutores ou sons) das tomadas que o constituem. 
A detecção de cenas em segmentos semanticamente complexos envolve basicamente duas situações que devem ser analisadas. A primeira, consiste na mudança de assunto, e consequentemente mudança de cena, sem que existam diferenças visuais e/ou sonoras entre as tomadas que fazem parte das duas cenas subsequentes. Um exemplo pode ser visto na Figura 2.2. Nessa figura estão ilustrados os quadros-chave de nove tomadas subsequentes que compõem duas cenas do filme De Volta para o Futuro. A ordem cronológica delas é dada da esquerda para a direita e de cima para baixo. O mesmo vale para as demais figuras deste trabalho que apresentam quadros-chave de tomadas. A primeira cena é composta pelas três primeiras tomadas. Nelas, os personagens falam sobre o fato de Jenniffer ligar para Marty. Entretanto, nos seis quadros posteriores, o assunto muda e passa a ser o passado dos pais de Marty. Essa mudança é caracterizada pela alteração no tom de voz da mãe de Marty, que diminui o tom de voz e começa a conversar com a filha sobre como conheceu seu marido, caracterizando a troca de cena.
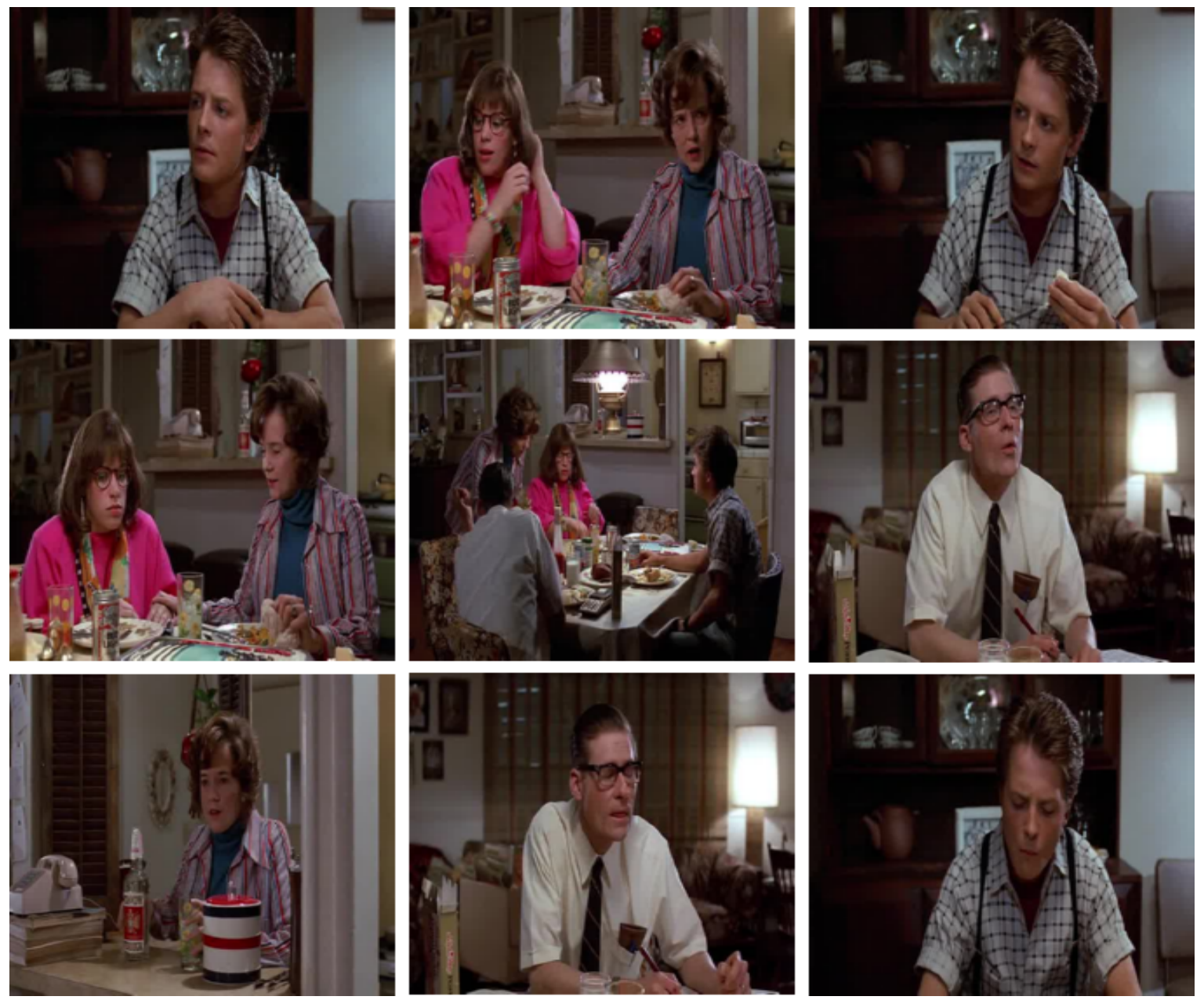

Figura 2.2: Cenas do filme De Volta para o Futuro com mudança de assunto sem alterações visuais.

É importante observar que apesar do ambiente ser o mesmo nas nove tomadas, neste caso a sala de jantar da casa de Marty, e dos mesmos personagens estarem presentes, o assunto muda. Essa mudança de cena é difícil de ser caracterizada utilizando somente a parte visual, dadas as 
similaridades visuais entre as tomadas, o que causaria dificuldades para técnicas que usam somente a parte visual detectarem essa mudança.

A segunda situação ocorre na situação oposta e pode ser vista na Figura 2.3. Nessa figura, existem nove quadros-chave de nove tomadas que compõem uma das cenas do filme Piratas do Caribe. Nessa cena, apesar de existir uma mudança abrupta na parte visual entre o quarto e o quinto quadros, o tema da cena, que é a fuga do pirata Jack, permanece o mesmo. Ou seja, apesar das diferenças visuais, todas as tomadas fazem parte de uma única cena.

A detecção de cenas em segmentos semanticamente complexos será abordada em maiores detalhes nos capítulos 3 e 4 . As limitações das técnicas presentes na literatura expostas nesse capítulo abrem espaço para novas pesquisas que considerem mais características, não somente visuais, e que possam ser aplicadas em diversos domínios diferentes sem que haja uma variação muito grande na sua eficiência.
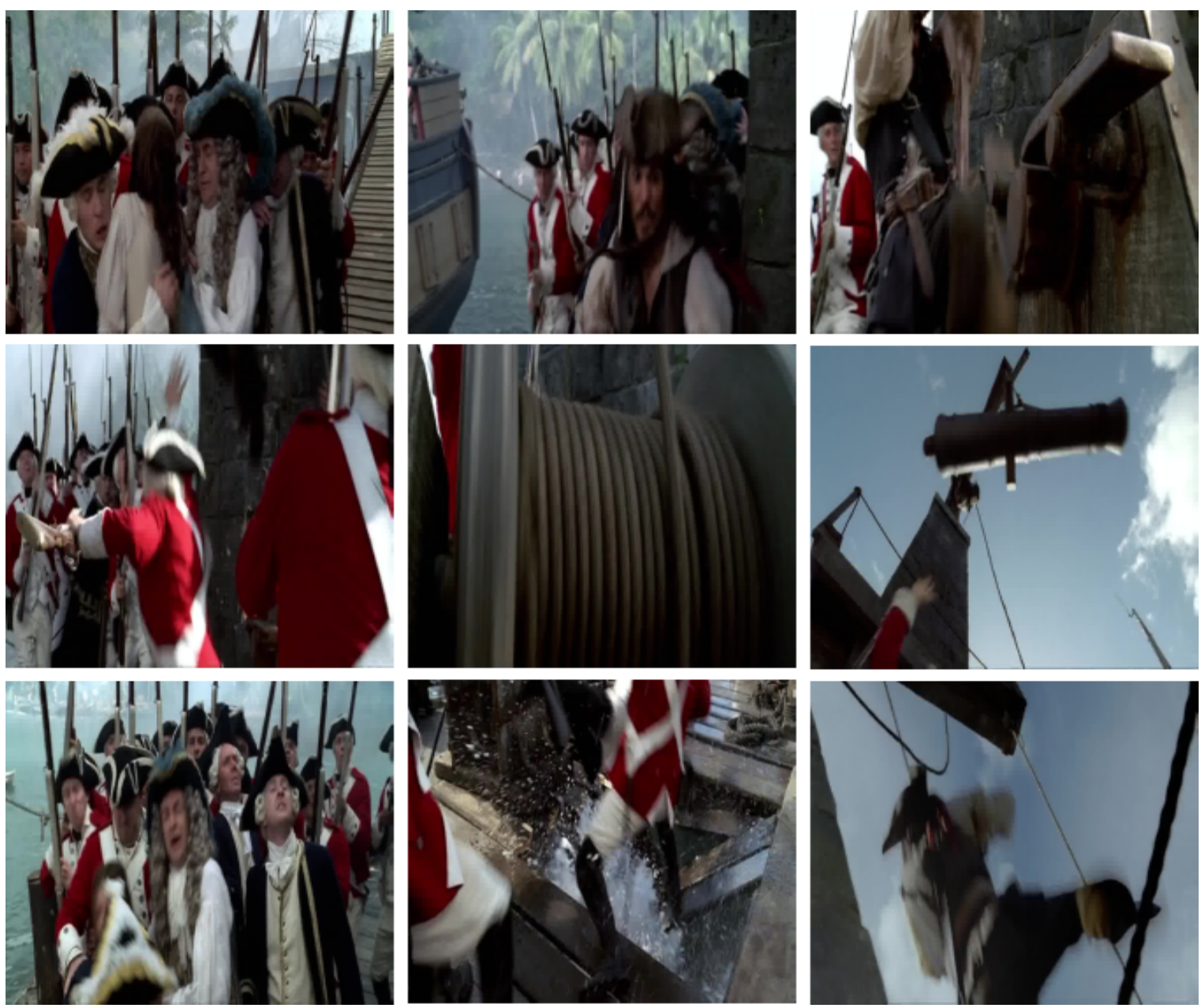

Figura 2.3: Cena do filme Piratas do Caribe sem mudança de assunto e com alterações visuais. 


\subsection{Descritores de Características}

Essa seção aborda os descritores de características, que são fundamentais para o entendimento da técnica proposta nessa Dissertação. A organização da seção é a seguinte: A seção 2.3.3 apresenta o conceito de descritor de características. Na seção 2.3.3 é realizada uma revisão dos descritores visuais, de modo especial, descritores globais e locais, ressaltando as diferenças entre eles, bem como sua utilização, com enfoque nos descritores SIFT e SURF. A seção 2.3.3 apresenta os descritores sonoros, com ênfase para os descritores MFCC e para os descritores LPCC.

\subsubsection{Definição de Descritores de Características}

Tanto sinais digitais de áudio quanto de vídeo apresentam um alto grau de redundância, a qual pode ser explorada como meio de obter uma representação compacta do conteúdo, sem, contudo, perder capacidade de representação e discriminação do conteúdo.

A extração de características tem como objetivo reduzir a dimensionalidade dos dados eliminando informações redundantes (Duda et al., 2001). Com esse intuito, representações matemáticas podem ser utilizadas, e consequentemente eliminar informações redudantes. Por meio delas, é possível descrever o conteúdo digital de maneira compacta e manter a capacidade de distinção dos conteúdos, e, por exemplo, reconhecer músicas de um determinado gênero ou detectar bordas de objetos em uma imagem.

No entanto, para que isso seja possível, é preciso que essas representações consigam capturar alguma informação que seja relevante e compreensível para seres humanos, ou em outros termos, devem identificar alguma característica. Por isso, essas representações são chamadas de descritores de características, os quais definem a sintaxe e a semântica da representação de uma característica (Manjunath et al., 2000).

Os descritores são definidos por uma dupla $\left(\epsilon_{D}, \delta_{D}\right)$ sendo $\epsilon_{D}$ um extrator de características, e $\delta_{D}$ uma medida de similaridade. Um extrator de características é um algoritmo ou função utilizado para encontrar uma representação compacta do conteúdo. Essa representação é chamada de vetor de característica. A medida de similaridade, por sua vez, tem como objetivo permitir a comparação dessas representações, possibilitando identificar o quão semelhantes são. As medidas de similaridade serão abordadas em maiores detalhes na seção 2.6.

É importante ressaltar que a definição de descritores de características aqui apresentada diverge de outras existentes na literatura, nas quais o descritor de características é definido unicamente como o vetor de características extraído. É importante considerar também a medida de similaridade, uma vez que por meio dela é que é determinada a geometria do espaço de descrição (Penatti et al., 2012). Além disso, ela influencia fortemente a eficiência do método que utiliza os vetores de características. As subseções seção 2.3.3 e seção 2.3.3 tratam respectivamente dos descritores visuais e sonoros, que são amplamente utilizados em uma variedade de técnicas, como classifica- 
ção de imagens e sons (Mansano et al., 2012; Chaudhuri et al., 2011) e recuperação de conteúdo (Zagoris et al., 2011; Raoui et al., 2011).

\subsubsection{Extratores e Descritores de Características Visuais}

A análise de vídeos e imagens digitais é uma tarefa complexa e computacionalmente custosa, uma vez que os dados tendem a apresentar volumes que podem chegar a casa de gigabytes. Além disso, existe a necessidade de uma maneira de representar adequadamente os conteúdos analisados, possibilitando, por exemplo, sua comparação. No entanto, a representação dos vídeos e imagens deve ser independente da qualidade dos mesmos.

Os descritores visuais procuram resolver esses dois problemas, reduzindo a alta dimensionalidade dos dados, e provendo a possibilidade de representação e comparação dos elementos visuais. Por exercerem esses papéis fundamentais, os descritores visuais influenciam diretamente no grau de eficiência alcançado pelo método ou técnica que os utiliza. Quanto maior a capacidade do descritor de identificar e caracterizar as propriedades da imagem, maior a eficiência da técnica.

Essas propriedades, ou características, conforme ressaltado anteriormente, devem estar associadas a características significativas para os seres humanos, uma vez que as técnicas criadas exploram essas características, como por exemplo buscar um determinado rosto em uma foto.

Além disso, segundo Barroso e Whelan (2011), os descritores visuais devem ser não somente suficientemente distintos para diferenciar objetos similares, mas também robustos o bastante para permitir a identificação de objetos mesmo com a presença de ruídos, erros de localização, bem como com mudanças na escala, iluminação e ponto de vista.

Os descritores visuais podem ser divididos em duas categorias: globais e locais. Descritores globais de características são computados sobre todo o elemento visual (imagem ou vídeo), e criam uma única representação para ele, ou seja, um vetor de características único. Sendo assim, essa generalização do elemento pode ser usada de modo direto na comparação de dois ou mais elementos (Lisin et al., 2005). Segundo Lisin et al. (2005), entre esses descritores estão inclusos descritores de textura, de forma e contorno, além dos descritores de cor.

A textura é uma das características usadas pelo sistema visual humano e pode ser definida como um arranjo repetitivo de padrões em uma região (Schwartz et al., 2012). Diversos descritores globais de textura foram propostos na literatura em trabalhos como (Montoya-Zegarra et al., 2007; Costa et al., 2012; Manjunath et al., 2000).

A forma é uma das características primárias das imagens e se dividem em dois tipos de representação (Zhang e Lu, 2003): região e contorno. O primeiro tipo de representação é mais abrangente, podendo ser aplicado em mais situações, no entanto, em geral, exigem mais recursos computacionais. O segundo tipo, como o nome sugere, descreve os contornos presentes na imagem. O contorno é uma característica muito importante para a percepção visual e facilita a busca por esboços. 
Os descritores de cor apresentam os melhores resultados para a busca de imagens (Rao et al., 2011; Sandeep e Rajagopalan, 2002; Yang e Ahuja, 1998). O mais básico descritor de cor é o histograma de cores (Messing et al., 2001). Nesse tipo de descritor, deve-se inicialmente escolher um espaço de cores, sendo os mais comuns RGB (Red, Green and Blue) e HSV, no qual a imagem será representada. Após essa definição, são escolhidas partições (do inglês, bins), que consistem em amostragens arbitrárias de cada uma das dimensões do espaço de cor. Cada pixel da imagem é então analisado e somado a quantidade de pixels que fazem parte de uma mesma partição. Para cada dimensão do espaço de cores é gerado um vetor com essas somas, e o conjunto desses vetores é denominado histograma de cores.

Os descritores globais apresentam em geral as seguintes vantagens: Baixa dimensionalidade, transformações computacionais eficientes, invariantes a rotatividade (Gerstmayr-Hillen et al., 2011). Por essas características têm sido utilizadas em diversas áreas como navegação visual de robôs autônomos (Gerstmayr-Hillen et al., 2011), descoberta automática de famílias de imagens (Aly et al., 2009), e reconhecimento de objetos (Choksuriwong et al., 2008).

Um descritor global que vem atraindo a atenção de diversos pesquisadores é o GIST (o nome é um acrônimo de essência de cena, do inglês, gist of the scene (Murthy e Hanmandlu, 2011)), inicialmente proposto em (Oliva e Torralba, 2001). Originalmente, a ideia desse descritor é prover uma descrição de cenário de baixa dimensão, que não necessite de segmentação (Oliva e Torralba, 2001). Esse descritor é invariante a transformações de luminância, obscuridade, escala, entre outras. No entanto, não é invariante a operações de translação, rotação e oclusão (Douze et al., 2009).

Diferentemente dos descritores globais, os descritores locais não são computados sobre toda a imagem, mas sim sobre regiões, bordas ou pontos de interesse. Com isso, para uma determinada imagem, podem ser gerados centenas, ou até milhares de descritores (Lejsek et al., 2006).

$\mathrm{O}$ alto número de descritores gerados é uma importante qualidade dos descritores locais, uma vez que aumenta sua robustez. Os descritores locais têm se mostrado mais robustos a problemas como oclusão, aglomeração e transformações geométricas. Essa característica é denominada repetibilidade, uma vez que dadas, por exemplo, duas imagens de um mesmo local, mas com pontos de vista diferentes, tendem a apresentar os mesmos elementos, e portanto as mesmas características, possivelmente sujeitas aos problemas mencionados, ou seja, ocorre uma repetição das características encontradas.

Os descritores de características locais que atuam sobre pontos de interesse são os mais populares exatamente por apresentarem uma maior robustez em relação aos demais (Ke e Sukthankar, 2004; Mikolajczyk e Schmid, 2005). Os pontos de interesse são pontos presentes na imagem que podem ser localizados de maneira única. Usualmente, ao localizar esses pontos, os descritores utilizam um pequeno trecho ao redor do ponto, e com ele computam um vetor de características. Normalmente uma orientação e uma escala são associadas ao ponto, covariantes a qualquer deformação que a imagem possa sofrer, permitindo ao descritor ficar invariante a essas transformações. 
Por causa desses diferenciais, os descritores locais têm sido utilizados com sucesso em diversas tarefas, como classificação e busca de imagens (Raoui et al., 2011). Dentre esses descritores, dois se destacam pelo alto número de trabalhos na literatura, bem como por sua capacidade de detectar a semântica latente presente nas imagens: SIFT e SURF.

Segundo Wu et al. (2009), os descritores SIFT e a técnica Bag of Visual Words fazem parte do estado da arte em grandes sistemas de recuperação de imagem. Os descritores SIFT foram propostos por Lowe $(1999,2004)$ para permitir o reconhecimento de objetos por meio de correspondência ponto-a-ponto eficiente. Eles representaram um grande avanço devido à sua característica de invariabilidade em relação a translações, rotações, escala.

Além disso, são robustos a pequenas distorções residuais e apresentam melhor performance (Mikolajczyk e Schmid, 2005). Por esses motivos, são os mais utilizados em tarefas de reconhecimento (de Avila, 2013).

Os descritores SIFT são amplamente utilizados em trabalhos que fazem uso de Bag of Visual Words. Originalmente foram propostos como a combinação de um detector de regiões de interesse por diferença de gaussiano e um descritor de características composto por um histograma de localizações e orientações gradientes. No entanto, ambos têm sido usados separadamente com sucesso, sendo que estudos apontam que os descritores SIFT pode ser utilizado com uma série de extratores diferentes apresentando bons resultados (Mikolajczyk e Schmid, 2005).

A ideia utilizada para a criação desses descritores é computar um vetor gradiente para cada pixel na vizinhaça da característica e construir um histograma normalizado de direções de gradiente (Mortensen et al., 2005). A vizinhança com dimensão de 16 x 16 pixels, é dividida em 16 subregiões, cada qual com dimensão de 4 x 4 pixels. Para cada sub-região, é calculado o histograma de orientação do gradiente ponderado pela magnitude do gradiente. O descritor, um histograma com 128 dimensões, é a concatenação dos histogramas de todas as sub-regiões, seguida de uma normalização unitária (Moreno et al., 2009). Associadas a esse descritor, temos as distâncias L1 ou L2 (de Avila, 2008).

Outro descritor visual que pode ser utilizado em conjunto com o método Bag of Words é o SURF (Speeded-Up Robust Features) (Bay et al., 2006, 2008). O SURF é um descritor e detector de pontos de interesse invariante a operações de escala e rotação.

O detector SURF tem como base a matriz Hessiana, no entanto, ao invés de utilizar uma medida diferente para selecionar a localização e escala, tal como é feito no detector Hessian-Laplace, Bay et al. (2006) utilizam o determinante do Hessiano para ambos.

Já o descritor SURF representa a distribuição das respostas da wavelet Haar na vizinhança do ponto de interesse. Assim como o SIFT, o descritor SURF também consiste em codificar uma região em torno da característica em um vetor de componentes de frequencia (Botterill et al., 2008).

Uma das vantagens dos descritores SURF em relação aos descritores SIFT, é seu desempenho melhor tanto em velocidade, quanto em precisão para extração de correspondência da imagem (Botterill et al., 2008). Isso ocorre pois esse descritor possui uma rápida computação dos opera- 
dores diferenciais no espaço de escala, além de utilizar apenas 64 dimensões. Com isso, o tempo para computar as características e fazer a correspondência entre elas é reduzido.

\subsubsection{Extratores e Descritores de Características Sonoras}

Um descritor sonoro é definido como qualquer aspecto de um áudio qualitativamente ou quantitativamente mensurável (Bullock, 2007). Para Peeters (2004), o descritor sonoro pode ser visto por qualquer característica capaz de descrever o som. Um exemplo facilmente percebido é a intensidade do som, a qual pode ser qualificada como forte ou fraca.

Mitrovic et al. (2010) tratam a extração de características sonoras como uma atividade que visa obter informação significativa sobre um sinal de áudio para obter uma descrição compacta e expressiva que seja processável. Sendo assim, os descritores sonoros são uma representação do áudio em um determinado instante de tempo. É possível traçar uma analogia entre um determinado instante de áudio com uma imagem que compõe um determinado período de um vídeo.

Diversos descritores sonoros foram propostos ao longo da história (Peeters, 2004; Breebaart e McKinney, 2004), sendo que existem diversas taxonomias para classificá-los. Segundo Mitrovic et al. (2010), não existe uma única, não ambígua e geral taxonomia, pois, em geral, elas são definidas para campos de pesquisa específicos. Liu et al. (1998), no entanto, afirmam que em geral, os descritores sonoros podem ser divididos em domínio do tempo e domínio da frequência. A aplicação de descritores sonoros abrange várias áreas (Zhang e Kuo, 2001), sendo explorada em trabalhos sobre segmentação e classificação de áudio (Pfeiffer et al., 1996), recuperação de conteúdo baseado em áudio (Smith et al., 1998), análise de áudio para indexação (Liu e Huang, 1998) e integração de áudio e vídeo para segmentação e indexação de vídeo (Huang et al., 1998). Alguns descritores são utilizados recorrentemente em trabalhos encontrados na literatura devido à sua capacidade de caracterizar aspectos do áudio com precisão, sendo utilizados em diversas tarefas diferentes. Alguns exemplos desses descritores são: Zero Crossing Rate (ZCR), Mel Frequency Cepstral Coefficients (MFCC), Linear Predictive Cepstral Coefficients (LPCC), Energia (E) e Volume (V).

Os coeficientes lineares de prediçao (do inglês Linear Prediction Coefficients), também conhecidos como LPCs podem parametrizar bem o espectro da fala humana. Eles podem ser calculados segundo a Equação 2.1.

$$
X(z)=G(z) \frac{1}{A(z)}=G(z) \frac{1}{1+a_{1} z^{-1}+a_{2} z^{-2}+\ldots+a_{P} z^{-P}}
$$

Onde $X(z)$ é o espectro do sinal da fala e $G(z)$ é o espectro da excitação glótica. $1 / A(z)$ é o espectro do trato vocal, e $A(z)$ é modelado como uma função polinomial de $z$.

Os LPCs são os coeficientes $a_{1}, a_{2}, \ldots, a_{P}$, estimados a partir de um frame de dados, dado o modelo de produção de fala. Uma sequencia LPC pode ser computada diretamente da sequencia de correlação correspondente de mesmo comprimento. Um vetor LPC de comprimento 12 pode 
ser derivado de uma autocorrelação de mesmo comprimento, a qual é interpretada como espectro de Fourier suavizado.

Vetores de coeficientes cepstrais são características adequadas para sistemas de reconhecimento, uma vez que reduzem a taxa de erros nesses sistemas. Esses vetores são obtidos a partir da decomposição de um sinal no domínio do tempo em uma série de vetores, sendo que cada vetor contém informações sobre o espectro estacionário do sinal no domínio do tempo.

O cepstrum de uma série de tempo apresenta algumas propriedades interessantes, tais como sua capacidade de mapear a convolução em adição, além de comprimir a faixa do espectro de magnitude, e reduzir a correlação entre os coeficientes.

O fato de mapear a convolução em adição permite separar facilmente a excitação glótica do trato vocal, pois dado um sinal composto da convolução dos dois sinais, pode-se produzir o cepstrum que é a soma do cepstra dos dois sinais.

Já a compressão da faixa do espectro de magnitude é benéfica uma vez que picos e vales no espectro ficam menos pronunciados, e portanto possíveis de serem representados com menos coeficientes. Entre as variantes dos coeficientes cepstrais, dois bastante populares são os Linear Predictive Cepstral Coefficients (LPCCs) e Mel-Frequency Cepstral Coefficients (MFCCs).

A partir dos LPCs é possível fazer um mapeamento para uma sequencia infinita de LPCCs. Para isso, o primeiro passo para calcular um vetor LPCC de um sinal é estimar seus respectivos LPCs, e posteriormente transformá-los em LPCCs. No entanto, por não ser viável calcular uma sequencia infinita de LPCCs, ela deve ser truncada em algum ponto. $\mathrm{O}$ truncamento, entretanto, apresenta as vantagens citadas anteriormente dos coeficientes ceptrais, como a diminuição da correlação e compressão.

Os Linear Predictive Cepstral Coefficients (LPCCs) são derivados dos Linear Predictor Coefficients (LPCs), os quais são capazes de detectar eventos vocais em áudio (Atrey et al., 2006). Como vantagem em relação aos LPCs, os LPCCs são maisrobustos contra mudanças bruscas do sinal, ou ruido, pois são derivados da resposta do impulso domodelo de fala (Atrey et al., 2006).

Dados os coeficientes lineares preditivos $a_{k}, k=1, \ldots, N$, os LPCCs podem ser determinados pela Equação 2.2 (Atal, 1974):

$$
\left\{\begin{array}{c}
c_{1}=a_{1} \\
c_{n}=\sum\left(1-\frac{k}{n}\right) a_{k} c_{n-k}+a_{k}, n=1, \ldots, P
\end{array}\right.
$$

onde $P$ é o número desejado de coeficientes cepstrais.

O Mel Frequency Cepstral Coefficient (MFCC) é uma característica sonora amplamente utilizada em trabalhos para reconhecimento de voz em trabalhos como (Hasan e Jamil, 2004; Muda et al., 2010). O MFCC explora a percepção não linear do som pelo ouvido humano, e devido a isso consegue modelar de forma compacta o envelope espectral, porque suprime a frequência fundamental (Jensen et al., 2009). Além disso, torna possível a comparação entre dois sinais de áudio utilizando entre 15 e 30 pontos, ao invés do espectro original de 1024 pontos (Brent, 2011). 
O cálculo dos MFCCs envolve algumas etapas, conforme a Figura 2.4. É importante observar que inicialmente o sinal deve passar por um processo de janelamento, o qual divide o sinal em segmentos de mesma duração, tornando-o apto para a aplicação da Transformada de Fourier (TF), representado pelo bloco $|D F T|^{2}$. As amplitudes resultantes da TF são filtradas por janelas triangulares na escala Mel, sendo aplicado o logaritmo, seguido da Transformada Discreta do Cosseno (bloco DCT), cujas amplitudes são os MFCC (Logan, 2000).

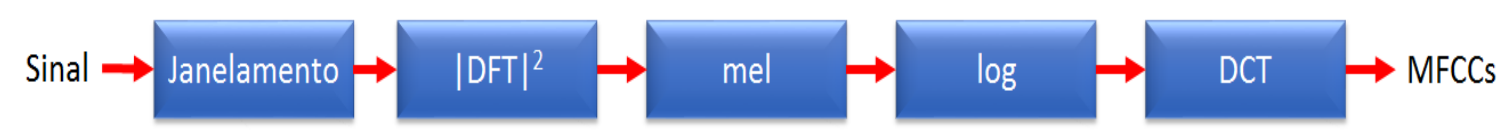

Figura 2.4: Etapas para o cálculo dos MFCCs.

\subsection{Bag of Visual Words}

A técnica Bag of Visual Words, também chamada de Bag of Features, é uma adaptação da conhecida técnica Bag of Words, utilizada na área de Recuperação de Informação (Renals et al., 2000), para recuperação de textos, com o intuito de permitir aplicar essa técnica à recuperação de imagens.

A técnica Bag of Words consiste em representar um documento textual como um conjunto de palavras, que pertencem a um vocabulário fixo, adquirido através de uma base de documentos, ignorando qualquer estrutura inerente ao documento (Valle e Cord, 2009). Sua função é estimar a probabilidade de uma palavra estar em um determinado contexto.

Sendo assim, dado um conjunto de documentos textuais, é gerado um dicionário contendo todas as palavras dos documentos. As ocorrências de cada palavra são contadas, a fim de criar uma matriz com o número dessas ocorrências em cada texto. Dessa forma, tem-se uma representação do texto pela frequência das palavras presentes nele, ou seja, um modelo no espaço vetorial. Segundo (Jiang et al., 2010), a grande vantagem de obter esse modelo é a possibilidade de aplicar facilmente algoritmos de classificação.

A técnica Bag of Visual Words é constituída de quatro fases: extração de características; aprendizado do vocabulário visual; quantificação dos recursos utilizando o vocabulário visual e representação das imagens por meio das frequências de palavras visuais. Cada uma dessas fases será detalhada a seguir.

A extração de características consiste em identificar ponto locais de interesse em um conjunto de imagens, utilizado para o aprendizado, através de técnicas como grid regular (Vogel e Schiele, 2004; Fei-Fei e Perona, 2005), detector de ponto de interesse (Lowe, 2004), amostragem aleatória (Ullman et al., 2002), diferença de gaussianas, ou Maximally Stable Extremal Regions (MSER) (Matas et al., 2002; Wu et al., 2009). Cada ponto de interesse é então representado por descritores, que são vetores de dimensão elevada, tais como os descritores SIFT (Scale Invariant Feature 
Transform) (Lowe, 2004), e normalmente recebem o nome de features ou características. Aplicase sobre as características extraídas algum método de agrupamento, como por exemplo, $K$-Means, de modo a criar grupos com as características extraídas do conjunto de imagens. $\mathrm{O}$ centro de cada agrupamento será a representação de uma palavra visual. Sendo assim, obter-se-á um vocabulário visual composto pelas palavras visuais identificadas. Esse vocabulário é denominado code book ou dicionário. Outras possíveis formas de gerar o dicionário têm sido apresentadas em trabalhos, com resultados similares. Em Kinnunen et al. (2009), utiliza-se mapas auto-organizáveis (Self-Organising Map - SOM), já em Zhang et al. (2010) é proposta uma abordagem estatística.

Tendo sido definido o dicionário, torna-se possível quantificar as ocorrências de cada palavra visual em uma determinada imagem. Um histograma da imagem é então gerado de acordo com o número de ocorrências de palavras visuais nela, e passa a ser a representação da imagem. Com isso, podem ser aplicados classificadores e/ou modelos de categoria para definir categorias para as imagens, como por exemplo, retrato de uma pessoa, paisagens, fotos de carro, entre outros.

A Figura 2.5 mostra os quatro passos citados. É importante notar que em cada uma das 3 imagens, há pontos verdes, representando a localização dos pontos de interesse. Os pontos de interesse extraídos das 3 imagens são então agrupados por meio de um algoritmo de agrupamento, tal como o K-Means, sendo que cada grupo representará uma imagem visual do dicionário. A seguir, as características extraídas de cada imagem são associadas ao grupo que representam, e posteriormente é gerado um histograma de palavras visuais que é a representação da imagemna técnica Bag of Visual Words. É possível perceber que a técnica Bag of Visual Words é capaz de extrair semântica das imagens, permitindo a identificação de imagens semelhantes, fato que é particularmente interessante na segmentação de vídeos, visto que quadros ou tomadas com visual semelhante tem uma boa chance de fazerem parte da mesma cena. Essa característica, associada à representação no espaço vetorial, é explorada em vídeos para a detecção de ações (Klaser et al., 2010b).

No entanto, a simples aplicação da técnica Bag of Visual Words na segmentação de vídeos apresenta algumas dificuldades. Por considerar somente o aspecto visual, tomadas que apresentem similaridade visual entre si, mas que se refiram a assuntos diferentes, tendem a ser erroneamente classificadas como pertencentes a uma mesma cena. De maneira análoga, tomadas visualmente diferentes, que tratem de um mesmo assunto, seriam classificadas como pertencendo a cenas diferentes. Portanto essas limitações impõem restrições à aplicação dessa técnica na segmentação de vídeo.

Além disso, a técnica Bag of Visual Words apresenta um importante parâmetro: o número de palavras visuais que compõem o dicionário de palavras visuais. Um vocabulário muito grande perde poder de generalização, uma vez que as palavras visuais representam detalhes não discriminativos (Rothacker et al., 2012). Por outro lado, se for muito pequeno, pode não ser suficientemente discriminativo.

Trabalhos na literaturam reportam diferentes tamanhos de dicionário, que variam desde algumas dezenas, até milhares de palavras, não havendo consenso quanto a esse fator. Entretanto, 

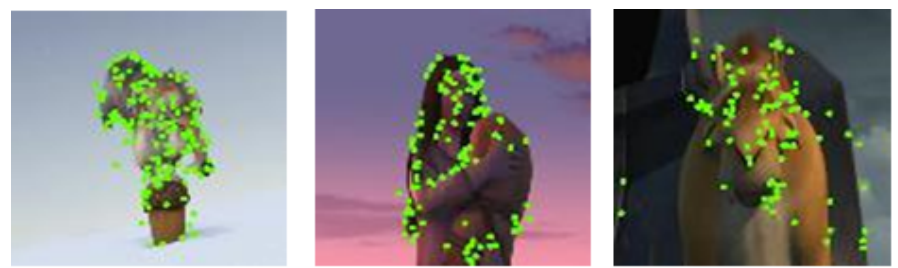

\section{Extração de Características}

e Agrupamento
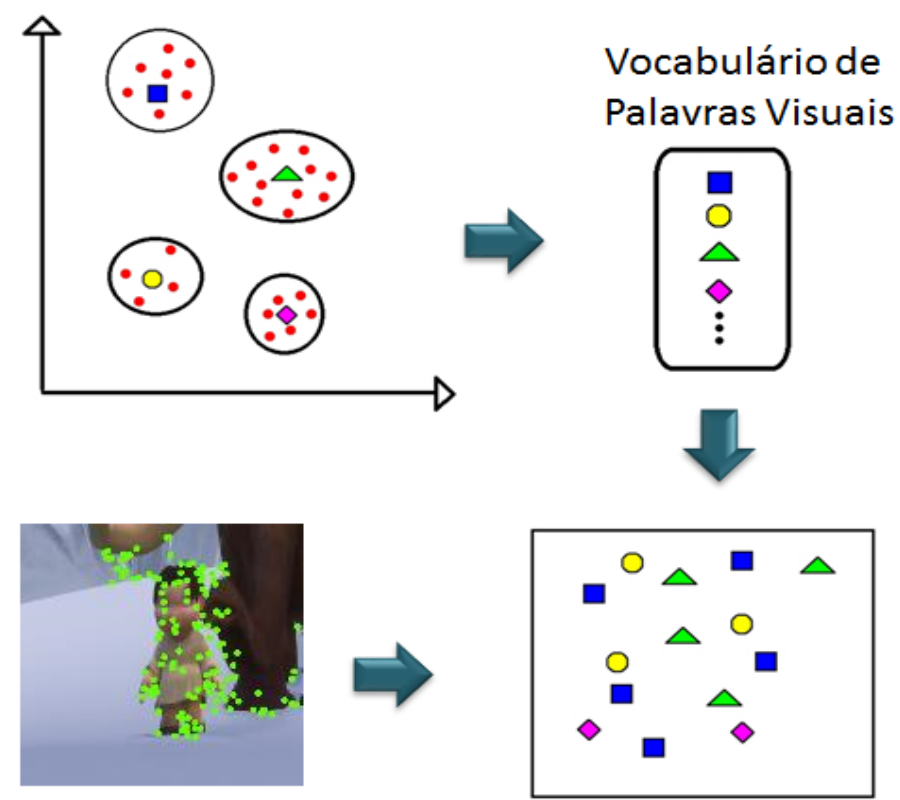

Conjunto de

Palavras Visuais

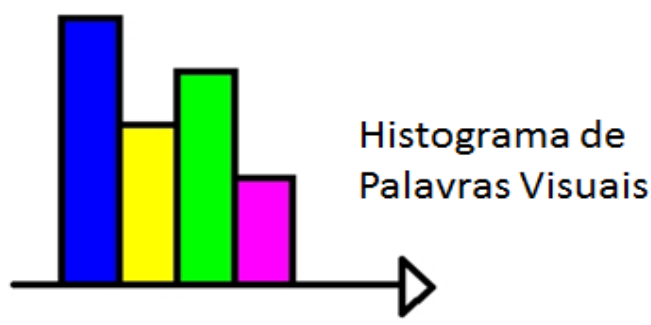

Figura 2.5: Passos da técnica Bag of Visual Words.

alguns trabalhos sugerem que quanto maior o dicionário mais eficiente se torna o método (Rothacker, 2011).

Diversas abordagens têm sido propostas para a determinação automática do tamanho do dicionário. Elas variam desde estratégias baseadas em variância (Sugar et al., 2003) e agrupamento hierárquico (Feng e Hamerly, 2007), até reamostragem (McLachlan e Khan, 2004). Contudo, essas abordagens parecem estar ligadas diretamente ao domínio da aplicação, sendo difícil sua aplicação de maneira genérica (Rothacker, 2011).

Por essa dificuldade, geralmente trabalhos que fazem uso de Bag of Visual Words fazem experimentos considerando uma faixa de valores para o número de palavras visuais para avaliar o comportamento da técnica. 


\subsection{Multimodalidade}

Esta seção trata da multimodalidade, termo que se refere a utilização de dois ou mais modos em conjunto para a realização de uma determinada tarefa. Na seção 2.5.5 esse conceito é apresentado com maiores detalhes. A seção 2.5.5 traz algumas estratégias para a fusão de características, em especial fusão prévia (seção 2.5.5.5), fusão tardia (seção 2.5.5.5) e fusão híbrida (seção 2.5.5.5).

\subsubsection{Definições e Conceitos de Multimodalidade}

Murray (2013) apresenta a definição de multimodalidade como uma composição dos modos textuais, aurais e visuais em combinação com meios de comunicação e de materialidade para criar significado.

Para Nigay e Coutaz (1993), a multimodalidade está associada a capacidade de um sistema se comunicar com seus usuários, utilizando mais de um canal de comunicação, e extrair e transmitir significado automaticamente.

Num contexto mais orientado a vídeos, Calic et al. (2005) definem multimodalidade como a capacidade do autor de expressar uma ideia pré-definida, combinando ao menos dois canais de informação, entre visual, aural e textual. Snoek e Worring (2002) acrescentam que em um documento de vídeo, a modalidade visual inclui tudo que pode ser visto em um vídeo, já a modalidade aural inclue diálogos, música, e sons do ambiente que podem ser ouvidos em um vídeo. Por fim, a modalidade textual consiste de recursos de texto que descrevem o conteúdo de um vídeo.

Essas definições de multimodalidade demonstram não somente a possibilidade de combinação de diversos modos, em contextos distintos, mas também a capacidade desses modos se complementarem aumentando a semântica, e consequentemente o significado que um conteúdo é capaz de representar em relação à utilização de um único modo.

O conceito de multimodalidade é bem extenso, e tem sido utilizado em diversos contextos, tais como interação multimodal (Taib e Ruiz, 2008; Oviatt, 1999), sistemas de aprendizado (Yu et al., 2006) e recuperação de conteúdo (Hoi e Lyu, 2007).

Para Manzato (2011), a multimodalidade contribui para diminuir alguns dos problemas da área de Personalização e Adaptação de Conteúdo uma vez que são analisadas diferentes informações provindas dos canais as quais se complementam.

A multimodalidade também tem sido aplicada com sucesso na área de segmentação de vídeos. Uma revisão dos trabalhos de segmentação de vídeos em cenas presentes na literatura pode ser conferida na seção 2.2. Nas subseções 2.5.5.5, 2.5.5.5, e 2.5.5.5 são apresentadas técnicas de fusão de características, as quais permitem explorar a multimodalidade presente nos conteúdos digitais. 


\subsubsection{Fusão de Características}

Para explorar a multimodalidade de um determinado conteúdo é necessário processar dados provenientes das diversas mídias desse conteúdo. O objetivo dessa atividade é permitir adquirir informações relevantes sobre os dados, situações ou atividades de mais alto nível semântico.

Nesse contexto, a fusão de diversos modos tem atraído a atenção de diversos pesquisadores recentemente. Atrey et al. (2010) destacam que os dados utilizados nesse processo de fusão podem ser tanto sensoriais, como áudio e vído, quanto não-sensoriais, tais como número de interações dos usuários e links entre os contéudos.

Trabalhos recentes tem demonstrado que a utilização de vários modos permite a obtenção de resultados melhores, devido a possível complementaridade desses modos. Neste trabalho, o foco é a fusão de modos obtida a partir da fusão de características, sendo uma característica definida como uma propriedade distinguível do conteúdo. Conforme visto no seção 2.3, os descritores de caracaterísticas apresentam grande capacidade de extrair a semântica latente presente no conteúdo. Por isso, a fusão de caracaterísticas é importante para combinar e aumentar semântica latente extraída a partir de cada mídia do conteúdo.

A fusão de caracaterísticas apresenta alguns desafios importantes (Atrey et al., 2010):

- Mídias diferentes em geral são capturadas em formatos e taxas de amostragem diferentes Um exemplo é o vídeo e o áudio, podendo o primeiro ser capturado a uma taxa de 30 quadros por segundo, e o último a uma taxa de 44100 amostras por segundo.

- Os tempos de processamento das mídias é diferente - Esse fato pode influenciar diretamente na estratégia de fusão adotada, tema que será abordado posteriormente.

- As modalidades podem ser correlacionadas ou independentes - Na primeira situação, a correlação entre as modalidades pode ser usada para confirmar a decisão delas, já no segundo caso, uma modalidade pode complementar as informações obtidas a partir das demais.

- Modalidades podem apresentar diferentes níveis de confiança na execução de um determinado tipo de tarefa

Segundo Atrey et al. (2010), para tentar resolver ou ao menos diminuir os problemas causados pelos desafios apresentados, a investigação de técnicas de fusão de características deve responder algumas perguntas importantes: Em que nível em que a fusão será realizada? Como fundir? Quando fundir? O que fundir?

Todas essas questões serão abordadas neste trabalho de forma sucinta, com vistas a contextualizar alguns dos problemas enfrentados nesse trabalho, bem como justificar algumas das decisões tomadas.

A primeira questão, que trata do nível da fusão, se refere a duas possíveis estratégias: early fusion e late fusion, além de uma estratégia híbrida entre as duas, as quais serão apresentadas respectivamente nas subseções 2.5.5.5, 2.5.5.5, e 2.5.5.5. 
A segunda questão sobre como fundir envolve a definição de um método adequado para realizar a fusão. Diversos métodos propostos tentam resolver esse problema, e de forma geral, podem ser divididos em três categorias: baseados em regras, baseados em classificação e baseados em estimação. Os primeiros combinam os resultados por meio de regras, por exemplo, fundindo os resultados por meio de combinação linear. A segunda categoria trata o problema como um problema de classificação, usando por exemplo SVM (Support Vector Machines). Os últimos usam a combinação de características para fazer a estimativa do resultado. Neste trabalho, foi utilizado um método da primeira categoria, que será discutido na seção 3.3.

O terceiro ponto de análise consiste em definir o momento mais adequado para realizar a fusão das características. Um dos problemas a ser resolvido é a obtenção de dados em diferentes taxas. Outro problema consiste em sincronizar os processos de extração das diferentes características. Nas seções seção 3.1 e seção 3.2 são apresentados os métodos utilizados para extrair as características visuais e sonoras, respectivamente.

O último ponto se refere a seleção das características adequadas para a fusão, e a determinação do número de características que serão combinadas por meio do processo de fusão. Diferentes características podem apresentar informações contraditórias, o que pode prejudicar a eficiência do método. No Capítulo 3 é realizada uma discussão sobre os motivos que levaram a escolha das características visuais e sonoras utilizadas.

\subsubsection{Fusão Prévia}

A estratégia de fusão prévia (do inglês, early fusion) consiste em fundir as características no nível dos vetores de características. Com isso, é possível explorar a correlação existente entre características extraídas a partir de diferentes modos em uma fase inicial. Outra vantagem é o fato de toda a análise posterior deve ser feita sobre um único vetor de características.

No entanto, a fusão prévia exige a representação das diversas características em um mesmo formato, o que nem sempre é simples, devido a diferença na natureza dessas características. Além disso, as características devem ser sincronizadas, tarefa que se torna mais complexa com o aumento do número de características utilizadas.

Uma representação dessa estratégia pode ser vista na Figura 2.6. Inicialmente são escolhidas $N$ características para serem combinadas. Após serem combinadas, elas dão origem a um único vetor de características, sobre o qual é feita a decisão da técnica, obtendo um resultado final.

Como benefícios, essa estratégia permite explorar a correlação entre as características em um estágio inicial, facilitando tarefas posteriores. Outra vantagem é a utilização de um único vetor de características (Atrey et al., 2010).

\subsubsection{Fusão Tardia}

A estratégia de fusão tardia (do inglês, late fusion), representada na Figura 2.8, por sua vez, utiliza as diversas características inicialmente de maneira independente. Cada característica passa 


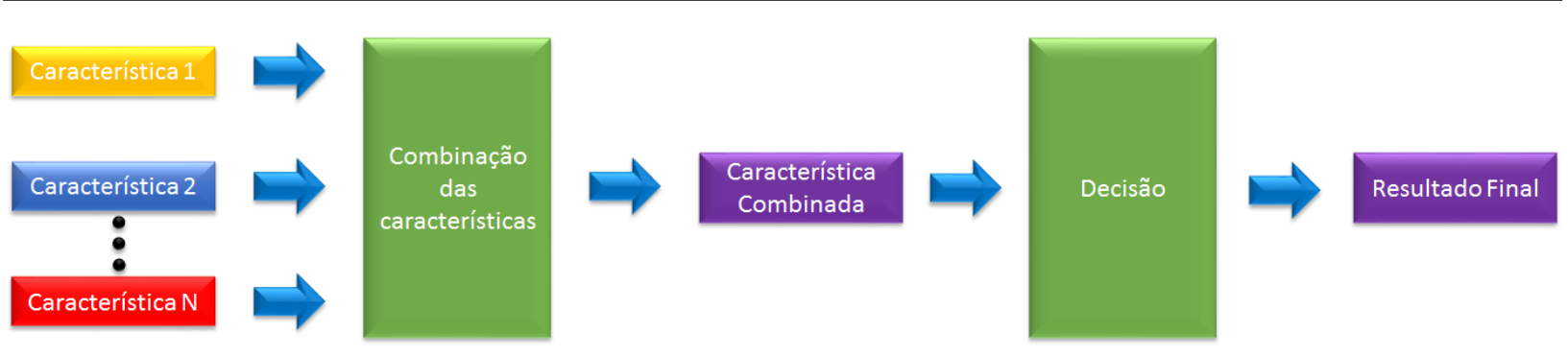

Figura 2.6: Estratégia de fusão prévia.

por um processo de decisão, representado na figura pelos elementos $D 1, D 2$ e $D N$, gerando respectivamente as resposta $R 1, R 2$ e $R N$ para cada uma delas. Em um segundo momento, as respostas obtidas a partir da utilização individual das características passam por um processo de decisão, dando origem ao resultado final da tarefa em questão.

Nessa abordagem, cada característica é tratada de forma independente, o que permite, por exemplo, o uso de técnicas diferentes em cada uma das características, e possivelmente mais adequadas a cada caso. Nessa estratégia não existe o problema da sincronização das características, porém a correlação entre os vetores de características não é explorada, além de que a utilização de métodos diferentes pode exigir maior tempo de processamento.

Outra vantagem dessa técnica em relação a fusão prévia é a escalabilidade, ou seja, a adição de novas características pode ser feita de modo muito mais simples, em relação a fusão prévia, dado que em geral, a representação das respostas tende a ser igual, o que facilita o processo de fusão. Isso não ocorre na fusão prévia, já que as características que serão fundidas podem ser bem diferentes.

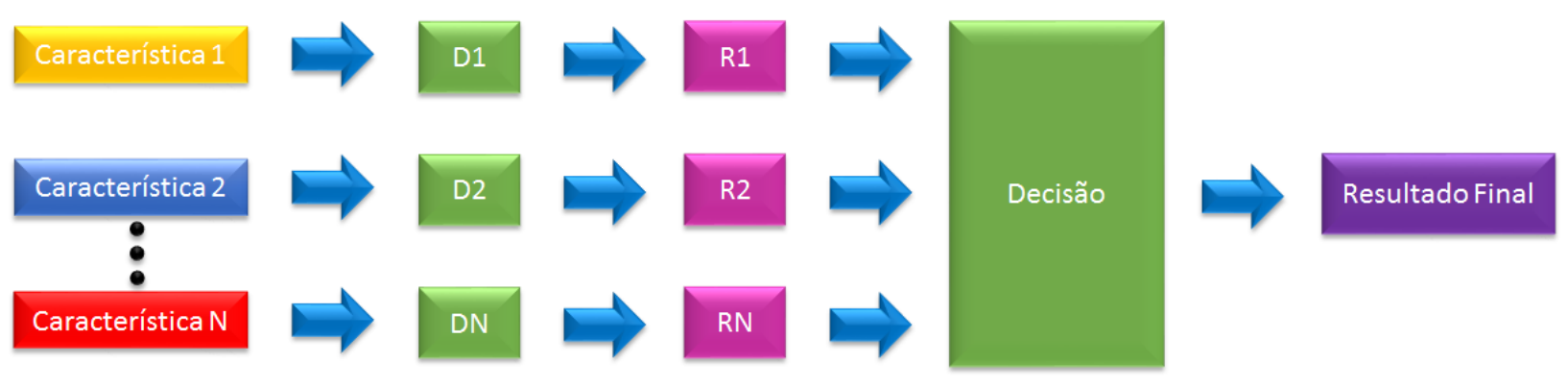

Figura 2.7: Estratégia de fusão tardia.

\subsubsection{Fusão Híbrida}

Já a estratégia híbrida tenta se aproveitar das vantagens das outras duas estratégias, combinando por exemplo, algumas características com a estratégia early fusion e combinando o resultado com as demais usando a abordagem late fusion. Qualquer combinação entre as estratégias prévia e tardia é considerada híbrida,

Essa estratégia pode ser vista na Figura 2.7, na qual as características de 1 a $N-M$ são combinadas usando a estratégia de fusão prévia gerando a característica combinada $C C 1$, bem 
como as características de $N-M+1$ até $N$, que geram a característica combinada $C C 2$. Sobre cada característica combinada, é tomada uma decisão $D 1$ e $D 2$ que geram as respostas parciais $R 1$ e $R 2$. Essas respostas então são combinadas com a estratégia de fusão tardia, gerando a resposta final.

Essa estratégia pode ser adequada em um contexto que envolva o uso de muitas características, as quais podem ser muito diferentes entre si. Nesse caso, características divergentes poderiam ser combinadas usando fusão tardia e características semelhantes usando fusão prévia. Entretanto, essa estratégia é computacionalmente mais custosa, pois a decisão não é tomada em um único passo, pois exige dois ou mais níveis de decisão.

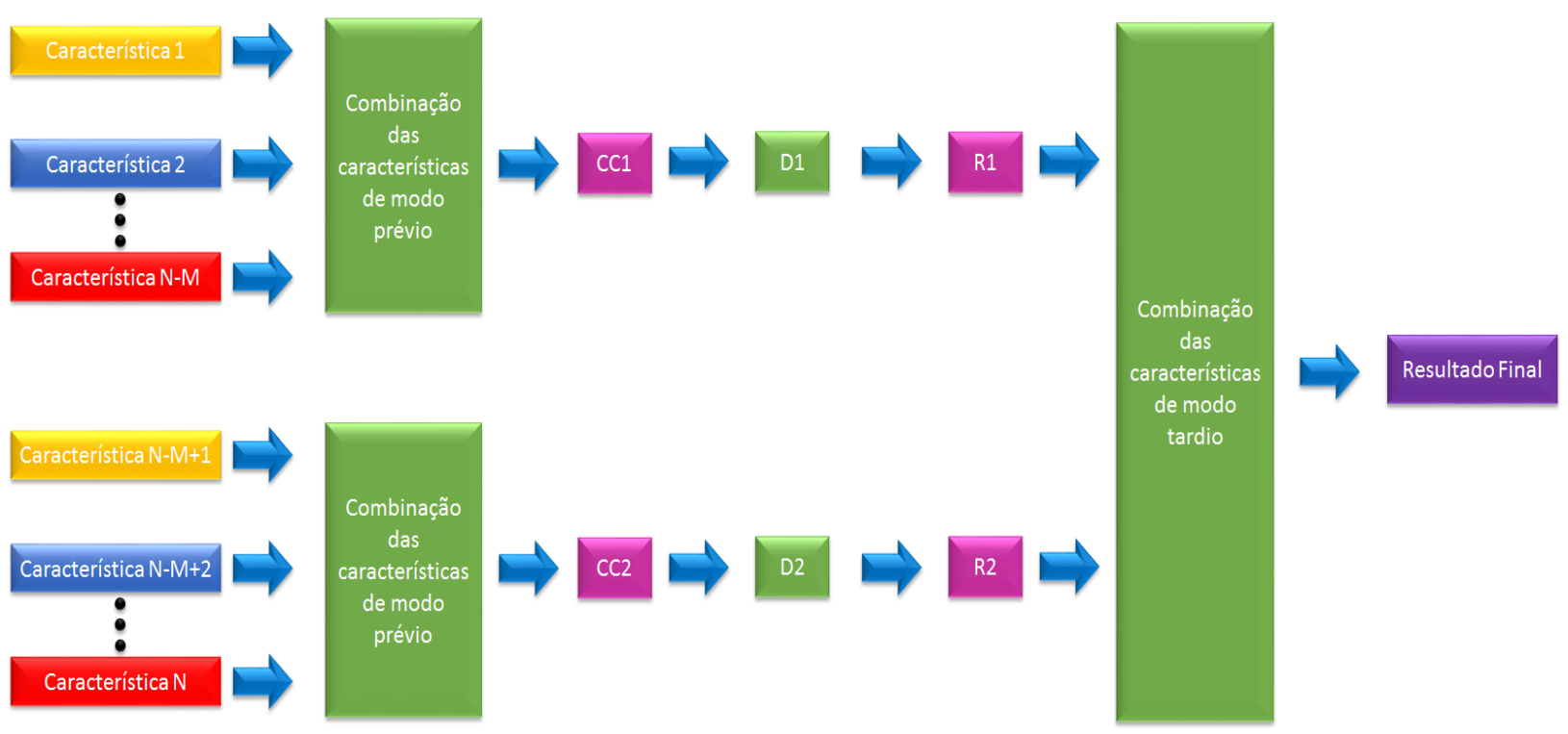

Figura 2.8: Estratégia de fusão híbrida.

\subsection{Avaliação}

Nesta seção serão apresentados dois tipos de medida: medidas de avaliação e medidas de similaridade. Enquanto as primeiras são utilizadas para avaliar os resultados obtidos por uma determinada técnica, as últimas são utilizadas para avaliar o quão semelhantes são dois elementos. Elas são apresentadas respectivamente nas subseções 2.6.6 e 2.6.6

\subsubsection{Medidas de Avaliação}

As medidas de avaliação são importantes para métodos de recuperação de informação. Por meio delas, é possível conhecer o quão eficiente o método utilizado é em relação à capacidade de recuperar informações, e o quão corretas estão essas informações (Davis e Goadrich, 2006).

Duas medidas muito utilizadas para essa finalidade são a Precisão e Abrangência (do inglês, Precision and Recall) (Rijsbergen, 1979; Hua et al., 2002). A Precisão avalia a proporção de termos 
corretos retornados pela pesquisa em relação aos termos extraídos. Um alto valor indica que dos resultados retornados pela técnica, a maioria está correta. A Precisão é definida pela Equação 2.3, na qual $V_{p}$ representa o número de verdadeiros positivos, ou seja, o número de termos corretamente identificados, e $F_{p}$ o número de falsos positivos, termos identificados erroneamente.:

$$
P=\frac{V_{p}}{V_{p}+F_{p}}
$$

A Abrangência por sua vez, avalia a proporção de termos corretos retornados em comparação aos termos corretos existentes na base. Ou seja, um alto valor indica que a maioria dos termos corretos foi encontrado. Formalmente são a Abrangência é definida pela Equação 2.4, na qual $V_{p}$ representa o número de verdadeiros positivos, e $F_{n}$ o número de falsos negativos, ou seja, termos que não foram identificados de modo incorreto:

$$
A=\frac{V_{p}}{V_{p}+F_{n}}
$$

Outra medida comumente usada para avaliar a eficiência de métodos de recuperação é a $F$ Measure.

A F-Measure é definida como a média harmônica da precisão e a da abrangência. A $F_{1}$ é um tipo de F-Measure e determina o mesmo peso para a Precisão e para a Abrangência (Rijsbergen, 1979). No contexto deste trabalho, essa é uma característica desejável, uma vez que ambas medidas são igualmente importantes para avaliar uma técnica para detecção de cenas. O único modo de uma determinada técnica apresentar um valor alto de $F_{1}$ é ter uma alta precisão e uma alta abrangência (Qi et al., 2003). Em outras palavras, a técnica tem que encontrar a maior parte das cenas reais, e a maioria das cenas identificadas deve ser correta. A $F_{1}$ é dada pela Equação 2.5 (Rijsbergen, 1979), na qual $P$ é a Precisão, e $A$ é a Abrangência.

$$
F_{1}=\frac{2 \times P \times A}{P+A}
$$

Considerando o contexto de avaliação de um segmentador de cenas de vídeo, percebe-se que essas medidas podem ser aplicadas para avaliar sua eficiência. Para isso, deve-se considerar cada fronteira entre cenas apontada corretamente pelo segmentador como sendo um $V_{p}$. De maneira análoga, cada fronteira apontada erroneamente deve ser encarada como um $F_{p}$. Já cada fronteira real não identificada pela técnica é um $F_{n}$. Sendo assim, pode-se utilizar as medidas apresentadas para a avaliação de um segmentador de vídeo tal qual em (Mitrovic et al., 2010; Kumar et al., 2011). 


\subsubsection{Medidas de Similaridade}

As medidas de similaridade estão presentes em diversas áreas do conhecimento humano, tais como matemática, física e biologia. O objetivo delas é permitir a comparação de algum tipo de dado ou padrão (Cha, 2007). Essa característica permite identificar elementos semelhantes.

Formalmente, uma medida de similaridade tem como principal característica avaliar o quão semelhantes são dois elementos. De maneira oposta, funções de distância, ou medidas de dissimilaridade, são caracterizadas por avaliar o nível de diferença entre dois elementos. Percebe-se que elas têm naturezas opostas, e dada uma medida de similaridade $M S$ e uma função de distância $F D$, é possível estabelecer a seguinte relação:

$$
M S_{i, j}=1-F D_{i, j}
$$

onde $M S_{i, j}$ é a similaridade entre os elementos $i$ e $j$, e $F D_{i, j}$ é a distância entre eles, sendo que $F D_{i, j} \leq 1$.

Algumas medidas frequentemente empregadas em trabalhos presentes na literatura são: Distância Euclideana, Distância do Valor Estatístico $\chi^{2}$, e Intersecção de Histogramas. Enquanto as duas primeiras são funções de distância, a última é uma medida de similaridade. Elas serão apresentadas a seguir, visto que podem ser usadas na elaboração dos dicionários visuais e dos histogramas da técnica Bag of Visual Words.

A Distância Euclideana faz parte da família de distâncias Minkowski (Wilson e Martinez, 1997), denominada $L_{p}$. Essa família de distâncias é geralmente empregada em espaços vetoriais. Para um espaço ser denominado vetorial, é necessário que os objetos de um determinado domínio $D$ sejam representados por valores numéricos estruturados em vetores.

Supondo um espaço vetorial com dimensão $n$, dois objetos podem ser representados por dois vetores com $n$ coordenadas de valores reais, sendo respectivamente $X=\left(x_{1}, x_{2}, \ldots, x_{n}\right)$ e $Y=$ $\left(y_{1}, y_{2}, \ldots, y_{n}\right)$. Nessa situação, a família de distâncias $L_{p}$ entre eles é definida pela Equação 2.9.

$$
L_{p}(X, Y)=\sqrt[p]{\sum_{i=1}^{n}\left|x_{i}-y_{i}\right|^{p}}
$$

A distância Euclideana, também chamada de Distância $L_{2}$ (Sinha e Shukla, 2013; Patil e Talbar, 2012), pode ser calculada para dois pontos $X=\left(x_{1}, x_{2}\right)$ e $Y=\left(y_{1}, y_{2}\right)$ de acordo com a Equação 2.8:

$$
D_{e}(X, Y)=\sqrt{\left(x_{1}-y_{1}\right)^{2}+\left(x_{2}-y_{2}\right)^{2}}
$$

Essa equação pode ser generalizada para pontos com mais de duas dimensões (ou vetores), como por exemplo $X=\left(x_{1}, x_{2}, \ldots, x_{n}\right)$ e $Y=\left(y_{1}, y_{2}, \ldots, y_{n}\right)$, com dimensão dois, por meio da Equação 2.9 (Patil e Talbar, 2012):

$$
D_{e}(a, b)=\sqrt{\left(x_{1}-y_{1}\right)^{2}+\left(x_{2}-y_{2}\right)^{2}+\ldots\left(x_{n}-y_{n}\right)}
$$


ou de forma simplificada, pela Equação 2.10, que está de acordo com a Equação 2.7:

$$
D_{e}(a, b)=\sqrt{\sum_{i=1}^{n}\left(x_{i}-y_{i}\right)^{2}}
$$

Por se tratar de uma distância, quanto maior for o valor resultante, menos similares são os vetores. Por essa razão, a Distância Euclidiana é chamada de medida de dissimilaridade. Essa distância têm sido utilizada em diversos trabalhos para a comparaçao de histogramas gerados pela técnica Bag of Visual Words, apresentando bons resultados (Sivic e Zisserman, 2003; Yang et al., 2010; Wang et al., 2011), fator que motivou a sua escolha neste trabalho. Além disso, essa distância é uma das mais utilizadas da família de distâncias $L_{p}$.

A Distância do Valor Estatístico $\chi^{2}$ é calculada pela somatória da divisão da diferença ao quadrado entre cada frequencia observada e teórica para cada resultado possível pela frequencia teórica. Formalmente é dada pela Equação 2.11:

$$
D_{\chi^{2}}(X, Y)=\sum_{i=1}^{n} \frac{\left(y_{i}-m_{i}\right)^{2}}{m_{i}}
$$

Segundo Bugatti (2008), essa distância valoriza as discrepâncias entre dois vetores de características comparados, e mensura quão improvável é a distribuição, sendo muito adequada para a comparação de histogramas, um dos fatores que motivou sua escolha. Sua natureza estatística, diferente da família $L_{p}$, também favoreceu seu uso neste trabalho. Para efeitos de simplicidade, em todo o restante do texto, essa distância será denominada distância $\chi^{2}$.

A intersecção de histogramas, proposta em (Swain e Ballard, 1991), é uma técnica desenvolvida para a indexação de cores, com o objetivo de reconhecer objetos. Apesar de originalmente ser aplicada somente em histogramas de cores, outros tipos de histograma tem sido utilizados em conjunto com essa técnica, e ela tem sido utilizada em diversos trabalhos de segmentação de vídeo com bastante sucesso (Ngo et al., 2000; Zhai e Shah, 2005a; Chen et al., 2008). Essa medida avalia a similaridade entre dois histogramas, sendo capaz de tratar mesmo mudanças de escala.

Dados dois histogramas $A$ e $B$, com $m$ partições, a intersecção de histogramas $H_{i}$ entre eles é dada pela Equação 2.12:

$$
H_{i}\left(h_{1}, h_{2}\right)=\sum_{i=1}^{m} \min \left(h_{1 i}, h_{2 i}\right)
$$

\subsection{Considerações Finais}

Nesse capítulo foram apresentados alguns conceitos importantes para a compreensão deste trabalho como descritores de características, medidas de similaridade e de avaliação. Além disso, foi explicitada a relação entre esses conceitos. 
A técnica Bag of Visual Words foi apresentada e foi ressaltada sua capacidade de capturar a semântica latente presente em imagens, o que reforça a premissa de utilizá-la para a segmentação de vídeo. Alguns problemas dessa técnica também foram discutidos.

Uma revisão da literatura foi realizada sobre segmentação de vídeo em cenas, apresentando a evolução e o estado da arte dessa área. Algumas lacunas foram expostas, em especial a dependência de bases de teste, dependência do domínio de vídeo, não-tratamento de segmentos semanticamente complexos. Essas limitações inspiraram a elaboração do presente trabalho, que visa tratar algumas dessas lacunas. No Capítulo 3 a técnica desenvolvida é descrita, com argumentação sobre as decisões tomadas. Também são apresentados os passos necessários para a sua utilização. 


\section{3}

\section{Segmentação em Cenas Baseada em Bag of Visual Words Multimodal}

Neste capítulo será apresentada a técnica multimodal de segmentação de vídeo baseada em Bag of Visual Words desenvolvida neste trabalho. Essa técnica faz uso de características visuais (seção 3.1), sonoras (seção 3.2) e combina seus resultados (seção 3.3) utilizando fusão tardia, gerando os resultados finais da segmentação. Cada parte da técnica será apresentada na seção correspondente, onde serão discutidos seus detalhes.

\subsection{Segmentação em Cenas com Descritores Visuais}

A parte visual de vídeos tem sido utilizada em diversos trabalhos de detecção de cenas em vídeos (Mohanta et al., 2010). Esse fato pode ser explicado pela capacidade da parte visual de transmitir uma grande parte da semântica latente presente em um vídeo, comprovada em vários trabalhos (Fabro e Böszörmenyi, 2013; Coimbra, 2011; Iurgel et al., 2001).

Várias abordagens puramente visuais para a detecção de cenas têm sido propostas, como (Tapu e Zaharia, 2012; Bredin, 2012; Zhai e Shah, 2005b). Uma das lacunas dessas abordagens é o fato de considerarem somente aspectos como similaridade visual e quantidade de movimento como modo de segmentar cenas, sem levar em conta a semântica envolvida.

Visando superar essa limitação, uma das abordagens que se destaca é o uso de descritores visuais (Mohanta et al., 2010). A literatura apresenta trabalhos que utilizam diferentes descritores visuais como SIFT (Lowe, 1999, 2004), SURF (Bay et al., 2006, 2008) e MSER (Maximally Stable 
Extremal Regions)(Matas et al., 2002). Em comum, esses descritores tem a capacidade de representar as imagens de um modo compacto. Essa representação compacta das imagens é explorada por técnicas como a Bag of Visual Words, que, como mencionado anteriormente, é capaz de extrair a semântica latente das imagens, por meio da utilização de descritores visuais. No contexto da segmentação de vídeos em cenas, essa propriedade pode ser muito útil, uma vez que tomadas pertencentes a uma mesma cena tendem a preservar alguns elementos visuais, tais como atores ou objetos (Kumar et al., 2011).

Portanto, a tarefa de segmentar um vídeo em cenas pode ser vista como o ato de agrupar tomadas subsequentes semanticamente relacionadas (Rui et al., 1999; Cour et al., 2008). No entanto, a técnica Bag of Visual Words foi proposta originalmente com o intuito de representar imagens por meio de histogramas de palavras visuais, e não tomadas. Sendo assim, é necessária a definição de uma representação adequada para a tomada, capaz de capturar a semântica latente da tomada, assim como é feito para uma imagem.

Com essa representação, passa a ser possível identificar as tomadas semanticamente semelhantes e agrupá-las. Uma possível abordagem, seria representar a tomada com o conjunto de histogramas de palavras visuais de todos os quadros presentes na tomada. Para isso, seria necessário aplicar a técnica Bag of Visual Words para todo os quadros de um vídeo, tarefa computacionalmente cara, uma vez que um vídeo pode ter um grande número de quadros.

Para contornar esse problema, uma possibilidade é selecionar um conjunto reduzido de quadros de cada tomada capaz de representá-la adequadamente. Essa abordagem é denominada seleção automática de quadros-chave, e várias soluções deste problema foram propostas na literatura. Algumas das mais simples são a utilização do primeiro, último ou quadro mediano da tomada, ou mesmo uma combinação deles (Rui et al., 1998). Outra abordagem, proposta em (Doulamis et al., 2000), é o cálculo do fluxo ótico, seguido da detecção de mínimos locais de uma determinada medida de movimento. Os mínimos locais indicam os quadro-chave. Truong e Venkatesh (2007) apresentam uma extensa revisão bibliográfica de técnicas de seleção automática de quadros-chave.

Neste trabalho, optou-se pela utilização da técnica de seleção de quadros-chave descrita na seção 3.1.1, que apresenta algumas características interessantes, como utilização de número váriavel de quadros-chave para cada tomada, e determinação automática desse número.

Após a seleção dos quadros representativos de cada tomada, descritores visuais são extraídos de cada quadro, e a ténica Bag of Visual Words é aplicada para computar um histograma representante de cada tomada, que é dado pela soma das palavras visuais presentes em cada um dos quadroschave. Cada histograma é suavizado e os cortes de cena são detectados. Esses dois passos são detalhados na seção 3.1.1.

\subsubsection{Detecção de Quadros-Chave}

A seleção de quadros-chave de uma tomada envolve a escolha de um número potencialmente bem menor de quadros que compõem a tomada, mas que consigam representá-la mesmo assim. 
Essa atividade permite uma representação compacta da tomada, sem que, no entanto ela perca sua representatividade. A representação compacta da tomada oferece entre outros benefícios a redução do custo computacional da análise da tomada, bem como do espaço necessário para armazená-la (Pimentel Filho et al., 2008).

Existem várias abordagens para a seleção de quadros-chave, que variam desde a seleção de um único quadro, como por exemplo, o primeiro, ou o do meio, até técnicas que selecionam números diferentes de quadros-chave, de acordo com cada tomada. Nesse trabalho, optou-se pelo método proposto em (Chasanis et al., 2008). Esse método foi escolhido por determinar automaticamente o número de quadros-chave necessários para representar cada tomada, e por apresentar altas taxas de similaridade média e SRD (Shot Reconstruction Degree) (Chasanis et al., 2008), superiores a outros métodos de seleção de quadros-chave.

Esse método tem como pressuposto que as tomadas já foram previamente segmentadas, ou seja, foi realizada uma definição de quais quadros fazem parte de cada tomada do vídeo. Uma base com a segmentação de todos os filmes utilizados neste trabalho foi gerada, e será discutida no Capítulo 4.

É importante destacar, que o método aqui apresentado não tem como objetivo segmentar um vídeo em tomadas, mas sim determinar os quadros-chave de uma determinada tomada. Para realizar essa atividade, o método escolhido utiliza histogramas HSV normalizados, com dezesseis partições, sendo oito para a matiz, quatro para a saturação e quatro para o valor (brilho). Uma representação do método é ilustrada na Figura 3.1.

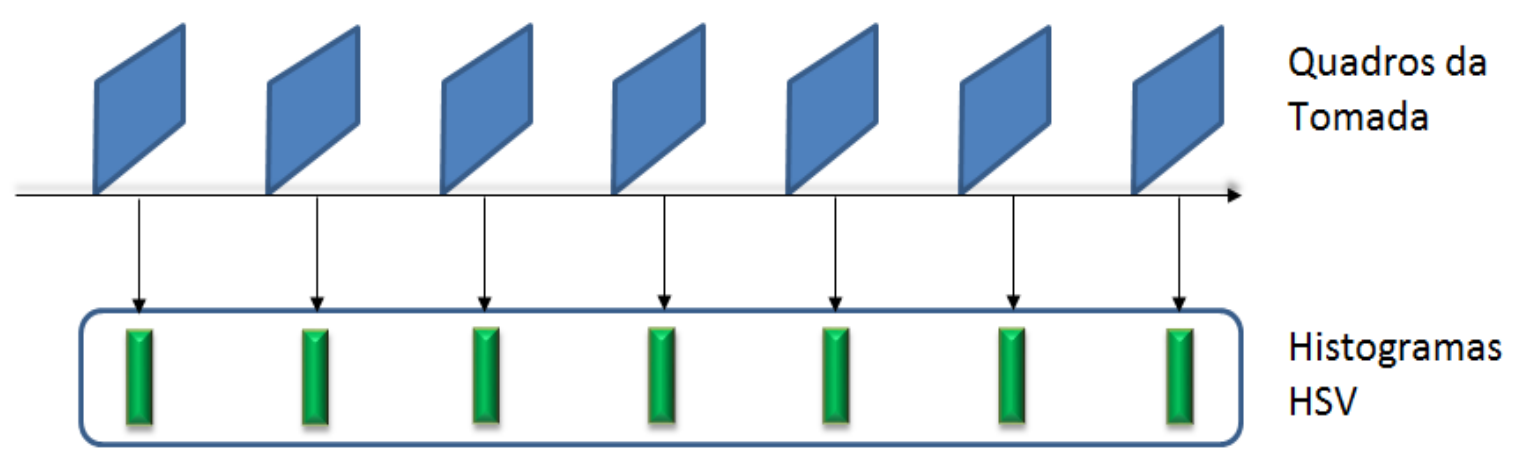

Algoritmo de Agrupamento

Espectral

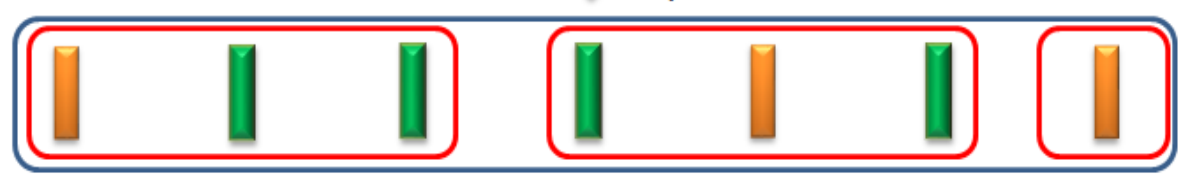

Grupos e

Quadros-Chave

Figura 3.1: Método para detecção de quadros-chave de uma tomada.

Nessa figura, os retângulos azuis na parte superior representam os $N$ quadros de uma determinada tomada. Para cada um desses quadros, são computados histogramas HSV, representados pelos retângulos verdes da figura. O algoritmo de agrupamento espectral ( $\mathrm{Ng}$ et al., 2001) é então aplicado sobre esse conjunto de histogramas HSV. Além desse algoritmo determinar automaticamente 
o número $k$ de grupos, ainda ele apresenta desempenho melhor em relação a outros algoritmos de agrupamento, como K-Means (Ng et al., 2001).

Na Figura 3.1, os grupos encontrados estão circulados em vermelho. Sendo assim, para o exemplo dessa figura, foram encontrados três grupos, sendo dois grupos constituídos de três elementos, e um grupo com apenas um elemento.

Para cada grupo encontrado, é selecionado o medóide, que é definido como o quadro que apresenta a maior similaridade média para os demais componentes do grupo (Struyf et al., 1997). Essa característica é importante na determinação de quadros-chave, já que esses são representantes da tomada, e como tal devem ser parecidos com os demais quadros que representam. Por isso, o medóide de cada grupo é denominado quadro-chave da tomada. Na Figura 3.1 os medóides são representados por retângulos laranja. Como para cada tomada, o algoritmo de agrupamento espectral encontra um ou mais grupos, o conjunto de quadros-chave obtidos é a representação compacta da tomada.

Após essa breve descrição do método, será apresentada a seguir uma definição formal do mesmo. Supondo a existência de um conjunto $S=s_{1}, s_{2}, \ldots, s_{N}$ com $N$ quadros em uma determinada tomada, e considerando que serão determinados $K$ quadros-chave, sendo $K$ determinado automaticamente (detalhes desse procedimento serão discutidos mais adiante), os passos desse algoritmo de seleção de quadros-chave são apresentados abaixo:

1. Computar a matriz de similaridade $A$ e $R_{N \times N}$, sendo $a_{i, j}$ a similaridade entre o quadro $i$ e o quadro $j$.

2. Definir a matriz diagonal $D$, tal que cada elemento $d_{i, i}$ é a soma dos elementos da linha $i$ da matriz $A$.

3. Obter a matriz Laplaciana $L$, tal que:

$$
L=I-D^{-\frac{1}{2}} \cdot A D^{-\frac{1}{2}}
$$

4. Encontrar os $K$ principais autovetores $X$, com dimensões $N \times K$, tal que:

$$
X=\left[x_{1}, x_{2}, \ldots, x_{K}\right]
$$

5. Normalizar cada linha da matriz $X$ para ter o tamanho unitário e formar a matriz $Y$ tal que:

$$
y_{i j}=\frac{x_{i j}}{\sum_{j}\left(x_{i j}^{2}\right)^{\frac{1}{2}}}
$$

6. Agrupar as linhas de $Y$ em $K$ grupos usando o algoritmo $K$-Means.

7. Determinar que o quadro $i$ faz parte do grupo $j$ se, e somente se, a linha $i$ da matriz $Y$ for designada ao grupo $j$. 
8. Para cada grupo, determinar o medoide do grupo, tal que a similaridade média dele em relação aos demais componentes do grupo seja a maior. O quadro representado pelo medoide é escolhido como um dos quadros-chave da respectiva tomada.

É importante ressaltar o modo pelo qual o número $K$ é determinado no passo 4 . São considerados os primeiros $K$ autovalores ordenados de forma decrescente que são maiores que um determinado limiar. Segundo Chasanis et al. (2008), o valor do autovalor $\lambda_{K+1}$ representa a melhoria que a adição do grupo $K+1$ proporciona no critério de otimização da solução. Portanto, quanto menor esse incremento, menos significativa é a utilização de mais um grupo, ou seja, de mais um quadro-chave.

Sendo assim, a utilização de um limiar impede que sejam adicionados quadros-chave que promoverão uma melhoria insignificante ou desprezível. No caso deste trabalho, foi utilizado o limiar 0,05, que segundo Chasanis et al. (2008) apresenta bons resultados. Limiares na faixa de 0,01 até 0,10 foram testados, e o limiar 0,05 se confirmou como o melhor limiar.

Também se faz necessário informar que a similaridade entre dois quadros computada no passo 1 é definida utilizando a distância Euclideana entre os histogramas normalizados HSV dos quadros da tomada. Supondo que o conjunto de histogramas normalizados de uma tomada sejam dados pela Equação 3.4:

$$
H=H_{1}, H_{2}, \ldots, H_{N}
$$

na qual $H_{i}$ representa o histograma normalizado do quadro $i$, então o elemento $a(i, j)$ é computado pela Equação 3.5:

$$
a_{i, j}=1-\sqrt{\sum_{h \in b i n s}\left(H_{i}(h)-H_{j}(h)\right)^{2}}
$$

Chasanis et al. (2008) reporta que esse método apresenta alta precisão em representar tomadas, e é capaz de definir automaticamente o número de quadros-chave para a tomada, duas propriedades interessantes para a técnica proposta.

\subsubsection{Detecção de Cortes de Cenas}

A técnica para a detecção de cortes de cenas, proposta em (Lopes e Goularte, 2013), tem como entrada as tomadas, previamente segmentadas, representadas pelos seus quadros-chave, que são determinados com a utilização do método apresentado na seção 3.1.1.

A partir de cada quadro-chave, são extraídos vetores de características visuais, com a utilização de algum descritor visual. Neste trabalho, são utilizados os descritores SIFT e SURF, e seus resultados são discutidos na seção 4.3. Essa situação é retratada na Figura 3.2, onde para cada quadro-chave (retângulos laranja) das $T$ tomadas de um determinado vídeo, são extraídos conjuntos de vetores de características, representados pelos círculos vermelhos. 

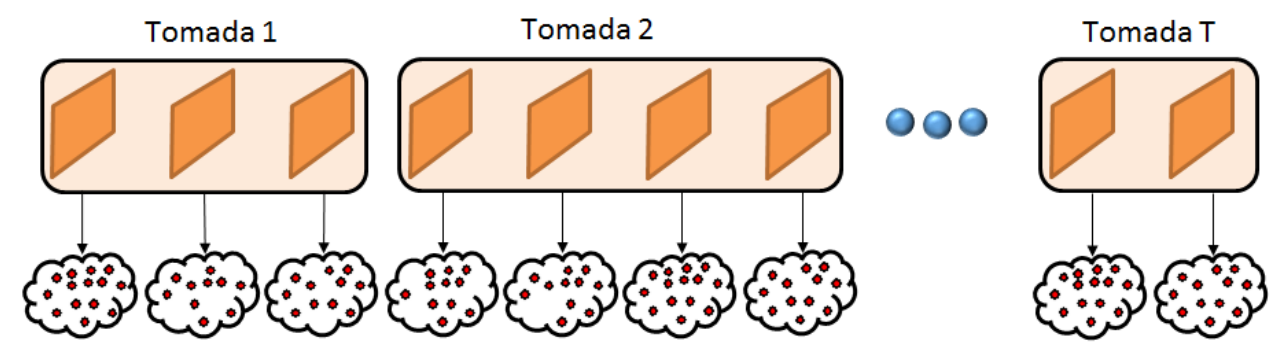

Conjuntos de

Descritores Visuais

Figura 3.2: Extração de vetores de características visuais dos quadros-chave de uma tomada.

O total de descritores extraídos a partir de todos os quadros-chave de todas as tomadas pertencentes a um determinado vídeo formam a base que vai ser utilizada pela técnica Bag of Visual Words. Essa técnica é a responsável pela geração de um vocabulário de palavras visuais, conforme ilustrado na Figura 3.3. Nessa figura, os vetores de características visuais extraídos são representados pelos círculos vermelhos. Após a utilização de um algoritmo de agrupamento, são encontrados grupos de vetores, e para cada grupo é encontrado o centróide, conforme explicado anteriormente. Na Figura 3.3 esses centróides são representados pelo triângulo verde, losango rosa, quadrado azul e hexágono amarelo. Esses centróides são escolhidos como as palavras visuais que compõem o vocabulário de palavras visuais.
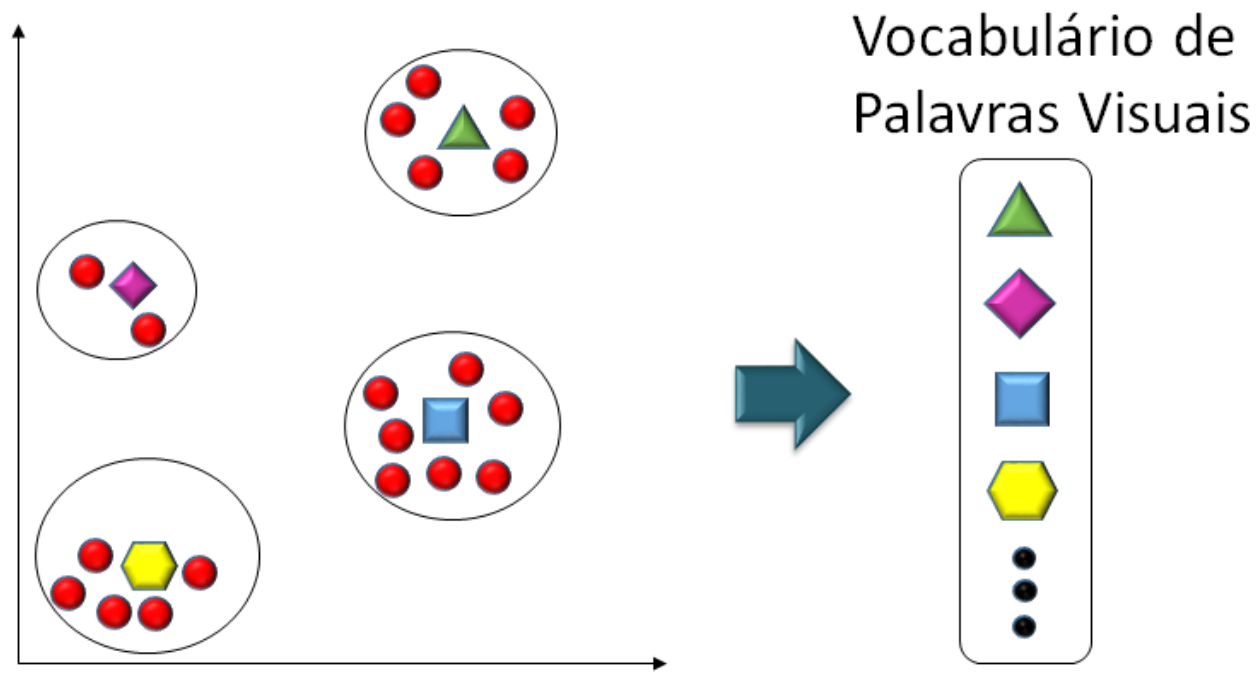

Figura 3.3: Geração do vocabulário de palavras visuais.

Com o vocabulário gerado, é possível definir um histograma para representar cada tomada. Isso é realizado aproximando cada vetor de características extraído dos quadros-chave de uma tomada pela palavra visual mais próxima, segundo uma medida de distância. Desse modo, é gerado um histograma com a quantidade de ocorrências das palavras do vocabulário na tomada.

Embora os histogramas gerados pela técnica Bag of Visual Words possam preservar a semântica presente em tomadas similares visualmente, há situações nas quais tomadas consecutivas são visualmente diferentes, contudo fazem parte da mesma cena. 
Um exemplo é uma cena que apresente o diálogo por telefone de dois personagens. Eles podem estar em lugares completamente diferentes, o que fará com que os histogramas das tomadas em que aparecem sejam bem diferentes, porém estarão intercalados. Nesse caso, uma técnica puramente visual possivelmente detectaria falsamente diversas cenas, ao invés de uma única cena, que apresenta tomadas visualmente diferentes, porém semanticamente relacionadas.

Uma situação análoga pode ser vista na Figura 3.4. Nessa figura, cada imagem é um quadrochave de cada tomada de uma cena retirada do filme 60 segundos, na qual ocorre um diálogo por rádio entre os ladrões do filme. Nessa cena, os ladrões estão em locais distintos, e visualmente bem diferentes. As tomadas estão intercaladas, e pode-se perceber que as tomadas quatro e sete (da esquerda para a direita e de cima para baixo) são visuamente bem diferentes das demais, contudo fazem parte da mesma cena.

Seria adequado ter um modelo capaz de representar a influência de tomadas vizinhas (temporalmente) em uma determinada tomada. Nesse modelo tomadas mais próximas exercem uma influência maior do que tomadas mais distantes.

Na Figura 3.5 temos a representação desse modelo. Nessa figura, a tomada analisada encontrase representada pelo retângulo verde no centro da imagem. As tomadas mais próximas apresentam maior influência nessa tomada, e por isso estão representadas em um tom de azul mais escuro. As demais tomadas, quanto mais distantes temporalmente da tomada analisada, apresentam menor influência e portanto são representadas em um tom de azul mais fraco.

No domínio de textos, a ideia de elementos vizinhos ou próximos influenciarem cada elemento tem sido investigada com a utilização de um kernel local de suavização (Lebanon et al., 2007). Esse kernel é responsável por determinar quanto uma palavra interfere nas palavras vizinhas.

No domínio dos vídeos, é possível aplicar uma ideia semelhante (Chasanis et al., 2009). Nessa situação, as palavras do texto podem ser vistas como as tomadas de um vídeo, e os parágrafos como cenas, uma vez que assim como cada parágrafo é um pedaço do assunto de todo o texto, as cenas representam um dos assuntos tratados por um vídeo.

Os histogramas normalizados das tomadas podem ser suavizados com o uso de um kernel gaussiano. Dada uma tomada $t$, seu histograma suavizado $H S$ é computado a partir de seu histograma normalizado $H_{t}$ de acordo com a Equação 3.6:

$$
H S_{t}=\sum_{n=1}^{N} H_{t-n} . K_{\sigma}(t-n),
$$

Onde $K$ é um kernel gaussiano (Evangelista et al., 2007), com média zero, e desvio-padrão $\sigma$, e $N$ é o número de tomadas. O número de histogramas de tomadas vizinhas que serão utilizados para computar o histograma suavizado depende do valor $\sigma$, portanto, ajustando esse valor é possível determinar esse número.

O valor $\sigma$ determina o nível de preservação da informação contextual. Quanto maior ele for, maior o número de histogramas de tomadas utilizados, e consequentemente haverá um agrupa- 

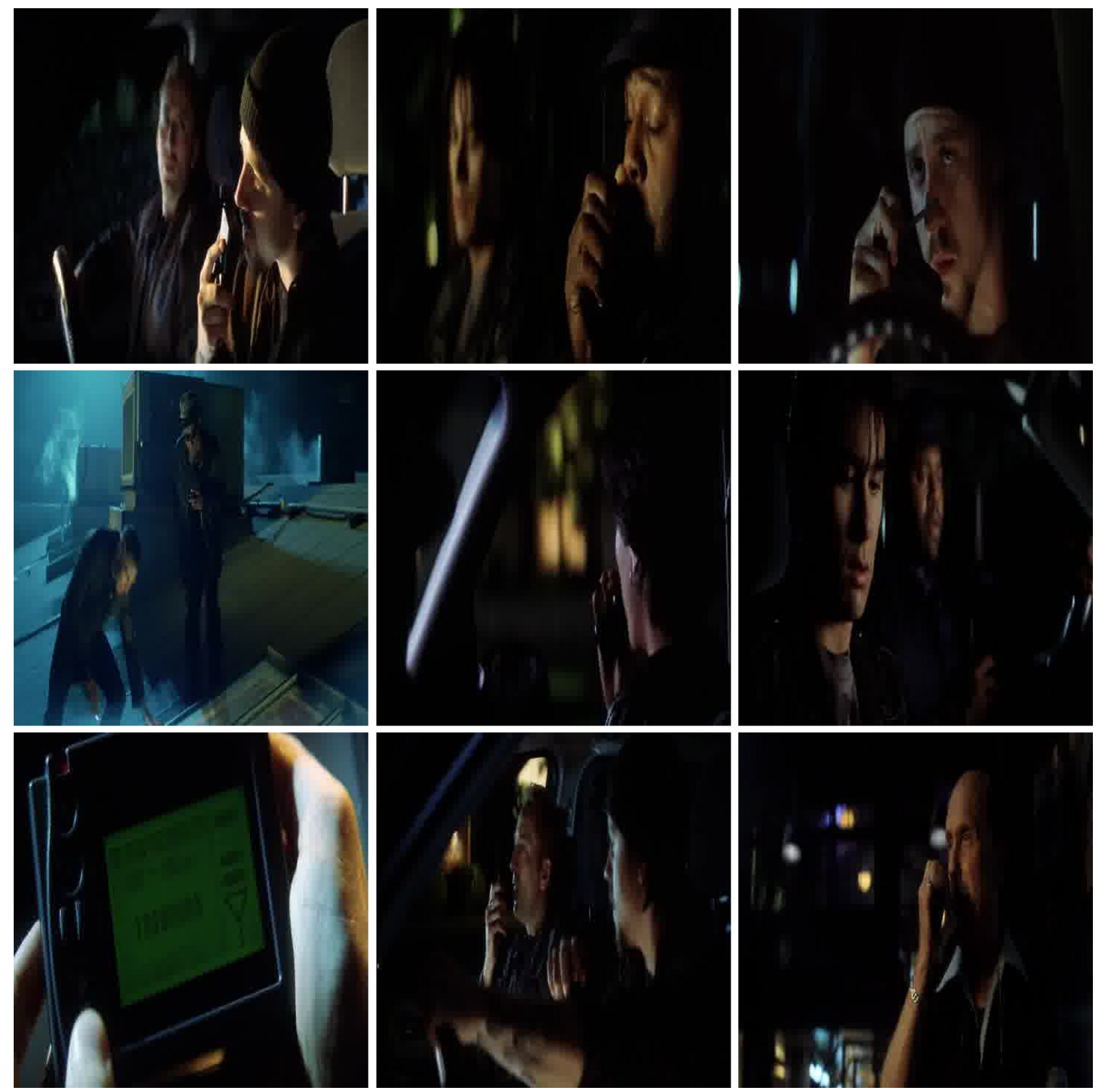

Figura 3.4: Quadros-chave de tomadas de cena do filme 60 Segundos.

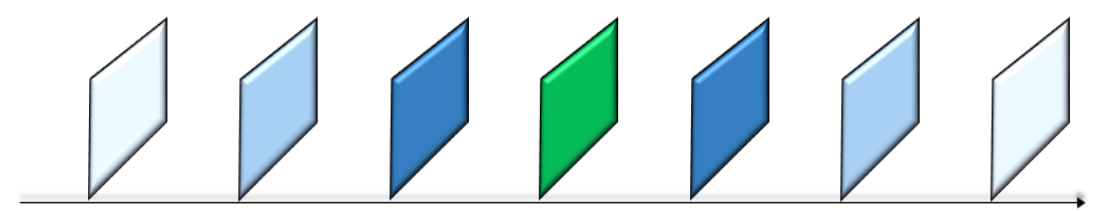

Figura 3.5: Grau de influência das tomadas vizinhas em uma determinada tomada.

mento de tomadas maior em uma cena, pois mais parecidos serão esses histogramas, devido a influência dos histogramas vizinhos. Uma faixa de valores inteiros, variando de quatro a doze foram utilizados, sendo que o valor oito apresentou os melhores resultados, e por isso foi utilizado nos experimentos.

Para determinar as fronteiras das cenas o seguinte procedimento é adotado. Para cada tomada, encontra-se a distância Euclideana entre seu histograma suavizado e o histograma suavizado da 
tomada seguinte (temporalmente). Essa sequencia de valores pode ser vista como uma função $y=f(x)$, onde y é a distância entre a tomada $x$ e a tomada $x+1$.

Os máximos locais da função y são encontrados, e determinam o corte de uma cena entre a tomada $x$ e a tomada $x+1$. Essa situação pode ser vista na Figura 3.6, cuja função $f$ foi feita com base na segmentação do vídeo Era do Gelo.

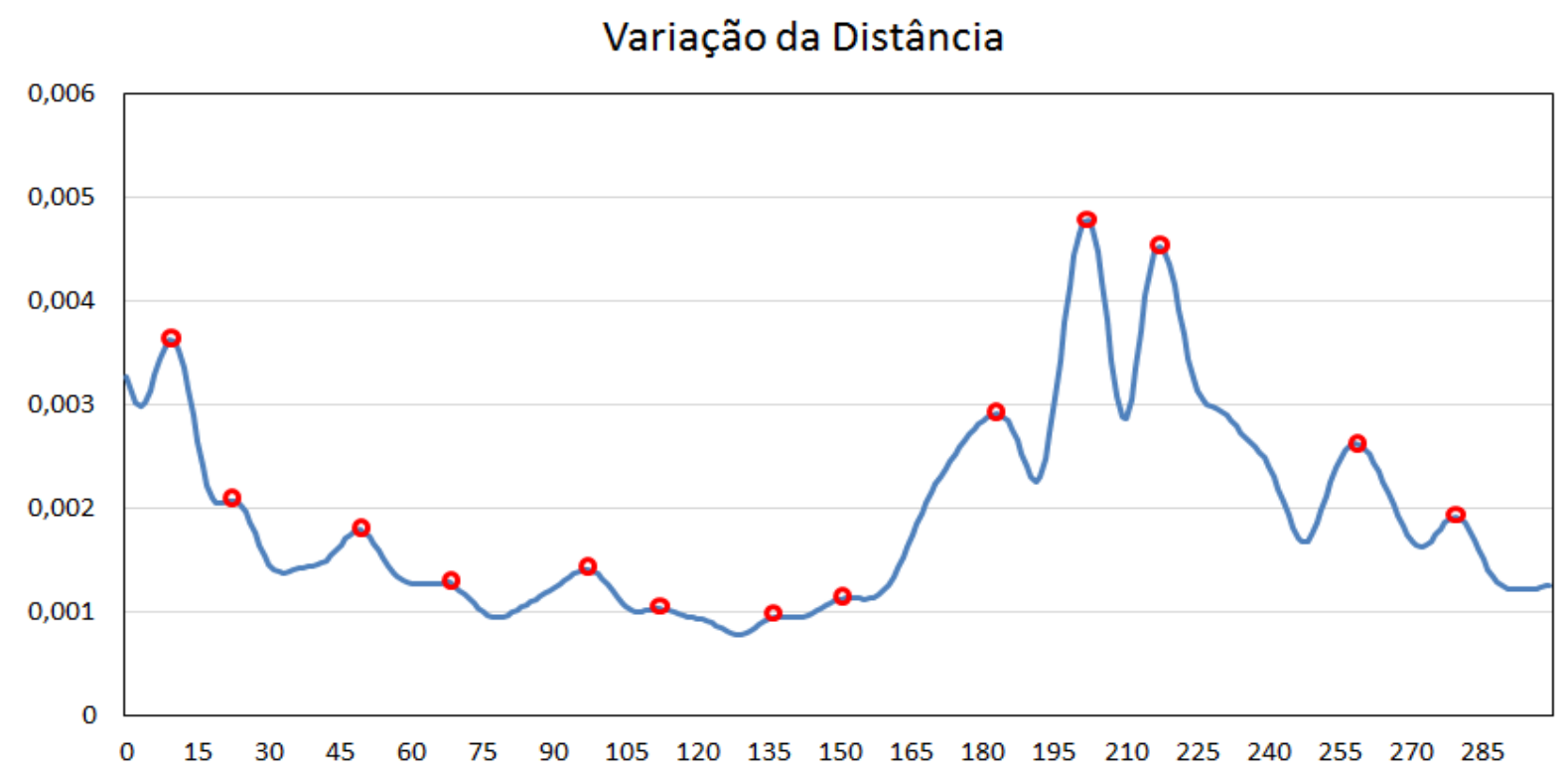

Figura 3.6: Variação da distância entre tomadas subsequentes e determinação de cortes de cenas.

\subsection{Segmentação em Cenas com Descritores Sonoros}

Descritores de áudio tem sido utilizados em diversos trabalhos que tratam problemas como identificação do falante (Hasan e Jamil, 2004), detecção de trechos de áudio falados e não-falados (Bachu e Kopparthi, 2008), recuperação de áudio e música baseada em conteúdo (Foote, 1997), detecção de cópia de vídeo (Liu et al., 2010), entre outros. Três dos descritores de áudio mais comumente utilizados são MFCC (Mel-Frequency Cepstrum Coefficients), LPCC (Linear Prediction Cepstral Coefficients) e Chroma (Giannakopoulos et al., 2010).

A capacidade desses descritores de representar o áudio é muito útil para a resolução de muitos problemas, como os mencionados. Essa capacidade pode ser utilizada para detectar cenas em casos como o ilustrado na 3.7. Nessa figura são apresentadas seis imagens, que são quadros-chave de tomadas do filme Uma Mente Brilhante. As três primeiras tomadas na parte superior compõem uma cena em que John e Alicia conversam sobre a possibilidade de John fazer as tarefas domésticas. Nas outras três tomadas, Alicia questiona John por achar estranho ele dizer que lixeiros trabalham a noite. Apesar das tomadas serem visualmente muito parecidas, inclusive ocorrendo no mesmo espaço físico e com os mesmos atores, em termos sonoros elas são razoavelmente dife- 

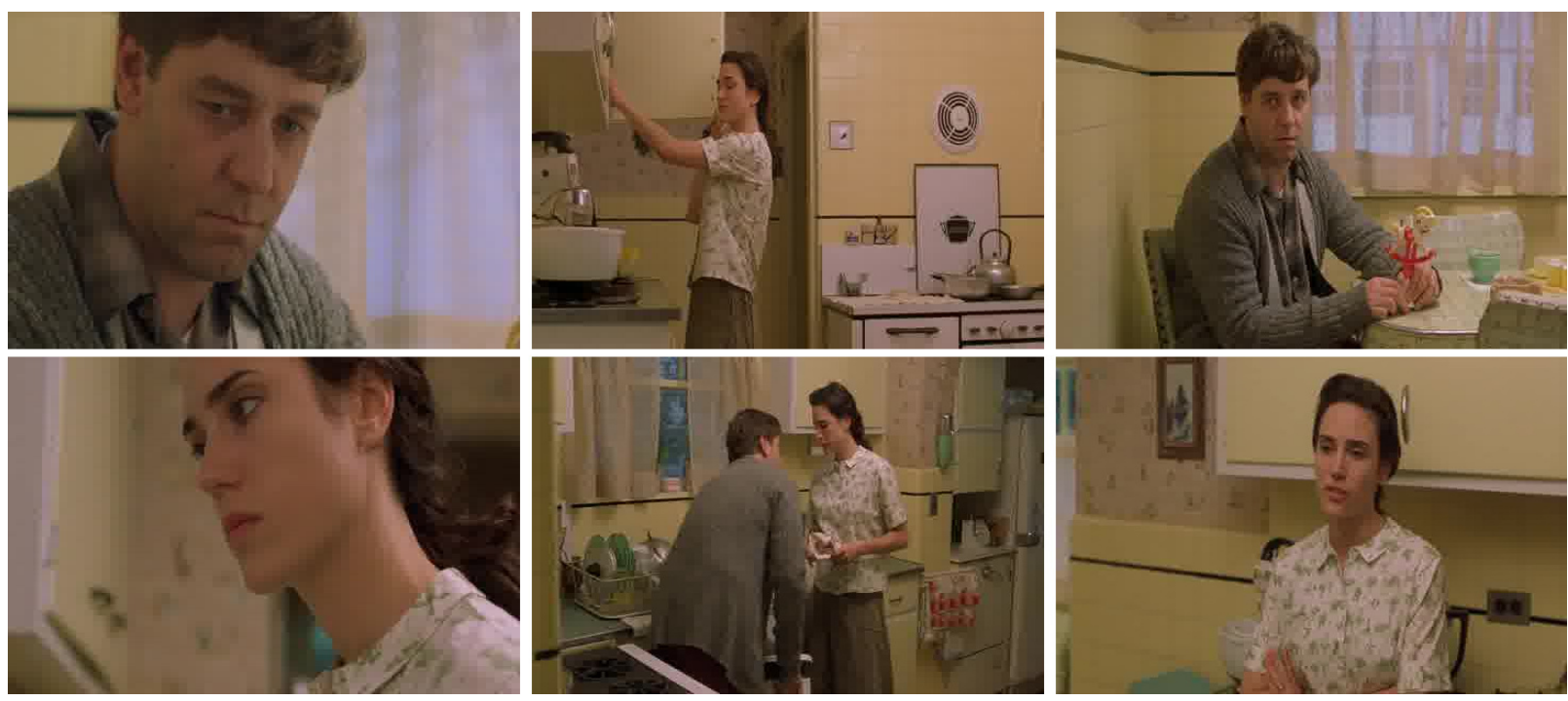

Figura 3.7: Quadros-chaves de tomadas de cena do filme Uma Mente Brilhante.

rentes, pois o diálogo cessa, e Alicia lava as louças, fazendo um barulho característico, e após um tempo recomeça o conversa, mudando o assunto.

Muitos trabalhos nas áreas de segmentação de áudio e vídeo fazem uso desses descritores Sundaram e Chang (2000). Entretanto, em geral, esses trabalhos propõem a utilização de uma base de treinamento para detectar alguns tipos de eventos, ou determinar regras para classificar as cenas. Por esse motivo, em geral, a precisão e a abrangência dessas técnicas tende a cair sse utilizada com vídeos ou áudios muito diferentes daqueles presentes na base. Por isso, utilizar uma técnica que não dependa de treinamento prévio é uma boa abordagem. Nesse trabalho, a técnica apresentada na seção 3.1 foi adaptada para usar descritores de áudio. Algumas adaptações foram necessárias e serão discutidas na seção 3.2.2.

\subsubsection{Ajustes para os Descritores de Áudio}

Como foi visto na seção 3.1, um descritor visual de características é aplicados à cada quadrochave de um vídeo. O descritor de caracteristicas detecta vários pontos de interesse em cada quadro-chave, e cada um desses pontos é descrito, dando origem a um vetor de características visuais. Portanto, um quadro-chave é descrito por um conjunto de vetores de características.

No caso do áudio, a situação é um pouco diferente. Um segmento de áudio pode ser amostrado com um período $T$ arbitrário. Com isso, são geradas $N$ amostras de áudio. $\mathrm{O}$ descritor de áudio atua sobre um subconjunto dessas amostras, gerando um único vetor de características sonoras, que é uma representação bastante compacta do áudio. Essa situação é representada na Figura 3.8. Nessa figura estão representados as $N$ amostras de um determinado segmento de vídeo. Esse conjunto está dividido em três subconjuntos com $M$ amostras cada. Para cada um desses subconjuntos, é aplicado um descritor de características sonoras, gerando um vetor de características sonoras. 


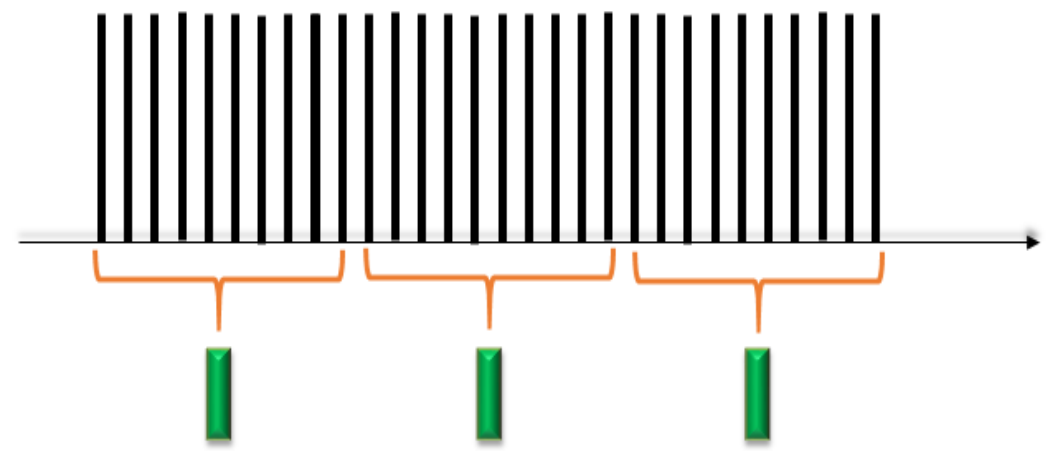

Amostras de Áudio

Vetores de Características Sonoras

Figura 3.8: Aplicação de descritores sonoros sobre subconjuntos de amostras de áudio.

Com o objetivo de criar uma representação, a qual denominaremos "quadro de áudio", que seja semelhante aos quadros de vídeo, pode-se dividir o intervalo entre dois quadros de vídeo em $p$ partes, de modo que existirão $p$ vetores de características para representar esse "quadro de áudio", que corresponde a um quadro de vídeo.

Desse modo, cada quadro de áudio será representado por mais de um vetor de características, assim como o quadro de vídeo, sendo possível, portanto, aplicar a mesma técnica da seção 3.1. Detalhes de como esses ajustes foram realizados encontram-se na 3.2.2.

\subsubsection{Técnica de Detecção de Cenas Adaptada para Descritores de Áudio}

Para a técnica de áudio foram selecionados os descritores de áudio MFCC e LPCC. Esses descritores têm sido utilizados com sucesso em tarefas de reconhecimento de falante (Hasan e Jamil, 2004). Para utilizar esses descritores, primeiro são gerados arquivos WAVE (WAVEform Audio File Format) dos vídeos da base com a ferramenta FFMPEG ${ }^{1}$, com uma taxa de amostragem de $44100 \mathrm{~Hz}$.

A ferramenta MARSYAS ${ }^{2}$ foi utilizada para computar os descritores de áudio. Esses descritores foram computados usando janelas não-sobrepostas com 256 amostras. Como os vídeos apresentam 24 quadros por segundo, existirão cerca de 1837 amostras de áudio entre cada quadro de vídeo. Como para cada 256 amostras, é calculado um vetor de características sonoras, existirão 7 vetores de caracteristicas para representar cada quadro de áudio. Essa situação é ilustrada na Figura 3.9.

Nessa figura, os retângulos azuis representam os quadros de um determinado vídeo. No intervalo entre eles, são computadas 7 amostras de áudio, representadas pelos retângulos laranja, que são utilizadas para representar um quadro de áudio.

\footnotetext{
${ }^{1}$ https://www.ffmpeg.org

${ }^{2}$ http://marsyas.info
} 


\section{Quadro de Vídeo}

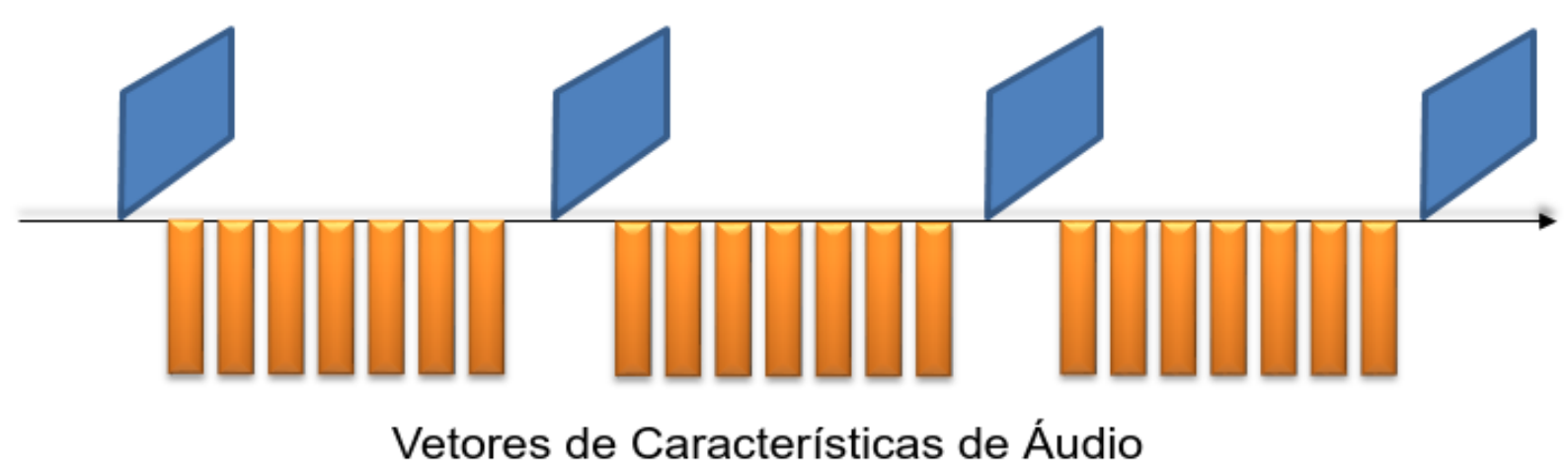

Figura 3.9: Variação da distância entre tomadas subsequentes e determinação de cortes de cenas.

Diferentemente da técnica visual, todos os quadros de áudio são utilizados, em vez de uma seleção de quadros-chave (Lopes e Goularte, 2013). Desse modo, o número de descritores sonoros utilizados para representar uma tomada aumenta, bem como sua capacidade de representá-la.

Uma vez obtida a representação da tomada, a técnica Bag of Visual Words é aplicada do mesmo modo que foi realizado para a parte visual, gerando um vocabulário de palavras sonoras, e cada tomada é representada por um histograma que representa o número de ocorrências de cada palavra do vocabulário encontrada na tomada. Com essa representação compacta da tomada, é aplicada a técnica descrita na seção 3.1.1, gerando uma resposta com a segmentação do vídeo em cenas.

\subsection{Técnica de Segmentação em Cenas com Fusão Tar- dia}

Nas seções 3.1 e 3.2 foram apresentadas duas técnicas de segmentação de vídeos em cenas, sendo a primeira uma técnica que utiliza descritores de características visuais e a segunda descritores de características sonoras.

Ambas as técnicas, individualmente, apresentam algumas dificuldades na detecção de cenas. As principais são a detecção de falsos positivos, e a não-detecção de cortes verdadeiros.

A detecção de falsos positivos ocorre quando a técnica detecta um corte de cena que não existe na segmentação manual, a qual é admitida como a segmentação correta do filme. A detecção de falsos positivos pode ocorrer basicamente por dois motivos. O primeiro é a detecção de um corte verdadeiro, porém deslocado por algumas tomadas, o que causa um falso positivo. Outro motivo é quando existe uma diferença considerável na mídia utilizada pela técnica entre duas tomadas. Nesse caso, a técnica considera que houve uma mudança de semântica entre as tomadas, o que caracteriza um corte de cena. No entanto, pode ocorrer que mesmo com essa diferença, não tenha havido realmente uma mudança de semântica entre as tomadas, não existindo assim um corte verdadeiro. Um exemplo é apresentado na Figura 3.4. Conforme discutido na seção 3.1.1, apesar 
da diferença visual entre as tomadas, uma vez que os personagens estão em locais distintos, o assunto tratado é o mesmo.

Já a não-detecção de cortes verdadeiros pode ocorrer, por exemplo, quando a mídia utilizada pela técnica realmente não apresenta diferenças consideráveis entre as cenas. Sendo assim, a técnica falha em capturar a mudança da semântica, a qual nesses casos, só pode ser determinada com a análise de outras mídias presentes no vídeo. A Figura 2.2, discutida na seção 2.2, demonstra um caso no qual isso ocorre. Apesar de não haver grandes diferenças entre as tomadas, o assunto muda, caracterizando um corte de cenas.

Por essas características intrínsecas das técnicas, passar a ser interessante considerar a utilização de mais de uma mídia presente no vídeo. Esse é o princípio da multimodalidade. A utilização de multimodalidade abre a possibilidade de encontrar corretamente cenas em um segmento semanticamente complexo, como o apresentado na Figura 3.10. Nessa figura, é apresentado um segmento um pouco mais extenso que o da figura Figura 3.7. É possível ver mais três quadroschave, que representam três tomadas. O último deles mostra Alicia e John deitados em seu quarto, após a conversa na cozinha. Nesse segmento existem três cenas, sendo a primeira representada pelas três primeiras tomadas, a segunda pelas 5 tomadas seguintes e a terceira representada pela última tomada. $\mathrm{O}$ corte entre as duas primeiras cenas pode ser feito pela parte sonora, conforme apresentado na seção 3.2. Já o corte entre a segunda e a terceira cena pode ser determinado pela parte visual. A parte sonora teria dificuldades em encontrar esse corte, dado que são os mesmos atores conversando, portanto, sem grandes alterações na parte sonora.

Para explorar a multimodalidade, em especial as mídias visual e sonora, é necessária a utilização de alguma estratégia capaz de realizar a fusão de características dessas duas mídias, conforme discutido na seção 2.5 .

Essencialmente há três possíveis modos de fazer a fusão de características: fusão prévia, fusão tardia e a fusão híbrida. No primeiro modo, as características são combinadas em um estado inicial, para que a correlação entre elas possa ser explorada. Uma dificuldade nessa abordagem é a sincronização das características (Atrey et al., 2010). A segunda abordagem é a fusão tardia, que consiste em combinar decisões locais, baseadas nas caracaterísticas individuais, de modo a produzir uma decisão final (Atrey et al., 2010). A terceira abordagem é alguma combinação entre as duas primeiras abordagens.

Neste trabalho, a fusão tardia foi a abordagem selecionada para combinar os resultados das técnicas visual e sonora. A decisão final da técnica multimodal segue as seguintes regras: 1) Se dois cortes de cenas detectados respectivamente pelo vídeo e pelo áudio, estão a menos de 3 tomadas de distância, eles são fundidos em um único corte, que é dado pela média entre eles; 2) Caso contrário, cada corte é mantido.

Com essa abordagem, falsos positivos da técnica visual e sonora podem ser fusionados em um único corte, o que diminui o número total de falsos positivos. Além disso, em algumas situações, essa fusão pode gerar verdadeiros positivos, quando a média entre eles fica correta. Por outro lado, 

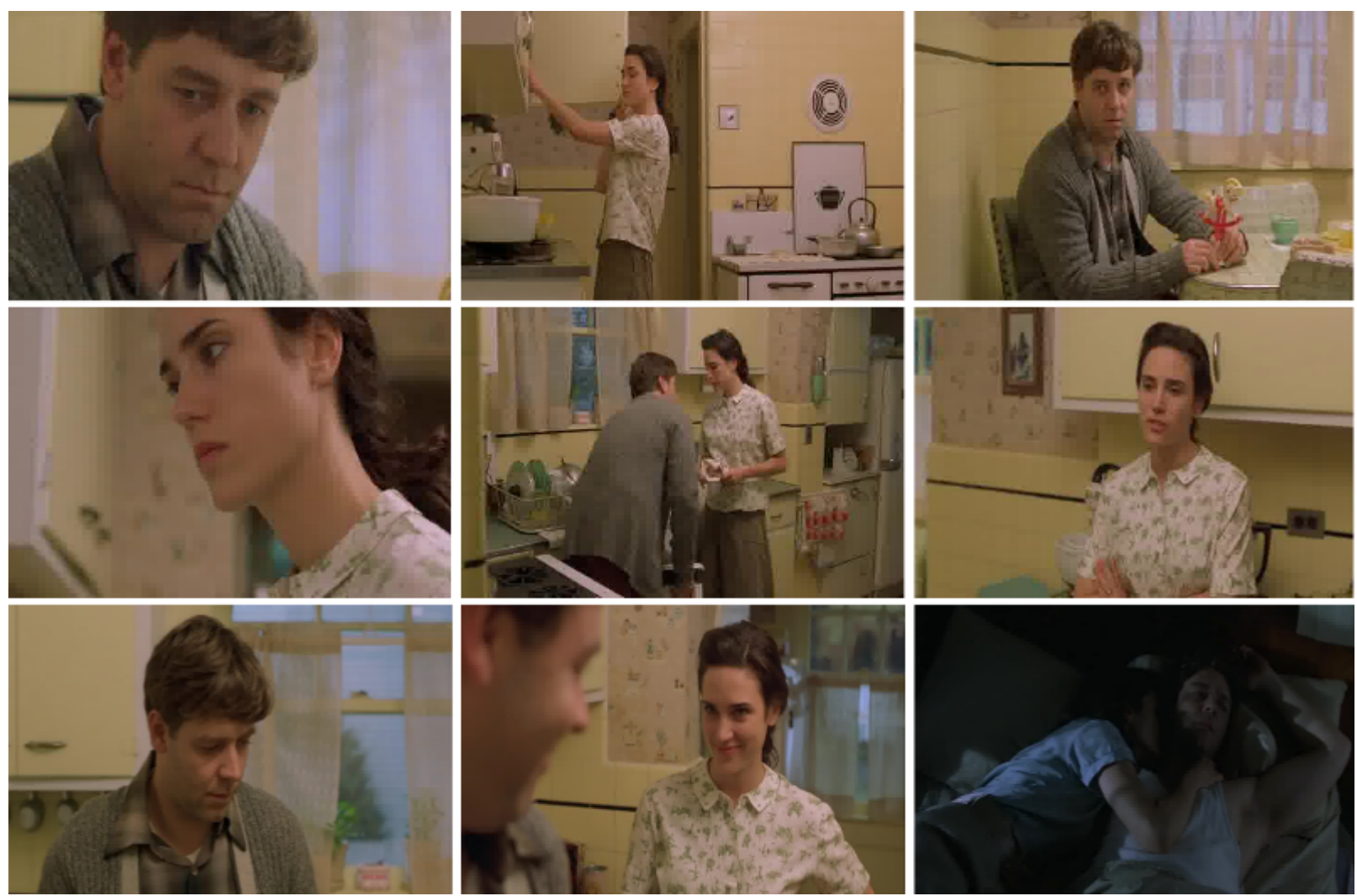

Figura 3.10: Segmento semanticamente complexo no filme Uma Mente Brilhante.

positivos verdadeiros distantes provenientes da duas técnicas serão mantidos, aumentando seu número em relação as técnicas individuais, o que melhora a abrangência da técnica. O problema é que falsos positivos distantes também serão mantidos, o que pode afetar a precisão da técnica. A análise da técnica é apresentada no Capítulo 4.

Um importante ponto sobre a técnica desenvolvida, é que ela visa estabelecer a relação semântica entre duas cenas, por meio da semântica latente dessas tomadas. Em outras palavras, a técnica não é capaz de detectar a semântica existente na tomada, por exemplo identificando que o assunto é futebol, mas ela consegue identificar tomadas que apresentem um mesmo tema ou assunto. 


\section{Experimentos e Resultados}

Neste capítulo serão descritos os experimentos (seções 4.3, 4.4, 4.6 e 4.7) que foram realizados e seus respectivos resultados. Também será discutido o ambiente (seção 4.2) no qual foram realizados os testes, bem como a formação das bases de segmentação em cenas e tomadas que foram desenvolvidas (seção 4.1).

\subsection{Formação das Bases de Segmentação em Tomadas e Cenas}

A definição de cena utilizada nesse trabalho apresenta algumas diferenças em relação as definições comumente encontradas na literatura. Com isso, surgem alguns desafios extras. O primeiro deles é a escolha de uma base de vídeos adequadas para a realização dos experimentos. Uma base de vídeos bastante utilizada é a TRECVID ${ }^{1}$. No entanto, essa base é composta de vídeos de curta duração, com poucas cenas, e pouquíssimos segmentos semanticamente complexos, o que torna sua utilização inviável para os experimentos.

Como outras bases analisadas também utilizam conceitos de cenas diferentes, não foi possível utilizá-las nesse trabalho. A ausência de bases de vídeo adequadas é um problema já conhecido (Hu et al., 2011; Money e Agius, 2008). Por essa razão, uma nova base de vídeos segmentados manualmente em cenas, que utiliza a definição de cenas aqui apresentada, e considera segmentos semanticamente complexos, foi desenvolvida. Uma coleção de filmes conhecidos, e com um número considerável de segmentos semanticamente complexos, foi selecionada para compor essa

\footnotetext{
${ }^{1}$ http://trecvid.nist.gov/
} 
base, que será referenciada como BFSSC (Base de Filmes com Segmentos Semanticamente Complexos).

Um observador humano determinou manualmente os quadros iniciais e finais de cada tomada dos filmes. Depois, foram determinadas as tomadas iniciais e finais de cada cena dos filmes. As tomadas finais de cada cena são chamadas de corte de cena, ou seja, indicam que ocorreu o término de uma cena e o começo de uma nova cena. Esses cortes de cena detectados manualmente são admitidos como verdadeiros, e são chamados de groundtruth.

Essa atividade é manual e bem custosa, uma vez que a definição precisa dos cortes de tomada, e de cenas envolve assistir cada trecho de um determinado filme, as vezes mais de uma vez, para encontrar o correspondente (quadro ou tomada). Além disso, a anotação do início e fim de cada segmento tem que ser feita com cuidado para evitar erros. Com isso, várias horas são necessárias para a segmentação correta de um vídeo, atividade que em geral não é realizada de uma única vez, sendo feita em partes.

As medidas de avaliação apresentadas na seção 2.6 foram empregadas considerando como verdadeiros positivos um corte de cena detectado com até três tomadas de distância da tomada verdadeira. Com isso, forma-se uma janela com sete tomadas, centralizada na tomada verdadeira segundo o groundtruth. Se a técnica detectar alguma dessas tomadas como um corte de cena, esse corte é admitido como verdadeiro. Essa abordagem é utilizada em (Hanjalic et al., 1999a), e deve-se ao fato de que existem casos em que as tomadas finais de uma determinada cena podem apresentar maior similaridade com as tomadas iniciais da cena seguinte, o que pode causar uma detecção de cena pela técnica antes da fronteira real. Do mesmo modo, se as tomadas iniciais da cena seguinte apresentarem maior similaridade com as tomadas finais da cena avaliada, a fronteira detectada pode ser posterior a fronteira verdadeira.

Para compor a BFSSC foram selecionados os seguintes filmes: Uma Mente Brilhante, De Volta para o Futuro, 60 Segundos, Era do Gelo e Piratas do Caribe. Os filmes selecionados pertencem a diferentes gêneros, como drama, ação e aventura, e já foram utilizados em outros trabalhos de segmentação de cenas encontrados na literatura. A duração em minutos, bem como o número de tomadas e cenas para cada filme da BFSSC são apresentadas na Tabela 4.1.

Tabela 4.1: Filmes que compõem a BFSSC, com sua duração, número de tomadas e cenas.

\begin{tabular}{|l|r|r|r|}
\hline Filme & Duração & Tomadas & Cenas \\
\hline Uma Mente Brilhante & 135 & 1656 & 95 \\
\hline De Volta para o Futuro & 116 & 1354 & 121 \\
\hline 60 Segundos & 117 & 2737 & 148 \\
\hline Era do Gelo & 81 & 1384 & 64 \\
\hline Piratas do Caribe & 133 & 2660 & 237 \\
\hline
\end{tabular}




\subsection{Configurações do Ambiente de Testes}

Os experimentos apresentados neste trabalho foram executados no laboratório do grupo de Sistemas Web e Multimidia Interativos do Instituto de Ciências Matemáticas e de Computação (ICMC). Nesse laboratório, foi utilizada uma máquina com as seguintes configurações:

- Procesador: Intel ${ }^{\circledR}$ Core $^{\mathrm{TM}}$ i7-3770 3.40GHz 8MB

- Memória RAM: 16Gb DDR3

- Tamanho do Disco: $1 \mathrm{~Tb}$

- Sistema Operacional: Linux

- Kernel do Sistema Operacional: Versão 2.6

- Distribuição: Ubuntu ${ }^{2}$ v12.04 64 bits

Também é importante definir as ferramentas e linguagem que foram utilizadas e que permitiram a realização deste trabalho. Abaixo encontram-se as ferramentas utilizadas de acordo com sua funcionalidade:

- Extração de Áudio e de Quadros: FFMPEG ${ }^{3}$ v1.1

- Extração de Características Sonoras: Marsyas $^{4}$ v0.4.8

- Extração de Características Visuais: OpenCV ${ }^{5}$ v2.4.0

- Desenvolvimento: Eclipse ${ }^{6}$

- Linguagem de Programação: Ansi C++

Conforme mencionado anteriormente, as bases de segmentação de filmes em tomadas e cenas são formadas por arquivos no formato CSV (Comma-Separated Values), devido a sua facilidade de geração e leitura. A ferramenta desenvolvida na linguagem Ansi C++ faz a leitura do arquivo com a segmentação em tomadas, gerando como uma saída intermediária um diretório para cada uma das tomadas, contendo os quadros-chaves da tomada. Posteriormente é lido o arquivo com a segmentação em cenas ( groundtruth). Esse arquivo é utilizado para a comparação com a segmentação gerada pela ferramenta.

Como saída final, obtém-se a segmentação em cenas, e cada cena sendo classificada como verdadeira ou falsa. Também são geradas automaticamente as medidas precisão, abrangência e $F_{1}$ obtidas pela técnica.

\footnotetext{
${ }^{2}$ http://www.ubuntu.com/

${ }^{3}$ http://www.ffmpeg.org

${ }^{4}$ http://marsyas.info

${ }^{5} \mathrm{http}: / /$ opencv.org/

${ }^{6} \mathrm{http}: / /$ eclipse.org/
} 


\subsection{Definição dos Descritor Visual e da Distância}

O primeiro dos experimentos realizados envolveu a análise da técnica puramente visual utilizando dois descritores visuais diferentes: SIFT e SURF. Além disso, foram utilizadas três medidas de similaridade diferentes para a geração dos vocabulários, a saber: Distância Euclideana, Distância $\chi^{2}$ e Intersecção de Histogramas. Nesse experimento foram utilizados 3 filmes da BFSSC: Uma Mente Brilhante, 60 Segundos e Era do Gelo.

Tabela 4.2: Resultados da técnica visual com descritores SIFT e SURF, e Distância Euclideana.

\begin{tabular}{|l|c|c|c|c|c|c|}
\hline \multicolumn{7}{|c|}{ Uma Mente Brilhante } \\
\hline Descritor & $V_{p}$ & $F_{p}$ & $F_{n}$ & $P$ & $A$ & $F_{1}$ \\
\hline SIFT & 49 & 30 & 45 & 62,25 & 52,13 & 56,65 \\
\hline SURF & 47 & 31 & 47 & 60,26 & 50,00 & 54,65 \\
\hline \multicolumn{7}{|c|}{ 60 Segundos } \\
\hline Descritor & $V_{p}$ & $F_{p}$ & $F_{n}$ & $P$ & $A$ & $F_{1}$ \\
\hline SIFT & 94 & 44 & 53 & 68,12 & 63,95 & 65,96 \\
\hline SURF & 75 & 65 & 72 & 53,57 & 51,02 & 52,26 \\
\hline \multicolumn{7}{|c|}{ Era do Gelo } \\
\hline Descritor & $V_{p}$ & $F_{p}$ & $F_{n}$ & $P$ & $A$ & $F_{1}$ \\
\hline SIFT & 34 & 50 & 29 & 53,13 & 53,97 & 53,54 \\
\hline SURF & 30 & 25 & 33 & 54,55 & 47,62 & 50,85 \\
\hline
\end{tabular}

O intuito desse experimento é avaliar qual a melhor combinação para a técnica visual. No total, 6 configurações foram geradas para cada filme, considerando os 2 descritores e as 3 medidas de similaridade, e estas foram testadas nos 3 filmes escolhidos. Para avaliar os resultados, foram utilizadas três medidas de avaliação: precisão, abrangência e $F_{1}$. Essas medidas são apresentadas na seção 2.6.6.

De modo resumido, a precisão avalia a porcentagem dos cortes de cena detectados pela técnica que estão de acordo com o groundtruth, ou seja, que são considerados corretos. Portanto a precisão avalia a eficiência da detecção de cenas.

A abrangência, por sua vez, avalia a porcentagem de cortes de cena do groundtruth que foram identificados corretamente pela técnica. Uma alto valor de abrangência implica que uma técnica foi capaz de identificar corretamente a maioria das cenas verdadeiras segundo o groundtruth.

Por último, a $F_{1}$ consiste de uma média ponderada da precisão e da abrangência, com o mesmo peso para ambas. Essa medida é importante pois ela apresenta valores altos somente quando tanto a precisão quanto a abrangência também apresentam valores expressivos. Esse fato é importante para técnicas de segmentação em cenas, pois indica que os cortes de cenas detectados pela técnica, além de em sua maioria serem corretos, ainda englobam uma porção considerável dos cortes verdadeiros de acordo o groundtruth. 
O resultados obtidos nos três filmes para os descritores SIFT e SURF para as medidas de similaridade Distância Euclideana, Distância $\chi^{2}$ e Intersecção de Histogramas podem ser vistos, respectivamente, nas tabelas $4.2,4.3$ e 4.4 .

Nos experimentos, o descritor SIFT apresentou resultados melhores para a $F_{1}$ que o descritor SURF para quase todas as configurações analisadas, exceto para o filme 60 Segundos e com a utilização da Intersecção de Histogramas. Esse fato está de acordo com trabalhos da literatura que sugerem uma maior capacidade dos descritores SIFT de extrair a semântica latente das imagens em relação aos descritores SURF (López-Garcia et al., 2011; El-gayar et al., 2013).

Já em relação as medidas de similaridade utilizadas, a Distância Euclideana apresentou os melhores resultados para a $F_{1}$ quando combinada com os descritores SIFT, não sendo a melhor escolha somente para o filme Era do Gelo. A segunda melhor foi a Intersecção de Histogramas, sendo a Distância $\chi^{2}$ a que apresentou os piores resultados.

Tabela 4.3: Resultados da técnica visual com descritores SIFT e SURF, e Distância $\chi^{2}$.

\begin{tabular}{|l|c|c|c|c|c|c|}
\hline \multicolumn{7}{|c|}{ Uma Mente Brilhante } \\
\hline Descritor & $V_{p}$ & $F_{p}$ & $F_{n}$ & $P$ & $A$ & $F_{1}$ \\
\hline SIFT & 46 & 32 & 48 & 58,97 & 48,94 & 53,49 \\
\hline SURF & 45 & 33 & 49 & 57,69 & 47,87 & 52,33 \\
\hline \multicolumn{7}{|c|}{ 60 Segundos } \\
\hline Descritor & $V_{p}$ & $F_{p}$ & $F_{n}$ & $P$ & $A$ & $F_{1}$ \\
\hline SIFT & 87 & 52 & 60 & 62,59 & 59,18 & 60,84 \\
\hline SURF & 81 & 55 & 66 & 59,56 & 55,10 & 57,24 \\
\hline \multicolumn{7}{|c|}{ Era do Gelo } \\
\hline Descritor & $V_{p}$ & $F_{p}$ & $F_{n}$ & $P$ & $A$ & $F_{1}$ \\
\hline SIFT & 35 & 28 & 28 & 55,56 & 55,56 & 55,56 \\
\hline SURF & 30 & 20 & 33 & 60,00 & 47,62 & 53,10 \\
\hline
\end{tabular}

Tabela 4.4: Resultados da técnica visual com descritores SIFT e SURF, e Intersecção de Histogramas.

\begin{tabular}{|l|c|c|c|c|c|c|}
\hline \multicolumn{7}{|c|}{ Uma Mente Brilhante } \\
\hline Descritor & $V_{p}$ & $F_{p}$ & $F_{n}$ & $P$ & $A$ & $F_{1}$ \\
\hline SIFT & 47 & 32 & 47 & 59,49 & 50,00 & 54,34 \\
\hline SURF & 46 & 32 & 48 & 58,97 & 48,94 & 53,49 \\
\hline \multicolumn{7}{|c|}{ 60 Segundos } \\
\hline Descritor & $V_{p}$ & $F_{p}$ & $F_{n}$ & $P$ & $A$ & $F_{1}$ \\
\hline SIFT & 86 & 52 & 61 & 62,32 & 58,50 & 60,35 \\
\hline SURF & 93 & 61 & 54 & 60,39 & 63,27 & 61,79 \\
\hline \multicolumn{7}{|c|}{ Era do Gelo } \\
\hline Descritor & $V_{p}$ & $F_{p}$ & $F_{n}$ & $P$ & $A$ & $F_{1}$ \\
\hline SIFT & 37 & 27 & 26 & 57,81 & 58,73 & 58,27 \\
\hline SURF & 34 & 33 & 29 & 50,75 & 53,97 & 52,31 \\
\hline
\end{tabular}


No entanto, quando combinada são utilizados os descritores SURF, os resultados da Distância Euclideana foram os piores, exceto para o filme Uma Mente Brilhante, no qual apresentou o melhor resultado. Com os descritores SURF, a Intersecção de Histogramas apresentou na média os melhores resultados, e a Distância $\chi^{2}$ foi a segunda melhor.

Esses resultados demonstram que a melhor configuração é a utilização de descritores SIFT com a Distância Euclideana. Por esse motivo, essa configuração foi utilizada nos demais experimentos que serão descritos na sequência.

\subsection{Análise Visual}

O objetivo do segundo experimento é demonstrar que técnicas do estado da arte não tratam o problema da segmentação de cenas em segmentos semanticamente complexos de maneira adequada. As técnicas de segmentação visual podem ser divididas basicamente em três grandes grupos. O primeiro é constituído de técnicas que utilizam somente características visuais, tais como histogramas de cores e ritmo visual. O segundo grupo é constituído por técnicas que fazem uso de vocabulários visuais. O terceiro grupo é formado por técnicas multimodais que combinam características de duas ou mais mídias presentes no vídeo, como visual e sonora.

Em especial, o segundo e o terceiro grupo são os que apresentam os melhores resultados (Snoek e Worring, 2005). Nesse experimento, por se tratar de uma análise somente da parte visual da técnica desenvolvida, decidiu-se comparar essa parte com técnicas do primeiro e segundo grupo, que também se utilizam somente dessa parte. Uma comparação da técnica multimodal desenvolvida com técnicas da literatura é apresentada na seção 4.7.

Sendo assim, o segundo experimento consitiu em comparar três técnicas visuais: a técnica visual proposta nesse trabalho (TV1), outra técnica visual baseada em Bag of Visual Features (Chasanis et al., 2009) (TV2), representante do grupo de técnicas que utilizam vocabulários e uma técnica baseada na técnica Backward Shot Coherence (Trojahn e Goularte, 2013) (TV3), representante do grupo de técnicas que utilizam somente características visuais.

A técnica TV2 foi selecionada por, assim como a técnica aqui proposta, utilizar a técnica Bag of Visual Words como base, fato que as aproxima. Além disso, na literatura foram encontradas duas técnicas que utilizam a técnica Bag of Visual Words para a geração dos vocabulários visuais: a técnica TV2 e a técnica proposta por Kumar et al. (2011). No entanto, a técnica TV2 apresentou os melhores resultados em termos de $F_{1}$, e por isso foi a técnica selecionada para a análise proposta.

Já a técnica TV3 é uma boa representante do grupo de técnicas que usam apenas características visuais. Essa técnica faz uso de características visuais de baixo custo computacional como histogramas e fluxo óptico, obtendo resultados que se aproximam do estado da arte, com um custo comptacional menor em relação a técnicas multimodais ou que utilizam vocabulários. Além disso, essa técnica utiliza um conceito de cena comum na literatura: "Conjunto de tomadas semanti- 
camente relacionadas". No entanto, nesse caso, a semântica é dada pela coerência visual e de movimento entre as tomadas, e não pelo assunto ou tema, como é proposto neste trabalho.

Tabela 4.5: Resultados das técnicas de vídeo aplicadas aos filmes "Uma Mente Brilhante", "60 Segundos" e "Era do Gelo".

\begin{tabular}{|c|c|c|c|c|c|c|}
\hline \multicolumn{7}{|c|}{ Filme: Uma Mente Brilhante } \\
\hline Técnica & $V_{p}$ & $F_{p}$ & $F_{n}$ & $P$ & $A$ & $F_{1}$ \\
\hline$T V_{1}$ & 49 & 30 & 45 & 62,25 & 52,13 & 56,65 \\
\hline$T V_{2}$ & 47 & 32 & 47 & 59,49 & 50,00 & 54,34 \\
\hline$T V_{3}$ & 58 & 54 & 36 & 51,79 & 61,70 & 56,31 \\
\hline \multicolumn{7}{|c|}{ Filme: 60 Segundos } \\
\hline Técnica & $V_{p}$ & $F_{p}$ & $F_{n}$ & $P$ & $A$ & $F_{1}$ \\
\hline$T V_{1}$ & 94 & 44 & 53 & 68,12 & 63,95 & 65,96 \\
\hline$T V_{2}$ & 87 & 52 & 60 & 62,59 & 59,18 & 60,84 \\
\hline$T V_{3}$ & 78 & 136 & 69 & 36,45 & 53,06 & 43,21 \\
\hline \multicolumn{7}{|c|}{ Filme: Era do Gelo } \\
\hline Técnica & $V_{p}$ & $F_{p}$ & $F_{n}$ & $P$ & $A$ & $F_{1}$ \\
\hline$T V_{1}$ & 34 & 30 & 29 & 53,13 & 53,97 & 53,54 \\
\hline$T V_{2}$ & 30 & 20 & 33 & 60,00 & 47,62 & 53,10 \\
\hline$T V_{3}$ & 44 & 110 & 19 & 28,57 & 69,84 & 40,55 \\
\hline
\end{tabular}

As técnicas TV2 e TV3 foram implementadas e utilizadas para realizar a segmentação em cenas dos vídeos presentes na BFSSC. Desse modo, é possível avaliar como essas técnicas respondem ao conceito de cena utilizado neste trabalho, e atingir o objetivo do experimento que é demonstrar que técnicas que fazem parte do estado da arte apresentando resultados expressivos na segmentação de vídeos em cenas, como as técnicas TV2 e TV3, não tratam adequadamente segmentos semanticamente complexos. Além disso, pretende-se demonstrar que a técnica Bag of Visual Features consegue lidar com esses segmentos tão bem, ou até melhor do que outras técnicas.

Para as técnicas TV1 e TV2, foram utilizados tamanhos de vocabulário com tamanhos que variavam de 100 a 600 palavras. Os melhores resultados encontrados para ambas foram com a utilização de vocabulários com 500 palavras. Os resultados de cada técnica para cada um dos filmes encontram-se na Tabela 4.5 , onde $V_{p}$ é verdadeiro positivo, $F_{p}$ é falso positivo e $F_{n}$ é falso negativo.

Já na Tabela 4.6 são apresentadas respectivamente as médias da $F_{1}$ das técnicas TV1, TV2 e TV3 nos trabalhos em que foram originalmente apresentadas, e posteriormente a média obtida quando executadas nos filmes da BFSSC.

Tabela 4.6: $F_{1}$ das técnicas de vídeo em seus respectivos trabalhos e aplicadas na BFSSC.

\begin{tabular}{|c|c|c|c|}
\hline Técnica & $F_{1}$ Original & $F_{1}$ na BFSSC & Diferença \\
\hline$T V_{1}$ & 60,51 & 60,51 & 0,00 \\
\hline$T V_{2}$ & 84,45 & 56,09 & $-28,35$ \\
\hline$T V_{3}$ & 85,89 & 46,69 & $-39,29$ \\
\hline
\end{tabular}


Os resultados das tabelas 4.5 e 4.6 sinalizam alguns aspectos interessantes. O primeiro deles é que as técnicas TV2 e TV3, quando utilizadas para segmentar filmes considerando a definição de cena utilizada nesse trabalho apresentaram resultados muito inferiores aos seus resultados originais, os quais utilizavam outras definições de cenas. Esse resultado era esperado, dada ao fato de que essas definições não tratam o problema da segmentação de cenas em segmentos semanticamente complexos.

Outro aspecto interessante é que a técnica proposta TV1 apresentou os melhores resultados em termos de precisão em dois filmes, sendo a segunda melhor apenas no filme Era do Gelo, seguida pela técnica TV2, também baseada em Bag of Visual Words. Isso reforça a capacidade da técnica Bag of Visual Words de detectar a semântica latente presente nas tomadas dos filmes, permitindo que seja agrupadas em cenas de modo mais correto.

Em termos de abrangência, a técnica TV3, baseada em BSC, foi a melhor em dois filmes, no entanto, a precisão dessa técnica foi a menor para os três filmes, o que indica claramente sobressegmentação, ou seja, apesar de ter encontrado mais cenas corretamente, a proporção de cenas classificadas de modo correto em relação ao total de cenas encontradas pela técnica foi bem baixa.

Isso é causado pela identificação errônea de cortes de cenas, provocada por mudanças no aspecto visual, sem que, contudo, tenha havido uma mudança de assunto ou tema. Essa situação é especialmente verdade em trechos com muitas mudanças visuais, como por exemplo cenas nas quais há diferentes ambientes, porém o tema é o mesmo, ou seja, a perseguição.

No filme A Era do Gelo, um exemplo de identificação incorreta de cenas pela técnica TV3 pode ser visto na Figura 4.1. Nessa figura são apresentados os quadros-chave de um conjunto de tomadas subsequentes. Nesse trecho do filme, o tigre Diego solta um grito, o que provoca uma avalanche. Para escaparem dessa avalanche, os personagens entram rapidamente na caverna. É importante observar que todas essas tomadas estão relacionadas ao mesmo tema, que nesse caso em específico é a fuga dos personagens da avalanche. No entanto, a técnica TV3 identificou uma mudança entre o quarto e o quinto quadro. A diferença visual entre esses quadros é bem evidente, uma vez que não só o fundo da imagem mas também os personagens mudam. As técnicas TV1 e TV2 agruparam corretamente essas tomadas em uma única cena.

\subsection{Definição do Descritor de Áudio}

O terceiro experimento consiste em avaliar a técnica de áudio desenvolvida. Nesse teste, foram avaliados dois descritores de áudio, MFCC e LPCC. Para ambos foi utilizada a Distância Euclideana, dado que esta apresentou os melhores resultados com os descritores visuais no primeiro experimento. O objetivo desse experimento foi verificar qual dois dois descritores utilizados proporciona a melhor $F_{1}$. os filmes utilizados foram os mesmos dos dois primeiros experimentos, e os resultados encontram-se na Tabela 4.7 

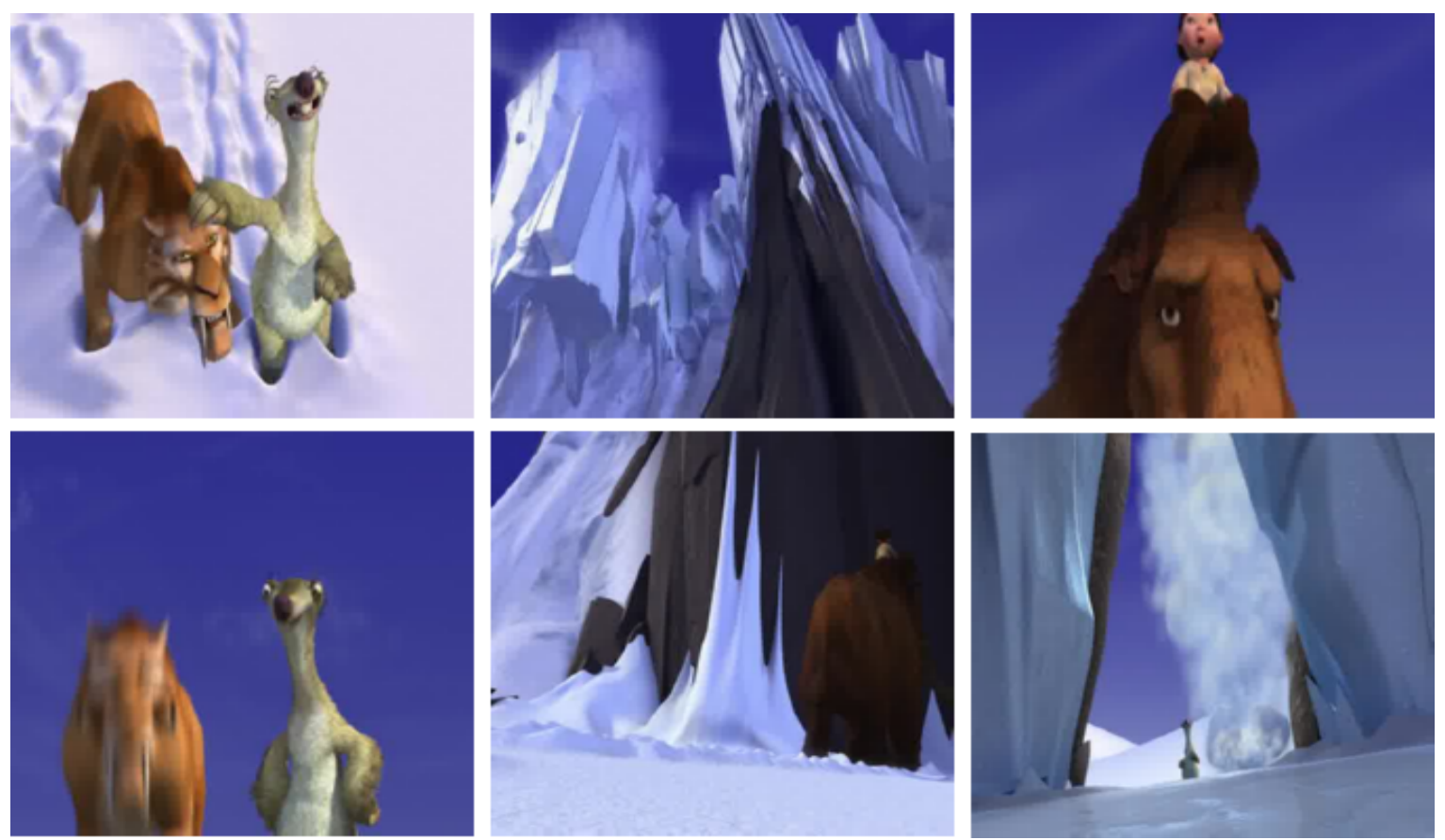

Figura 4.1: Cena do filme A Era do Gelo segmentada incorretamente pela técnica TV3.

Nos três filmes analisados, os descritores MFCC apresentaram resultados melhores tanto em precisão, quanto abrangência e $F_{1}$ em relação aos descritores LPCC. Somente no filme 60 Segundos os descritores LPCC apresentaram um resultado similar aos do MFCC. No filme Uma Mente Brilhante a $F_{1}$ do LPCC foi cerca de $6 \%$ inferior à do MFCC, e no filme Era do Gelo, a diferença foi ainda maior, cerca de $10 \%$.

Um fato que merece ser destacado, é que a parte sonora conseguiu identificar cortes de cena não identificados pela parte visual. Isso ocorreu em trechos nos quais a parte visual apresentava grande similaridade, mas o áudio denotava mudanças no assunto, como por exemplo momentos de silêncio, ou alterações no tom de voz dos personagens, indicando discussões. Na Figura 4.2 temos um exemplo dessa situação. Nessa figura estão ilustrados os quadros-chave de tomadas do subsequentes do filme Uma Mente Brilhante. Nas cinco primeiras tomadas, o psiquiatra conversa com John. Na sexta tomada, apesar de ser visualmente muito parecida com as demais, John dá um soco no psiquiatra e começa a fugir. Nesse caso, houve uma mudança de tema, sendo que o som do soco e da fuga de John, caracterizada pelo barulho dos passos e da respiração profunda, permitiram a identificação da mudança de cena pela parte sonora.

Também é importante destacar, que devido a dificuldade de encontrar implementações de técnicas de áudio da literatura, não foi possível verificar a eficiência dessas técnicas na BFSSC, como foi feito na parte visual. 
Tabela 4.7: Resultados da técnica sonora com descritores LPCC e MFCC, e Distância

Euclideana.

\begin{tabular}{|l|c|c|c|c|c|c|}
\hline \multicolumn{7}{|c|}{ Uma Mente Brilhante } \\
\hline Descritor & $V_{p}$ & $F_{p}$ & $F_{n}$ & $\mathrm{P}$ & $A$ & $F_{1}$ \\
\hline LPCC & 42 & 33 & 52 & 56,00 & 44,68 & 49,70 \\
\hline MFCC & 48 & 30 & 46 & 61,54 & 51,64 & 55,81 \\
\hline \multicolumn{7}{|c|}{ 60 Segundos } \\
\hline Descritor & $V_{p}$ & $F_{p}$ & $F_{n}$ & $\mathrm{P}$ & $A$ & $F_{1}$ \\
\hline LPCC & 64 & 64 & 83 & 50,00 & 43,54 & 46,55 \\
\hline MFCC & 65 & 60 & 82 & 52,00 & 44,22 & 47,79 \\
\hline \multicolumn{7}{|c|}{ Era do Gelo } \\
\hline Descritor & $V_{p}$ & $F_{p}$ & $F_{n}$ & $\mathrm{P}$ & $A$ & $F_{1}$ \\
\hline LPCC & 26 & 37 & 37 & 41,27 & 41,27 & 41,27 \\
\hline MFCC & 34 & 34 & 29 & 50,00 & 53,97 & 51,91 \\
\hline
\end{tabular}

\subsection{Análise da Técnica Multimodal Desenvolvida}

O quarto experimento consiste em comparar a técnica multimodal desenvolvida com a análise das partes visual e sonora. Os resultados são apresentados para os filmes da BFSSC na Tabela 4.8.

A análise da parte visual apresentou resultados melhores tanto em precisão quanto abrangência, quando comparada à parte sonora. Esse fato permite concluir que a parte visual consegue capturar uma parte importante da semântica do vídeo, em concordância com o trabalho de Fabro e Böszörmenyi (2013).

Por outro lado, a parte sonora pode apresentar em alguns casos, uma performance similar à da parte visual, com a vantagem de ser consideravelmente menos custosa computacionalmente. Outra característica importante da técnica sonora é sua capacidade de detectar cortes de cenas que não são identificados pela técnica visual, especialmente quando as tomadas são visualmente similares, mas o assunto tratado é diferente, conforme discutido na seção 4.5. Essa característica é extremamente importante, pois demonstra a possibilidade de haver uma complementaridade das tećnicas visuais e sonora, por meio da multimodalidade, que é o foco deste trabalho.

Esse é o principal motivo da técnica multimodal apresentar resultados consideravelmente melhores de abrangência, em comparação com as técnicas individuais. A técnica multimodal é capaz de combinar os verdadeiros positivos da técnicas individuais. No entanto, os falsos negativos de ambas as técnicas também são incorporados ao resultado final, o que causa redução da precisão. Por esse motivo, o número total de cenas detectadas para cada filme, que é dado pela soma das cenas detectadas corretamente $\left(V_{p}\right)$ e incorretamente $\left(F_{p}\right)$ teve um aumento expressivo na técnica multimodal.

Entretanto, o aumento na abrangência obtido pela técnica multimodal é maior do que o pequeno decréscimo da precisão, ou seja, o resultado $F_{1}$ para a técnica multimodal é maior do que os resultados obtidos pelas técnicas individuais, o que demonstra que a técnica multimodal tem um desempenho superior na segmentação em cenas. A variação da precisão, abrangência e $F_{1}$ para 
Tabela 4.8: Resultados das técnicas de áudio, vídeo e multimodal aplicadas aos vídeos da BFSSC.

\begin{tabular}{|c|c|c|c|}
\hline \multicolumn{4}{|c|}{ Filme: Uma Mente Brilhante } \\
\hline & Audio & Video & Multimodal \\
\hline Precisão & 61,54 & 62,25 & 58,18 \\
\hline Abrangência & 51,64 & 52,13 & 68,09 \\
\hline$F_{1}$ & 55,81 & 56,65 & 62,75 \\
\hline$V_{p}$ & 48 & 49 & 64 \\
\hline$F_{p}$ & 30 & 30 & 46 \\
\hline$F_{n}$ & 46 & 45 & 30 \\
\hline \multicolumn{4}{|c|}{ Filme: De Volta para o Futuro } \\
\hline & Audio & Video & Multimodal \\
\hline Precisão & 79,10 & 77,94 & 79,28 \\
\hline Abrangência & 44,17 & 44,17 & 73,33 \\
\hline$\overline{F_{1}}$ & 56,68 & 56,38 & 76,19 \\
\hline$V_{p}$ & 53 & 53 & 88 \\
\hline$F_{p}$ & 14 & 15 & 23 \\
\hline$F_{n}$ & 67 & 67 & 32 \\
\hline \multicolumn{4}{|c|}{ Filme: 60 Segundos } \\
\hline & Audio & Video & Multimodal \\
\hline Precisão & 52,00 & 68,12 & 58,42 \\
\hline Abrangência & 44,22 & 63,95 & 80,27 \\
\hline$F_{1}$ & 47,79 & 65,96 & 67,62 \\
\hline$V_{p}$ & 65 & 94 & 118 \\
\hline$F_{p}$ & 60 & 44 & 84 \\
\hline$\overline{F_{n}}$ & 82 & 53 & 29 \\
\hline \multicolumn{4}{|c|}{ Filme: Era do Gelo } \\
\hline & Audio & Video & Multimodal \\
\hline Precisão & 50,00 & 53,13 & 48,51 \\
\hline Abrangência & 53,97 & 53,97 & 77,78 \\
\hline$F_{1}$ & 51,91 & 53,54 & 59,76 \\
\hline$V_{p}$ & 34 & 34 & 49 \\
\hline$F_{p}$ & 34 & 30 & 52 \\
\hline$F_{n}$ & 29 & 29 & 14 \\
\hline \multicolumn{4}{|c|}{ Filme: Piratas do Caribe } \\
\hline & Audio & Video & Multimodal \\
\hline Precisão & 78,86 & 81,89 & 80,56 \\
\hline Abrangência & 41,10 & 44,07 & 73,73 \\
\hline$F_{1}$ & 54,04 & 57,30 & 76,99 \\
\hline$V_{p}$ & 97 & 104 & 174 \\
\hline$F_{p}$ & 26 & 23 & 42 \\
\hline$F_{n}$ & 139 & 132 & 62 \\
\hline
\end{tabular}


Capítulo 4 - Experimentos e Resultados
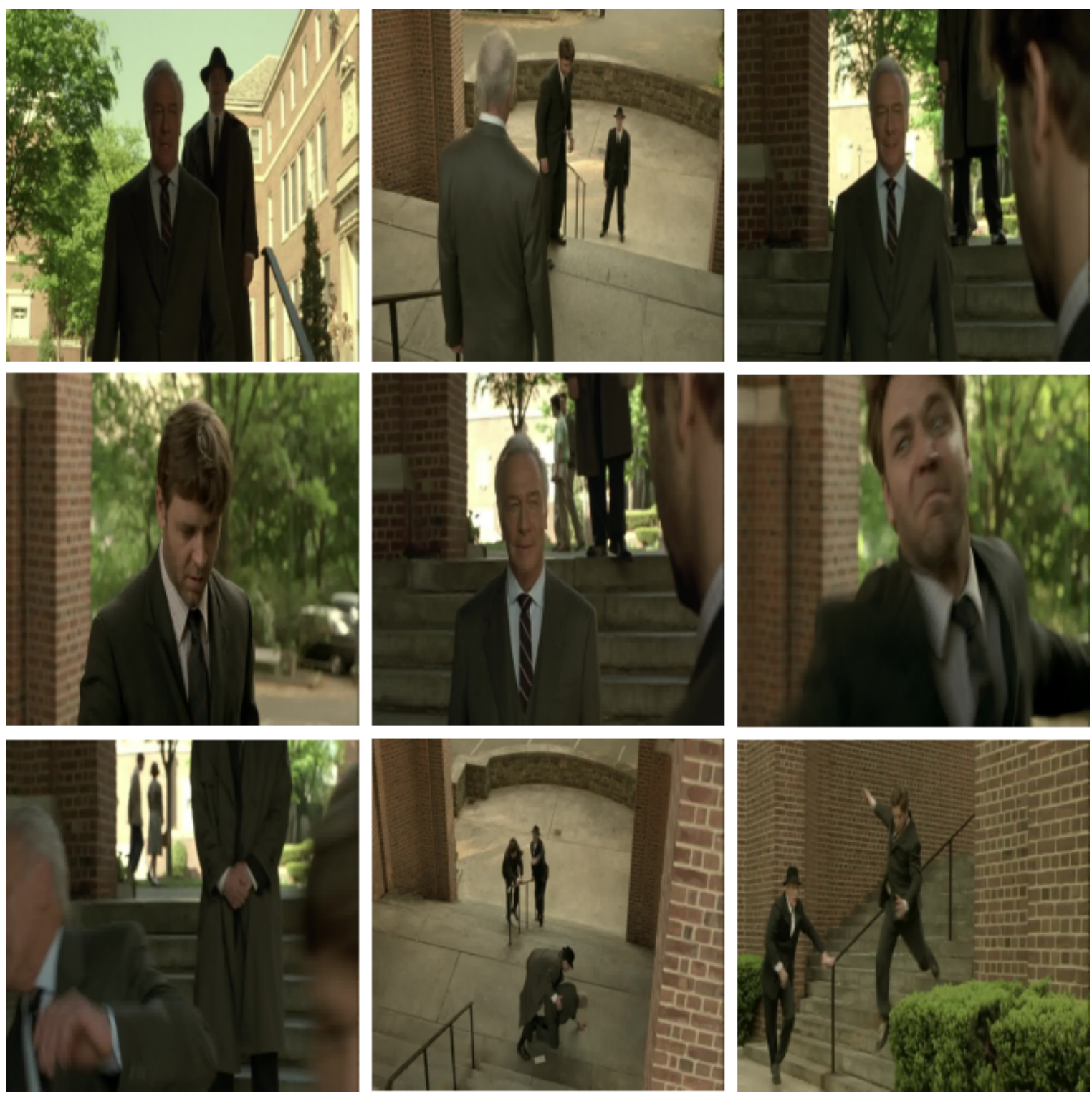

Figura 4.2: Cenas do filme Uma Mente Brilhante detectadas corretamente pela parte sonora.

cada filme da técnica multimodal em relação as partes visuais e sonoras, bem como a média para todos os filmes são apresentadas na Tabela 4.9.

Essa tabela mostra que em relação a parte sonora, a técnica multimodal apresentou precisão maior em três filmes, sendo levemente inferior somente nos filmes Uma Mente Brilhante e Era do Gelo. Na média, houve um aumento de precisão de 0,69\%. Em termos de abrangência, a técnica multimodal foi sempre bastante superior, e na média o aumento foi de 27,62\%. O mesmo ocorreu para a $F_{1}$, com um aumento médio de $15,42 \%$. No entanto para os dois filmes, Uma Mente Brilhante e Era do Gelo, o aumento da $F_{1}$ foi inferior a $10 \%$ (6,94\% e 7,85\% respectivamente).

Em relação a parte visual, a técnica multimodal apresentou um pequeno decrécimo (inferior a $10 \%$ ) em todos os filmes, exceto no filme De Volta para o Futuro, no qual apresentou um ganho de precisão de 1,34\%. Na média, o decréscimo de precisão foi de 3,68\%. Já em relação à abrangência, o comportamento foi semelhante em relação a parte sonora, e a média de ganho foi de 22,98\%. 
Já a $F_{1}$ foi superior em todos os casos, no entanto o aumento foi inferior a $10 \%$ em três filmes: Uma Mente Brilhante, 60 Segundos e Era do Gelo. O aumento medio da $F_{1}$ foi de $10,70 \%$, bastante expressivo.

Esses resultados demonstram que a técnica multimodal se mostrou capaz de detectar corretamente mais cenas do groundtruth em relação as técnicas individuais, com um pequeno decréscimo na precisão, o que indica sobressegmentação, ou seja, a técnica multimodal detectou duas ou mais cenas para uma única cena do groundtruth.

No entanto, segundo Rasheed e Shah (2005), essa é uma característica positiva, dado que posteriormente, pode ser aplicada alguma técnica para a detecção e remoção de falsos verdadeiros, pode fazer com que ocorra um aumento na precisão, mantendo a abrangência e ocasionando um aumento na $F_{1}$.

Além disso, um fato relevante é que a técnica multimodal foi capaz de detectar cenas em segmentos semanticamente complexos, como as exibidas nas figuras 3.4 e 3.7, ao contrário de técnicas presentes na literatura. Esse fato demonstra que combinar técnicas de naturezas distintas, tais como as técnicas visual e sonora, pode ser muito benéfico, uma vez que a semântica extraída por elas é diferente, e podem ser combinadas, usando por exemplo, fusão tardia.

\subsection{Comparação da Técnica Multimodal com Técnicas da Literatura}

Devido a outras técnicas multimodais encontradas na literatura apresentarem conceitos de cenas diferentes do utilizado neste trabalho, a tarefa de comparar diretamente a técnica desenvolvida com trabalhos da literatura se torna injusta. Mesmo se fosse aplicada a mesma abordagem utilizada na seção 4.4, os resultados não seriam realmente justos, uma vez que as técnicas da literatura têm objetivos diferentes. Além disso, não foram encontradas implementações das técnicas da literatura, e nem mesmo sua base de segmentação estava disponível.

Ainda assim, a título de curiosidade, os resultados da técnica multimodal desenvolvida (TM1) foram comparados com outras duas técnicas multimodais: AuViFuse (TM2) (Kyperountas et al., 2004) e a abordagem de segmentação estatística de vídeos em cena (MT3) (Parshin e Chen, 2006). A primeira é interessante pois além de usar o conceito de cenas semanticamente relacionadas, utiliza a parte visual como um modo de eliminar falsos positivos gerados pela técnica sonora. $\mathrm{Ou}$ seja, o resultado das técnicas individuais é combinado com fusão tardia, assim como neste trabalho.

Já a segunda técnica faz justamente o contrário. As características visuais e sonoras são inicialmente combinadas com fusão prévia, e o resultado é decidido analisando a combinação de ambas. Essa característica se contrapõe a estratégia de fusão tardia usada neste trabalho.

Essas duas técnicas não foram implementadas, e os resultados para comparação foram obtidos do trabalho original. Embora a definição de cena utilizada nesses trabalhos seja diferente da utilizada aqui, os resultados apresentados por este trabalho são comparáveis (em termos numéricos) a 
Tabela 4.9: Variação da técnica multimodal em relação as partes sonora e visual nos filmes da BFSSC, para as medidas precisão, abrangência e $F_{1}$.

\begin{tabular}{|c|c|c|}
\hline \multicolumn{3}{|c|}{ Filme: Uma Mente Brilhante } \\
\hline & Variação em relação ao Áudio & Variação em relação ao Vídeo \\
\hline Precisão & $-3,36$ & $-4,07$ \\
\hline Abrangência & 16,45 & 15,96 \\
\hline$F_{1}$ & 6,94 & 6,10 \\
\hline \multicolumn{3}{|c|}{ Filme: De Volta para o Futuro } \\
\hline & Variação em relação ao Áudio & Variação em relação ao Vídeo \\
\hline Precisão & 0,18 & 1,34 \\
\hline Abrangência & 29,16 & 29,16 \\
\hline$F_{1}$ & 19,51 & 19,81 \\
\hline \multicolumn{3}{|c|}{ Filme: 60 Segundos } \\
\hline & Variação em relação ao Áudio & Variação em relação ao Vídeo \\
\hline Precisão & 6,42 & $-9,7$ \\
\hline Abrangência & 36,05 & 16,32 \\
\hline$F_{1}$ & 19,83 & 1,66 \\
\hline \multicolumn{3}{|c|}{ Filme: Era do Gelo } \\
\hline & Variação em relação ao Áudio & Variação em relação ao Vídeo \\
\hline Precisão & $-1,49$ & $-4,62$ \\
\hline Abrangência & 23,81 & 23,81 \\
\hline$F_{1}$ & 7,85 & 6,22 \\
\hline \multicolumn{3}{|c|}{ Filme: Piratas do Caribe } \\
\hline & Variação em relação ao Áudio & Variação em relação ao Vídeo \\
\hline Precisão & 1,7 & $-1,33$ \\
\hline Abrangência & 32,63 & 29,66 \\
\hline$F_{1}$ & 22,95 & 19,69 \\
\hline \multicolumn{3}{|c|}{ Média dos filmes da base } \\
\hline & Variação em relação ao Áudio & Variação em relação ao Vídeo \\
\hline Precisão & 0,69 & $-3,68$ \\
\hline Abrangência & 27,62 & 22,98 \\
\hline$F_{1}$ & 15,42 & 10,70 \\
\hline
\end{tabular}

Tabela 4.10: Comparação de técnicas multimodais.

\begin{tabular}{|c|c|c|c|}
\hline Técnica & $P$ & $R$ & $F_{1}$ \\
\hline$T M_{1}$ & 66,62 & 74,70 & 70,43 \\
\hline$T M_{2}$ & 73,22 & 86,97 & 79,50 \\
\hline$T M_{3}$ & 72,40 & 67,10 & 69,65 \\
\hline
\end{tabular}


eles, sendo que o problema tratado aqui é mais complexo, uma vez que a definição de cenas aqui não impõe restrições sobre como deve ser determinada a semântica latente entre as tomadas que compõem uma cena.

Outro ponto digno de nota, é que provavelmente, ao utilizar essas técnicas com o conceito de cena apresentado neste trabalho, os resultados provavelmente serão reduzidos, já que sua definição de cena não considera segmentos semanticamente complexos. Os resultados são apresentados na Tabela 4.10, e representam a média dos resultados para cada filme testado. 



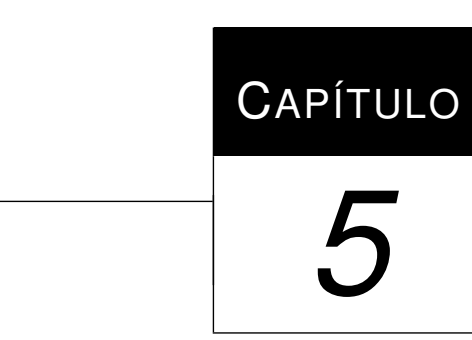

Conclusões

O objetivo deste trabalho foi o desenvolvimento de uma técnica multimodal de segmentação de vídeos capaz de detectar cenas com segmentos semanticamente complexos. O conceito de cena utilizado foi o seguinte: "Uma cena é um conjunto de tomadas subsequentes que apresentam um mesmo tema ou assunto".

A técnica multimodal desenvolvida consiste na análise individual das mídias visual e sonora de um determinado vídeo, por meio da utilização de descritores de características visuais e sonoros. Essa análise é inspirada na técnica Bag of Visual Words, que tem sido utilizada com sucesso na área de classificação de imagens, por sua capacidade de capturar a semântica latente presente nas imagens e permitir a identificação de imagens semanticamente relacionadas. Os resultados de ambas as análises são posteriormente combinados por meio da utilização de fusão tardia, ou seja, os resultados das análises individuais são combinados com o objetivo de encontrar um novo resultado, potencialmente melhor do que os resultados individuais.

O objetivo foi alcançado pois além da técnica multimodal desenvolvida utilizar duas mídias presentes nos vídeos (imagens e áudio), essas mídias se mostraram complementares, no sentido de que são capazes de fornecer informações semânticas distintas que podem ser combinadas para melhorar a identificação de cenas em comparação com a sua utilização individual, como apresentado na seção 4.6.

Com isso, a técnica se mostrou viável, uma vez que além de permitir a combinação de mídias diferentes, foi capaz de identificar cenas em segmentos semanticamente complexos, os quais se caracterizam pela presença de dois ou mais assuntos, podendo apresentar ou não diferenças visuais ou sonoras. 
É importante ressaltar que neste trabalho, a técnica foi testada somente no domínio de filmes, sendo necessário testá-la em outros domínios, como por exemplo, telejornais e programas de entrevista. No entanto, a técnica não foi baseada em nenhuma característica intrínseca do domínio analisado. Sendo assim, espera-se que possa ser aplicada de maneira eficiente em outros domínios.

Os seus resultados foram comparados com técnicas presentes na literatura, obtendo desempenho semelhante, embora essa comparação seja dificultada devido a natureza diferenciada da técnica proposta. A apresentação e discussão dos resultados foram discutidos na seção 4.7.

A técnica desenvolvida pode ser utilizada em áreas como Personalização e Adaptação, ajudando em tarefas como sumarização de conteúdo e recuperação baseada em conteúdo, que têm apresentado grande interesse da comunidade científica.

As principais contribuições desse trabalho são relatadas na seção 5.1, já as principais dificuldades estão na seção 5.2, possibilidade de trabalhos futuros encontram-se na seção 5.3.

\subsection{Resultados}

A principal contribuição do presente trabalho foi o desenvolvimento de uma técnica multimodal capaz de agrupar tomadas semanticamente relacionadas em cenas. Essa técnica foi testada em filmes de diversos gêneros, apresentando um desempenho superior à técnicas que consideram somente um modo, o que reforça a importância da multimodalidade.

Além disso, a técnica desenvolvida permite que outros descritores de vídeo e áudio sejam utilizados, dada a sua flexibilidade. Seu desempenho se mostrou próximo de outras técnicas multimodais presentes na literatura, ainda que o problema tratado aqui seja mais complexo.

Outra contribuição do presente trabalho foi trazer à tona o problema dos segmentos semanticamente complexos, os quais ainda não foram tratados na literatura. Ou seja, para o melhor do nosso conhecimento, esse trabalho é pioneiro nessa área.

Ainda como resultado deste trabalho, pode-se citar o desenvolvimento de uma base de vídeos, a BFSSC. Essa necessidade surgiu pois as bases de vídeo disponíveis não consideram esses segmentos. Essa base ficará disponível para futuros trabalhos que tratem o problema dos segmentos complexos, os quais poderão ser comparados com o presente trabalho.

É importante mencionar que esse trabalho deu origem a um artigo aceito e publicado no 19th Brazilian Symposium on Multimedia and the Web. Sua referência é apresentada a seguir:

- Bruno Lorenço Lopes and Rudinei Goularte. 2013. Multimodal late fusion bag of features applied to scene detection. In Proceedings of the 19th Brazilian symposium on Multimedia and the web (WebMedia '13). ACM, New York, NY, USA, 15-22.

DOI=10.1145/2526188.2526202 http://doi.acm.org/10.1145/2526188.2526202 
Por último, este trabalho contribuiu para avançar os conhecimentos do grupo de pesquisa do qual o autor faz parte em relação a técnicas de segmentação de vídeo. Esses conhecimentos têm sido divulgados em disciplinas de graduação e pós-graduação relacionadas a multimídia.

\subsection{Dificuldades Encontradas}

Dado o pioneirismo do presente trabalho, algumas dificuldades surgiram durante sua realização. A primeira delas foi a ausência de uma base de dados com detecção de cenas em segmentos semanticamente complexos com o conceito aqui utilizado. Como a identificação de cenas nesses segmentos é o foco desse trabalho, houve a necessidade de desenvolver uma base específica para esse fim.

Outra dificuldade foi a comparação dos resultados com técnicas da literatura, já que a definição de cenas que utilizam é diferente da utilizada aqui. Isso fez com que a comparação com essas técnicas fosse prejudicada. Além disso, como dificilmente a implementação das técnicas está disponível, não foi possível executar todas as técnicas na BFSSC, o que seria a situação ideal.

\subsection{Trabalhos Futuros}

Durante a realização deste trabalho, foram identificados alguns pontos que podem ser pesquisados em trabalhos futuros, não somente para melhorar os resultados aqui obtidos, mas também para fazer uso dos mesmos em outras atividades. Essas possibilidades de pesquisa serão discutidas a seguir.

Dada a flexibilidade da técnica proposta, a utilização de novos descritores de áudio e vídeo parece ser um caminho natural de pesquisa. Em especial, seria interessante comparar o desempenho de descritores visuais globais, tais como o GIST, em relação aos descritores locais, que foram utilizados nesse trabalho.

A determinação automática do número de palavras utilizadas no vocabulário da técnica Bag of Visual Words pode melhorar os resultados da técnica proposta, além de deixá-la mais independente das escolhas humanas.

A utilização de outras mídias presentes no vídeo, como legendas, closed-caption e OCR (Optical Character Recognition) pode ajudar a melhorar a detecção de cena, uma vez que essas mídias podem prover informações adicionais àquelas fornecidas pelas mídias visual e sonora.

Outra possibilidade é a utilização de uma estratégia mista de fusão de características. Por exemplo, uma técnica visual que combine as características visuais de modo prévio, e uma técnica sonora que combine as características de modo prévio, e posteriormente os resultados das duas técnicas sendo combinados de modo tardio. 
Também podem ser verificados os casos em que a técnica encontrou falsos positivos, procurando identificar padrões, os quais podem ser filtrados, melhorando a precisão da técnica, e consequentemente sua eficácia, medida pela $F 1$. 
Adomavicius, G.; Tuzhilin, A. Toward the next generation of recommender systems: A survey of the state-of-the-art and possible extensions. IEEE Trans. on Knowl. and Data Eng., v. 17 , n. 6, p. 734-749, 2005.

Disponível em: http://dx.doi.org/10.1109/TKDE.2005.99

Albanese, M.; D’Acierno, A.; Moscato, V.; Persia, F.; Picariello, A. A multimedia recommender system. ACM Trans. Internet Technol., v. 13, n. 1, p. 3:1-3:32, 2013.

Disponível em: http: //doi.acm.org/10.1145/2532640

Aly, M.; Welinder, P.; Munich, M.; Perona, P. Automatic discovery of image families: Global vs. local features. In: Image Processing (ICIP), 2009 16th IEEE International Conference on, 2009, p. 777-780.

Disponível em: http://dx.doi.org/10.1109/ICIP.2009.5414235

Anand, A.; Balachandran, A.; Akella, A.; Sekar, V.; Seshan, S. Enhancing video accessibility and availability using information-bound references. In: Proceedings of the Ninth ACM Conference on Emerging Networking Experiments and Technologies, CoNEXT '13, New York, NY, USA: ACM, 2013, p. 345-356 (CoNEXT'13, ).

Disponível em: http://doi.acm.org/10.1145/2535372.2535393

ATAL, B. S. Effectiveness of linear prediction characteristics of the speech wave for automatic speaker identification and verification. The Journal of the Acoustical Society of America, v. 55, n. 6, p. 1304-1312, 1974.

Disponível em: http://scitation.aip.org/getabs/servlet/ Getabs Servlet?prog=normal\&id=JASMAN0 $00055000006001304000001 \&$ idtype $=$ cvips\&gifs=yes

Atrey, P.; Hossain, M.; El Saddik, A.; Kankanhalli, M. Multimodal fusion for multimedia analysis: a survey. Multimedia Systems, v. 16, n. 6, p. 345-379, 2010.

Disponível em: http://dx.doi.org/10.1007/s00530-010-0182-0 
Atrey, P.; Maddage, M.; Kankanhalli, M. Audio based event detection for multimedia surveillance. In: Acoustics, Speech and Signal Processing, 2006. ICASSP 2006 Proceedings. 2006 IEEE International Conference on, 2006, p. V-V.

Disponível em: http://dx.doi.org/10.1109/ICASSP.2006.1661400

Avila, S. E. F. Uma Abordagem Baseada em Características de Cor para a Elaboração Automática e Avaliação Subjetiva de Resumos Estáticos de Vídeos. Dissertação de Mestrado, UFMG, 2008.

Disponível em: http://www.bibliotecadigital.ufmg.br/dspace/handle/ 1843 /RVMR-7LKLEM

AVILA, S. E. F. Extended bag-of-words formalism for image classification. Tese de Doutorado, UFMG, 2013.

Disponível em: http://www.bibliotecadigital.ufmg.br/dspace/handle/ $1843 / \mathrm{ESSA}-9 \mathrm{ACJ} 4 \mathrm{~K}$

Baber, J.; Afzulpurkar, N.; DAiley, M.; Bakhtyar, M. Shot boundary detection from videos using entropy and local descriptor. In: Digital Signal Processing (DSP), 2011 17th International Conference on, 2011, p. 1-6.

Disponível em: http://dx.doi.org/10.1109/ICDSP.2011.6004918

BACHU, R. G.; Kopparthi, S. Separation of voiced and unvoiced using zero crossing rate and energy of the speech signal. 2008.

Disponível em: http://spoken-number-recognition.googlecode.com/svn/ trunk/docs/End\%20point\%20detection/ASEE12008_0044_paper.pdf

Barroso, T. M.; Whelan, P. F. Enhancing surf feature matching using colour histograms. In: Proceedings of the 2011 Irish Machine Vision and Image Processing Conference, IMVIP '11, Washington, DC, USA: IEEE Computer Society, 2011, p. 111-112 (IMVIP '11, ).

Disponível em: http://dx.doi.org/10.1109/IMVIP.2011.31

Batista, N. C.; Lopes, A. P. B.; Albuquerque Araújo, A. Detecting buildings in historical photographs using bag-of-keypoints. In: SIBGRAPI, IEEE Computer Society, 2009, p. 276-283.

Disponível em: http://doi.ieeecomputersociety.org/10.1109/SIBGRAPI . 2009.31

Bay, H.; Ess, A.; TuytelaArs, T.; VAn Gool, L. Speeded-up robust features (surf). Comput. Vis. Image Underst., v. 110, n. 3, p. 346-359, 2008.

Disponível em: http://dx.doi.org/10.1016/j.cviu.2007.09.014

Bay, H.; TuytelaArs, T.; Gool, L. SURF: Speeded Up Robust Features. In: LeOnARdis, A.; Bischof, H.; PinZ, A., eds. Computer Vision - ECCV 2006, v. 3951 de Lecture Notes in 
Computer Science, Springer Berlin Heidelberg, p. 404-417, 2006.

Disponível em: http://dx.doi.org/10.1007/11744023_32

Botterill, T.; Mills, S.; Green, R. Speeded-up bag-of-words algorithm for robot localisation through scene recognition. In: Image and Vision Computing New Zealand, 2008. IVCNZ 2008. 23rd International Conference, 2008, p. 1-6.

Disponível em: http://dx.doi.org/10.1109/IVCNZ.2008.4762067

BREDIN, H. Segmentation of tv shows into scenes using speaker diarization and speech recognition. In: ICASSP, IEEE, 2012, p. 2377-2380.

Disponível em: http://dblp.uni-trier.de/db/conf/icassp/icassp2012. html\#Bredin12a

BreebaART, J.; MCKinney, M. Features for audio classification. 2004.

Disponível em: http://www. jeroenbreebaart.com/papers/soia/soia2004. pdf

BRENT, W. Physical and perceptual aspects of percussive timbre. Proquest, Umi Dissertation Publishing, 2011.

Disponível em: http: / /books.google.com.br/books?id=Us4vLgEACAAJ

Bugatti, P. H. Análise da influência de funções de distância para o processamento de consultas por similaridade em recuperação de imagens por conteúdo. Mestrado em ciências de computação e matemática computacional, Instituto de Ciências Matemáticas e de Computação, Universidade de São Paulo, 2008.

Disponível em: http://www.teses.usp.br/teses/disponiveis/55/55134/ tde-06052008-095020

BULlOCK, J. Libxtract: a lightweight library for audio feature extraction. In: Proceedings of the 2007 International Computer Music Conference, Copenhagen, Denmark: ICMA, 2007, p. $25-28$.

Disponível em: https://s3-eu-west-1.amazonaws.com/papers/ Libxtract-_a_lightweight_feature_extraction_library.pdf

Calic, J.; Campbell, N.; Dasiopoulou, S.; Kompatsiaris, Y. A survey on multimodal video representation for semantic retrieval. In: Computer as a Tool, 2005. EUROCON 2005.The International Conference on, 2005, p. 135-138.

Disponível em: http: //dx.doi.org/10.1109/EURCON.2005.1629877

CHA, S.-H. Comprehensive survey on distance/similarity measures between probability density functions. International Journal of Mathematical Models and Methods in Applied Sciences, v. 1, n. 4, p. 300-307, 2007.

Disponível em: http://www.gly.fsu.edu/ parker/geostats/Cha.pdf 
Chaisorn, L.; ChuA, T.-S.; LeE, C.-H. The segmentation of news video into story units. In: Multimedia and Expo, 2002. ICME' 02. Proceedings. 2002 IEEE International Conference on, 2002, p. 73-76 vol.1.

Disponível em: http://dx.doi.org/10.1109/ICME.2002.1035721

Chaisorn, L.; Chua, T.-S.; Lee, C.-H. A Multi-Modal Approach to Story Segmentation for News Video. World Wide Web, v. 6, n. 2, p. 187-208, 2003.

Disponível em: http://dx.doi.org/10.1023/A3A1023622605600

Chasanis, V.; Kalogeratos, A.; Likas, A. Movie segmentation into scenes and chapters using locally weighted bag of visual words. In: Proceedings of the ACM International Conference on Image and Video Retrieval, CIVR '09, New York, 2009, p. 35:1-35:7 (CIVR '09, ).

Disponível em: http://doi.acm.org/10.1145/1646396.1646439

Chasanis, V.; Likas, A.; Galatsanos, N. Efficient video shot summarization using an enhanced spectral clustering approach. In: Proceedings of the 18th ICANN, Berlin: SpringerVerlag, 2008, p. 847-856.

Disponível em: http://dx.doi.org/10.1007/978-3-540-87536-9_87

Chaudhuri, S.; Harvilla, M.; RAJ, B. Unsupervised learning of acoustic unit descriptors for audio content representation and classification. In: INTERSPEECH, ISCA, 2011, p. 2265-2268.

Disponível em: http://dblp.uni-trier.de/db/conf/interspeech/ interspeech2011.html\#ChaudhuriHR11

CHEN, H.; LI, C. A practical method for video scene segmentation. In: Computer Science and Information Technology (ICCSIT), 2010 3rd IEEE International Conference on, 2010, p. 153-156.

Disponível em: http://dx.doi.org/10.1109/ICCSIT.2010.5564930

Chen, L.-H.; LAI, Y.-C.; LiAO, H.-Y. M. Movie scene segmentation using background information. Pattern Recognition, v. 41, n. 3, p. 1056-1065, 2008.

Disponível em: http://dblp.uni-trier.de/db/journals/pr/pr4l.html\# ChenLL08

Chen, T.; Lu, A.; Hu, S.-M. Visual storylines: Semantic visualization of movie sequence. Computers \& Graphics, v. 36, n. 4, p. 241-249, applications of Geometry Processing, 2012.

Disponível em: http://www.sciencedirect.com/science/article/pii/ S0097849312000337

Chianese, A.; Moscato, V.; Penta, A.; Picariello, A. Scene detection using visual and audio attention. In: Proceedings of the 2008 Ambi-Sys Workshop on Ambient Media Delivery and Interactive Television, AMDIT '08, ICST, Brussels, Belgium, Belgium: ICST (Institute for 
Computer Sciences, Social-Informatics and Telecommunications Engineering), 2008, p. 4:1-4:7 (AMDIT '08, ).

Disponível em: http://dl.acm.org/citation.cfm?id=1413918.1413922

ChIU, S.-T.; Lin, G.-S.; CHANG, M.-K. An effective shot boundary detection algorithm for movies and sports. In: Innovative Computing Information and Control, 2008. ICICIC '08. 3rd International Conference on, 2008, p. 173-173.

Disponível em: http://dx.doi.org/10.1109/ICICIC.2008.135

CHOI, Y.; LEE, J. Reliability and validity of scene unit coding in the visual content analysis. Annual Meeting of the International Communication Association, p. 40, 2010.

Disponível em: http://citation.allacademic.com/meta/p404107_index. html

Choksuriwong, A.; Emile, B.; Rosenberger, C.; Laurent, H. Comparative study of global invariant descriptors for object recognition. Journal of Electronic Imaging, v. 17, n. 2, p. 023015-023015-10, 2008.

Disponível em: http://dx.doi.org/10.1117/1.2912071

Chung, M. G. Automatic video segmentation based on spatio-temporal features. Korea Telecom Journal, v. 4, n. 1, p. 4-14, 1999.

Disponível em: http://www.robots.ox.ac.uk/ nema/publications/ Apostoloff06.pdf

Colmbra, D. B. Segmentação de cenas em telejornais: uma abordagem multimodal. Mestrado em ciências de computação e matemática computacional, Instituto de Ciências Matemáticas e de Computação, Universidade de São Paulo, 2011.

Disponível em: http://www.teses.usp.br/teses/disponiveis/55/55134/ tde-28062011-103714/

Costa, A.; Humpire-Mamani, G.; Traina, A. An efficient algorithm for fractal analysis of textures. In: Graphics, Patterns and Images (SIBGRAPI), 2012 25th SIBGRAPI Conference on, 2012, p. 39-46.

Disponível em: http://dx.doi .org10.1109/SIBGRAPI.2012.15

Cour, T.; Jordan, C.; Miltsakaki, E.; TASkAR, B. Movie/script: Alignment and parsing of video and text transcription. In: Proceedings of the 10th European Conference on Computer Vision: Part IV, ECCV '08, Berlin, Heidelberg: Springer-Verlag, 2008, p. 158-171 (ECCV '08, ).

Disponível em: http://dx.doi.org/10.1007/978-3-540-88693-8_12 
DAnG, C.; KumAR, M.; RADHA, H. Key frame extraction from consumer videos using epitome. In: Image Processing (ICIP), 2012 19th IEEE International Conference on, 2012, p. 93-96. Disponível em: http://dx.doi.org/10.1109/ICIP.2012.6466803

DAVIS, J.; GOADRICH, M. The relationship between precision-recall and roc curves. In: Proceedings of the 23rd International Conference on Machine Learning, ICML '06, New York, NY, USA: ACM, 2006, p. 233-240 (ICML '06, ).

Disponível em: http://doi.acm.org/10.1145/1143844.1143874

DELEzoIDE, B. Hierarchical film segmentation using audio and visual similarity. In: in Proceedings of the IEEE International Conference on Multimedia \& Expo (ICME '05, 2005.

Disponível em: http://citeseerx.ist.psu.edu/viewdoc/summary?doi=10 . 1.1 .422 .5853

Doulamis, A.; Doulamis, N.; Kollas, S. Non-sequential video content representation using temporal variation of feature vectors. Consumer Electronics, IEEE Transactions on, v. 46, n. 3, p. 758-768, 2000.

Disponível em: http://dx.doi.org/10.1109/30.883444

Douze, M.; Jégou, H.; Sandhawalia, H.; Amsaleg, L.; Schmid, C. Evaluation of gist descriptors for web-scale image search. In: Proceedings of the ACM International Conference on Image and Video Retrieval, CIVR '09, New York, NY, USA: ACM, 2009, p. 19:1-19:8 (CIVR '09, ).

Disponível em: http://doi.acm.org/10.1145/1646396.1646421

Duda, R. O.; Hart, P. E.; Stork, D. G. Pattern classification. 2 ed. New York: Wiley, 2001.

DURAK, N. Semantic video modeling and retrieval with visual, auditory, textual sources. Tese de Doutorado, Middle East Technical University, 2004.

Disponível em: http://www.baskent.edu.tr/ ndurak/NurcanDurakThesis. $\operatorname{pdf}$

El-Gayar, M.; Soliman, H.; MEKY, N. A comparative study of image low level feature extraction algorithms. Egyptian Informatics Journal, v. 14, n. 2, p. 175-181, 2013.

Disponível em: http://www.sciencedirect.com/science/article/pii/ S1110866513000248

Evangelista, P. F.; Embrechts, M. J.; Szymanski, B. K. Some properties of the gaussian kernel for one class learning. In: Proceedings of the 17th ICANN, Berlin, Heidelberg: SpringerVerlag, 2007, p. 269-278.

Disponível em: http://dl.acm.org/citation.cfm?id=1776814.1776844 
FABro, M. D.; BÖszÖrmenYi, L. State-of-the-art and future challenges in video scene detection: A aurvey. Multimedia Systems, v. 19, n. 5, p. 427-454, 2013.

Disponível em: http://dx.doi.org/10.1007/s00530-013-0306-4

FEI-FEI, L.; PERONA, P. A bayesian hierarchical model for learning natural scene categories. In: Computer Vision and Pattern Recognition, 2005. CVPR 2005. IEEE Computer Society Conference on, 2005, p. 524-531 vol. 2.

Disponível em: http://dx.doi.org/10.1109/CVPR.2005.16

Feng, Y.; HAmerly, G. Pg-means: learning the number of clusters in data. In: ADVANCES IN NEURAL INFORMATION PROCESSING SYSTEMS 19, MIT Press, 2007, p. 393-400.

Foote, J. T. Content-based retrieval of music and audio. In: Multimedia Storage and Archiving Systems II, Proc. of SPIE, 1997, p. 138-147.

Disponível em: http://citeseerx.ist.psu.edu/viewdoc/summary?doi=10. 1.1 .16 .5235

Gerstmayr-Hillen, L.; Schluter, O.; Krzykawski, M.; Moller, R. Parsimonious loop-closure detection based on global image-descriptors of panoramic images. In: Advanced Robotics (ICAR), 2011 15th International Conference on, 2011, p. 576-581.

Disponível em: http://dx.doi.org/10.1109/ICAR.2011.6088548

Giannakopoulos, T.; Makris, A.; Kosmopoulos, D.; Perantonis, S.; Theodoridis, S. Audio-visual fusion for detecting violent scenes in videos. In: Artificial Intelligence: Theories, Models and Applications, v. 6040, p. 91-100, 2010.

Disponível em: http://dx.doi.org/10.1007/978-3-642-12842-4_13

Guimarães, S.; Couprie, M.; Leite, N.; Araujo, D. A. A method for cut detection based on visual rhythm. In: Computer Graphics and Image Processing, 2001 Proceedings of XIV Brazilian Symposium on, 2001, p. 297-304.

Disponível em: http://dx.doi.org/10.1109/SIBGRAPI.2001.963069

Hanjalic, A.; LagendiJK, R.; Biemond, J. Automated high-level movie segmentation for advanced video-retrieval systems. Circuits and Systems for Video Technology, IEEE Transactions on, v. 9, n. 4, p. 580-588, 1999a.

Disponível em: http://dx.doi.org/10.1109/76.767124

Hanjalic, A.; LagendiJK, R.; Biemond, J. Automatically Segmenting Movies into Logical Story Units. In: HuiJSmans, D.; Smeulders, A., eds. Visual Information and Information Systems, v. 1614 de Lecture Notes in Computer Science, Springer Berlin Heidelberg, p. 229236, $1999 b$.

Disponível em: http://dx.doi.org/10.1007/3-540-48762-X_29 
HASAN, M. R.; JAMIL, M. Speaker identification using mel frequency cepstral coefficients. In: 3rd International Conference on Electrical \& Computer Engineer, n. 2004, ICECE, 2004, p. $565-568$.

Disponível em: http://dx.doi.org/10.1109/CONIELECOMP .2012.6189918

Hauptmann, A. G.; Chen, M.; Christel, M. G.; Lin, W.-H.; 0003, J. Y. A hybrid approach to improving semantic extraction of news video. In: ICSC, IEEE Computer Society, 2007, p. 79-86.

Disponível em: http://dblp.uni-trier.de/db/conf/semco/icsc2007. html\#HauptmannCCLY0 7

HoI, S.; LYU, M. A multimodal and multilevel ranking framework for content-based video retrieval. In: Acoustics, Speech and Signal Processing, 2007. ICASSP 2007. IEEE International Conference on, 2007, p. IV-1225-IV-1228.

Disponível em: http://dx.doi.org/10.1109/ICASSP.2007.367297

Hu, W.; Xie, N.; Li, L.; Zeng, X.; Maybank, S. A survey on visual content-based video indexing and retrieval. Systems, Man, and Cybernetics, Part C: Applications and Reviews, IEEE Transactions on, v. 41, n. 6, p. 797-819, 2011.

Disponível em: http://dx.doi.org/10.1109/TSMCC.2011.2109710

HuA, X.-S.; ZHANG, D.; LI, M.; ZHANG, H.-J. Performance evaluation protocol for video scene detection algorithms. In: Workshop on Multimedia Information Retrieval, in conjunction with 10th ACM Multimedia, 2002.

Disponível em: http://citeseerx.ist.psu.edu/viewdoc/summary?doi=10. 1.1 .59 .3245

HuAng, C.-R.; Chen, C.-S. Video scene detection by link-constrained affinity-propagation. In: Circuits and Systems, 2009. ISCAS 2009. IEEE International Symposium on, 2009, p. 28342837.

Disponível em: http://dx.doi.org/10.1109/ISCAS.2009.5118392

HUANG, J.; LIU, Z.; WANG, Y. Integration of audio and visual information for content-based video segmentation. In: Image Processing, 1998. ICIP 98. Proceedings. 1998 International Conference on, 1998, p. 526-529 vol.3.

Disponível em: http://dx.doi.org/10.1109/ICIP.1998.727252

IONESCU, R.; POPESCU, M.; GROZEA, C. Local learning to improve bag of visual words model for facial expression recognition. In: Workshop on Challenges in Representation Learning, ICML (2013), 2013.

Disponível em: http://deeplearning.net/wp-content/uploads/2013/03/ VV-NN-LL-WREPL.pdf 
Ishtiaq, M.; JafFar, A.; Hussain, A.; Basit, A.; MirzA, A. Wavelet based video segmentation using self organizing map neural network. In: Computer Science and Information Technology - Spring Conference, 2009. IACSITSC '09. International Association of, 2009, p. $122-125$.

Disponível em: http://dx.doi.org/10.1109/IACSIT-SC.2009.114

Iurgel, U.; Meermeier, R.; Eickeler, S.; Rigoll, G. New approaches to audio-visual segmentation of tv news for automatic topic retrieval. In: Acoustics, Speech, and Signal Processing, 2001. Proceedings. (ICASSP '01). 2001 IEEE International Conference on, 2001, p. 1397-1400 vol.3.

Disponível em: http://dx.doi.org/10.1109/ICASSP.2001.941190

Jensen, J. H.; Christensen, M. G.; Ellis, D. P. W.; Jensen, S. H. Quantitative analysis of a common audio similarity measure. IEEE Transactions on Audio, Speech and Language Processing, v. 17, n. 4, p. 693-703, 2009.

Disponível em: http://dblp.uni-trier.de/db/journals/taslp/taslp17. html\# JensenCEJ0 9

Jiang, C.; Coenen, F.; Sanderson, R.; Zito, M. Text Classification using Graph Miningbased Feature Extraction. In: Bramer, M.; Ellis, R.; Petridis, M., eds. Research and Development in Intelligent Systems XXVI, Springer London, p. 21-34, 2010.

Disponível em: http://dx.doi.org/10.1007/978-1-84882-983-1_2

JIANG, X.; SUn, T.; LIU, J.; ZHANG, W.; CHAO, J. An video shot segmentation scheme based on adaptive binary searching and sift. In: Proceedings of the 7th International Conference on Advanced Intelligent Computing Theories and Applications: With Aspects of Artificial Intelligence, ICIC'11, Berlin, Heidelberg: Springer-Verlag, 2012, p. 650-655 (ICIC'11, ).

Disponível em: http://dx.doi.org/10.1007/978-3-642-25944-9_85

Kabary, I. A.; Giangreco, I.; Schuldt, H.; Matulic, F.; Norrie, M. Quest: Towards a multi-modal cbir framework combining query-by-example, query-by-sketch, and text search. In: Proceedings of the 2013 IEEE International Symposium on Multimedia, ISM '13, Washington, DC, USA: IEEE Computer Society, 2013, p. 433-438 (ISM '13, ).

Disponível em: http://dx.doi.org/10.1109/ISM.2013.84

Ke, Y.; SuKThAnKAR, R. Pca-sift: a more distinctive representation for local image descriptors. In: Computer Vision and Pattern Recognition, 2004. CVPR 2004. Proceedings of the 2004 IEEE Computer Society Conference on, 2004, p. II-506-II-513 Vol.2.

Disponível em: http://dx.doi.org/10.1109/CVPR.2004.1315206

KIM, J.-R.; SUH, S.; SUlL, S. Fast scene change detection for personal video recorder. Consumer Electronics, IEEE Transactions on, v. 49, n. 3, p. 683-688, 2003.

Disponível em: http://dx.doi.org/10.1109/TCE.2003.1233802 
Kinnunen, T.; Kamarainen, J.-K.; Lensu, L.; KÄlviäInen, H. Bag-of-features codebook generation by self-organisation. In: Proceedings of the 7th International Workshop on Advances in Self-Organizing Maps, WSOM '09, Berlin, Heidelberg: Springer-Verlag, 2009, p. 124-132 (WSOM'09, ).

Disponível em: http://dx.doi.org/10.1007/978-3-642-02397-2_15

Klaser, A.; MarszaleK, M.; LAPtev, I.; Schmid, C. Will person detection help bag-offeatures action recognition? Research Report RR-7373, INRIA, 2010a.

Disponível em: http://hal.inria.fr/inria-00514828

Klaser, A.; Marszalek, M.; Schmid, C.; Zisserman, A. Human focused action localization in video. In: Proceedings of the 11th European Conference on Trends and Topics in Computer Vision - Volume Part I, ECCV'10, Berlin, Heidelberg: Springer-Verlag, 2010b, p. 219-233 (ECCV'10, ).

Disponível em: http://dx.doi.org/10.1007/978-3-642-35749-7_17

Kumar, N.; Rai, P.; Pulla, C.; JaWAhar, C. V. Video scene segmentation with a semantic similarity. In: PRASAD, B.; LiNGRAS, P.; NEVATIA, R., eds. IICAI, IICAI, 2011, p. 970-981. Disponível em: http://dblp.uni-trier.de/db/conf/iicai/iicai2011. html \#KumarRP J11

Kundu, M.; Mondal, J. A novel technique for automatic abrupt shot transition detection. In: Communications, Devices and Intelligent Systems (CODIS), 2012 International Conference on, 2012, p. 628-631.

Disponível em: http://dx.doi.org/10.1109/CODIS.2012.6422281

Kyperountas, M.; Cernekova, Z.; Kotropoulos, C.; Gavrielides, M. Scene change detection using audiovisual clues. In: Proceedings of the NOBIM 2004, 2004.

Disponível em: http://www.researchgate.net/publication/ 200710048_Scene_change_detection_using_audiovisual_clues/file/ d912f50587b3ebe1ca.pdf

LAM, C.; LEE, M. Video segmentation using color difference histogram. In: IP, H.; SMEULDERS, A., eds. Multimedia Information Analysis and Retrieval, v. 1464 de Lecture Notes in Computer Science, Springer Berlin Heidelberg, p. 159-174, 1998.

Disponível em: http://dx.doi.org/10.1007/BFb0016496

Laptev, I.; MarszaŁeK, M.; Schmid, C.; Rozenfeld, B. Learning realistic human actions from movies. In: Conference on Computer Vision \& Pattern Recognition, 2008.

Disponível em: http: / / lear.inrialpes.fr/pubs/2008/LMSR0 8

Lazebnik, S.; Schmid, C.; Ponce, J. Beyond bags of features: Spatial pyramid matching for recognizing natural scene categories. In: Computer Vision and Pattern Recognition, 2006 
IEEE Computer Society Conference on, 2006, p. 2169-2178.

Disponível em: http://dx.doi.org/10.1109/CVPR.2006.68

Lebanon, G.; MAO, Y.; Dillon, J. The locally weighted bag of words framework for document representation. J. Mach. Learn. Res., v. 8, p. 2405-2441, 2007.

Disponível em: http://dl.acm.org/citation.cfm?id=1314498.1314576

Lehane, B.; Murphy, N. Dialogue scene detection in movies using low and mid-level visual features. In: proceedings of International Workshop on Image, Video, and Audio Retrieval, 2001, p. 20010427-0010.

Disponível em: http://citeseerx.ist.psu.edu/viewdoc/summary?doi=10. 1.1 .78 .4904

LejseK, H.; Ásmundsson, F. H.; Jónsson, B. T.; Amsaleg, L. Scalability of local image descriptors: A comparative study. In: Proceedings of the 14th Annual ACM International Conference on Multimedia, MULTIMEDIA '06, New York, NY, USA: ACM, 2006, p. 589-598 (MULTIMEDIA '06, ).

Disponível em: http://doi.acm.org/10.1145/1180639.1180760

LiAng, C.; Zhang, Y.; Cheng, J.; Xu, C.; Lu, H. A novel role-based movie scene segmentation method. In: Proceedings of the 10th Pacific Rim Conference on Multimedia: Advances in Multimedia Information Processing, PCM '09, Berlin, Heidelberg: Springer-Verlag, 2009, p. 917-922 (PCM'09, ).

Disponível em: http://dx.doi.org/10.1007/978-3-642-10467-1_82

Lisin, D.; Mattar, M.; Blaschko, M.; Learned-Miller, E.; Benfield, M. Combining local and global image features for object class recognition. In: Computer Vision and Pattern Recognition - Workshops, 2005. CVPR Workshops. IEEE Computer Society Conference on, 2005, p. 47-47.

Disponível em: http://dx.doi.org/10.1109/CVPR.2005.433

LIU, C.; WANG, D.; ZHU, J.; ZHANG, B. Learning a contextual multi-thread model for movie/tv scene segmentation. Multimedia, IEEE Transactions on, v. 15, n. 4, p. 884-897, 2013.

Disponível em: http://dx.doi.org/10.1109/TMM.2013.2238522

LIU, H.-Y.; HE, T. Using multimodal analysis for story segmentation of news video. In: Artificial Intelligence, 2009. JCAI '09. International Joint Conference on, 2009, p. 124-127. Disponível em: http://dx.doi.org/10.1109/JCAI.2009.20

LIU, J.; LI, M.; LIU, Q.; LU, H.; MA, S. Image annotation via graph learning. Pattern Recogn., v. 42, n. 2, p. 218-228, 2009.

Disponível em: http://dx.doi.org/10.1016/j.patcog.2008.04.012 
LiU, Y.; ZhaO, W.-L.; NGO, C.-W.; XU, C.-S.; Lu, H.-Q. Coherent bag-of audio words model for efficient large-scale video copy detection. In: Proceedings of the ACM International CIVR, ACM, 2010, p. 89-96.

Disponível em: http://doi.acm.org/10.1145/1816041.1816057

LiU, Z.; HuAng, Q. Classification of audio events in broadcast news. In: Multimedia Signal Processing, 1998 IEEE Second Workshop on, 1998, p. 364-369.

Disponível em: http://dx.doi.org/10.1109/MMSP.1998.738963

LIU, Z.; WANG, Y.; CHEN, T. Audio feature extraction and analysis for scene segmentation and classification. VLSI Signal Processing, v. 20, n. 1-2, p. 61-79, 1998.

Disponível em: http://dblp.uni-trier.de/db/journals/vlsisp/ vlsisp20.html\#LiuWC98

LogAn, B. Mel frequency cepstral coefficients for music modeling. In: Proceedings of 1st International Conference on Music Information Retrieval, Plymouth, MA, 2000.

Disponível em: http://citeseerx.ist.psu.edu/viewdoc/summary?doi=10. 1.1 .11 .9216

Lopes, B. L.; Goularte, R. Multimodal late fusion bag of features applied to scene detection. In: Proceedings of the 19th Brazilian Symposium on Multimedia and the Web, WebMedia '13, New York, NY, USA: ACM, 2013, p. 15-22 (WebMedia '13, ).

Disponível em: http://doi.acm.org/10.1145/2526188.2526202

LOWE, D. Object recognition from local scale-invariant features. In: Computer Vision, 1999. The Proceedings of the Seventh IEEE International Conference on, 1999, p. 1150-1157 vol.2. Disponível em: http://dx.doi.org/10.1109/ICCV.1999.790410

Lowe, D. G. Distinctive image features from scale-invariant keypoints. Int. J. Comput. Vision, v. 60, n. 2, p. 91-110, 2004.

Disponível em: http://dx.doi.org/10.1023/B:VISI.0000029664.99615.94

López-Garcia, F.; FdeZ-Vidal, X. R.; Pardo, X. M.; Dosil, R. Object recognition, cáp. Scene Recognition through Visual Attention and Image Features: A Comparison between SIFT and SURF Approaches. BedfordSt. Martin's series in rhetoric and composition InTech, 2011. Disponível em: http://dx.doi.ogr/10.5772/14343

Magalhães, J.; Pereira, F. Using mpeg standards for multimedia customization. Sig. Proc.: Image Comm., v. 19, n. 5, p. 437-456, 2004.

Disponível em: http://dblp.uni-trier.de/db/journals/spic/spic19. html \#MagalhaesP 04 
Manjunath, B.; Wu, P.; Newsam, S.; Shin, H. D. A texture descriptor for browsing and similarity retrieval. Journal of Signal Processing: Image Communication, v. 16, p. 33-43, 2000. Disponível em: http://citeseerx.ist.psu.edu/viewdoc/summary?doi=10. 1.1 .33 .3025

Mansano, A.; Matsuoka, J. A.; Afonso, L. C. S.; PAPa, J. P.; Faria, F.; S Torres, R. Improving image classification through descriptor combination. In: Graphics, Patterns and Images (SIBGRAPI), 2012 25th SIBGRAPI Conference on, 2012, p. 324-329.

Disponível em: http: / / dx.doi.org/10.1109/SIBGRAPI.2012.52

Manzato, M. G. Uma arquitetura de personalização de conteúdo baseada em anotações do usuário. Doutorado em ciências de computação e matemática computacional, Instituto de Ciências Matemáticas e de Computação, Universidade de São Paulo, 2011.

Disponível em: http://www.teses.usp.br/teses/disponiveis/55/55134/ tde-11042011-160836/

Matas, J.; Chum, O.; Urban, M.; PAjdla, T. Robust wide baseline stereo from maximally stable extremal regions. In: Proceedings of the British Machine Vision Conference, BMVA Press, doi:10.5244/C.16.36, 2002, p. 36.1-36.10.

Disponível em: http://dx.doi.org/doi:10.5244/C.16.36

MCLACHLAN, G.; KHAN, N. On a resampling approach for tests on the number of clusters with mixture model-based clustering of tissue samples. Journal of Multivariate Analysis, v. 90, n. 1, p. 90-105, special Issue on Multivariate Methods in Genomic Data Analysis, 2004.

Disponível em: http://www.sciencedirect.com/science/article/pii/ S0047259X04000284

Messing, D.; BEEK, P.; ERRICO, J. The mpeg-7 colour structure descriptor: image description using colour and local spatial information. In: Image Processing, 2001. Proceedings. 2001 International Conference on, 2001, p. 670-673 vol.1.

Disponível em: http://dx.doi.org/10.1109/ICIP.2001.959134

MikolajCZyK, K.; SChMid, C. A performance evaluation of local descriptors. Pattern Analysis and Machine Intelligence, IEEE Transactions on, v. 27, n. 10, p. 1615-1630, 2005.

Disponível em: http://dx.doi.org/10.1109/TPAMI.2005.188

Mitrovic, D.; Zeppelzauer, M.; Breiteneder, C. Features for content-based audio retrieval. Advances in Computers, v. 78, p. 71-150, 2010.

Disponível em: http://dblp.uni-trier.de/db/journals/ac/ac78.html\# MitroviczB10

Mittalkod, P. S.; SRinivasan, G. Shot boundary detection algorithms and techniques: A review. Journal of Computer Systems Engineering, v. 02, n. 02, p. 115-121, 2011. 
Disponível em: http://www.technicaljournals.org/JPDF/ RJCSE-02-IJ-02-33.pdf

Mohanta, P.; Saha, S. Semantic grouping of shots in a video using modified k-means clustering. In: Advances in Pattern Recognition, 2009. ICAPR '09. Seventh International Conference on, 2009, p. 125-128.

Disponível em: http://dx.doi.org/10.1109/ICAPR.2009.35

Mohanta, P. P.; SAha, S. K.; Chanda, B. A heuristic algorithm for video scene detection using shot cluster sequence analysis. In: Proceedings of the Seventh Indian Conference on Computer Vision, Graphics and Image Processing, ICVGIP '10, New York, NY, USA: ACM, 2010, p. 464-471 (ICVGIP' '10, ).

Disponível em: http://doi.acm.org/10.1145/1924559.1924621

Money, A. G.; Agius, H. Video summarisation: A conceptual framework and survey of the state of the art. Journal of Visual Communication and Image Representation, v. 19, n. 2, p. 121-143, 2008.

Disponível em: http://www.sciencedirect.com/science/article/pii/ S1047320307000247

Montoya-Zegarra, J.; Leite, N.; S.Torres, R. Rotation-invariant and scale-invariant steerable pyramid decomposition for texture image retrieval. In: Computer Graphics and Image Processing, 2007. SIBGRAPI 2007. XX Brazilian Symposium on, 2007, p. 121-128.

Disponível em: http://dx.doi.org/10.1109/SIBGRAPI .2007.42

Moreno, P.; Bernardino, A.; SAntos-Victor, J. Improving the sift descriptor with smooth derivative filters. Pattern Recogn. Lett., v. 30, n. 1, p. 18-26, 2009.

Disponível em: http://dx.doi.org/10.1016/j.patrec.2008.08.012

Mortensen, E.; Deng, H.; Shapiro, L. A sift descriptor with global context. In: Computer Vision and Pattern Recognition, 2005. CVPR 2005. IEEE Computer Society Conference on, 2005, p. 184-190 vol. 1.

Disponível em: http://dx.doi.org/10.1109/CVPR.2005.45

Muda, L.; Begam, M.; Elamvazuthi, I. Voice recognition algorithms using mel frequency cepstral coefficient $(\mathrm{mfcc})$ and dynamic time warping (dtw) techniques. CoRR, v. abs/1003.4083, 2010.

Disponível em: http: / / arxiv.org/abs/1003.4083

MurRay, J. Multimodal composition: A critical sourcebook, cáp. Composing Multimodality. Bedford/St. Martin's series in rhetoric and composition Bedford/St. Martin's, 2013. Disponível em: http://books.google.com.br/books?id=nhiZMwEACAAJ 
Murthy, O. R.; Hanmandlu, M. Article:a study on the effect of outliers in devanagari character recognition. International Journal of Computer Applications, v. 32, n. 10, p. 10-17, published by Foundation of Computer Science, New York, USA, 2011.

Disponível em: http://dx.doi.org/10.5120/3937-5183

NG, A. Y.; Jordan, M. I.; WeISS, Y. On spectral clustering: Analysis and an algorithm. In: Advances in Neural Information Processing Systems, 2001, p. 849-856.

Disponível em: http://citeseerx.ist.psu.edu/viewdoc/summary?doi=10. 1.1 .19 .8100

Ngo, C.-W.; Pong, T.-C.; CHIN, R. Detection of gradual transitions through temporal slice analysis. In: Computer Vision and Pattern Recognition, 1999. IEEE Computer Society Conference on., 1999, p. -41 Vol. 1.

Disponível em: http://dx.doi.org/10.1109/CVPR.1999.786914

NGO, C.-W.; Pong, T.-C.; ZHANG, H. Recent advances in content-based video analysis. Int. J. Image Graphics, v. 1, n. 3, p. 445-468, 2001.

Disponível em: http://dblp.uni-trier.de/db/journals/ijig/ijigl. html\#NgoP Z01

Ngo, C.-W.; Pong, T.-C.; ZhAng, H.-J.; ChIN, R. Motion-based video representation for scene change detection. In: Pattern Recognition, 2000. Proceedings. 15th International Conference on, 2000, p. 827-830 vol.1.

Disponível em: http://dx.doi.org/10.1109/ICPR.2000.905535

Nigay, L.; CoutAZ, J. A design space for multimodal systems: Concurrent processing and data fusion. ACM Press, 1993, p. 172-178.

Disponível em: http://dx.doi.org/10.1145/169059.169143

Ogawa, A.; TAKahashi, T.; IDE, I.; Murase, H. Cross-Lingual Retrieval of Identical News Events by Near-Duplicate Video Segment Detection. In: SAтон, S.; NACK, F.; Eтон, M., eds. Advances in Multimedia Modeling, v. 4903 de Lecture Notes in Computer Science, Springer Berlin Heidelberg, p. 287-296, 2008.

Disponível em: http://dx.doi.org/10.1007/978-3-540-77409-9_27

Oliva, A.; Torralba, A. Modeling the shape of the scene: A holistic representation of the spatial envelope. International Journal of Computer Vision, v. 42, p. 145-175, 2001.

Disponível em: http://dx.doi.org/10.1023/A:1011139631724

Oviatt, S. Ten myths of multimodal interaction. Commun. ACM, v. 42, n. 11, p. 74-81, 1999. Disponível em: http://doi.acm.org/10.1145/319382.319398 
PARShin, V.; Chen, L. Semantic-based visual information retrieval, cáp. Statistical AudioVisual Data Fusion for Video Scene Segmentation Idea Group Inc., p. 68-88, 2006.

Disponível em: http://liris.cnrs.fr/publis/?id=4208

PATIL, S.; TAlBAR, S. Content based image retrieval using various distance metrics. In: Proceedings of the Second International Conference on Data Engineering and Management, ICDEM'10, Berlin, Heidelberg: Springer-Verlag, 2012, p. 154-161 (ICDEM'10, ).

Disponível em: http://dx.doi.org/10.1007/978-3-642-27872-3_23

PEETERs, G. A large set of audio features for sound description (similarity and classification) in the CUIDADO project. Relatório Técnico, Icram, 2004.

Disponível em: http://recherche.ircam.fr/anasyn/peeters/ARTICLES/ Peeters_2003_cuidadoaudiofeatures.pdf

Penatti, O. A.; Valle, E.; S. Torres, R. Comparative study of global color and texture descriptors for web image retrieval. Journal of Visual Communication and Image Representation, v. 23, n. 2, p. $359-380,2012$.

Disponível em: http://www.sciencedirect.com/science/article/pii/ S1047320311001465

Pfeiffer, S.; Fischer, S.; EFfelsberg, W. Automatic audio content analysis. In: Aigrain, P.; Hall, W.; Little, T. D. C.; JR., V. M. B., eds. ACM Multimedia, ACM Press, 1996, p. 21-30.

Disponível em: http://dblp.uni-trier.de/db/conf/mm/mm96.html\# Pfeifferfe96

Pimentel Filho, C. A. F.; SAntos, C. A. S.; Buck, T. A. Integração de métodos baseados em diferença de quadros para sumarização do conteúdo de vídeos. In: Companion Proceedings of the XIV Brazilian Symposium on Multimedia and the Web, WebMedia '08, New York, NY, USA: ACM, 2008, p. 85-88 (WebMedia '08, ).

Disponível em: http://doi.acm.org/10.1145/1809980.1810003

QI, Y.; Hauptmann, A.; LIU, T. Supervised classification for video shot segmentation. In: Multimedia and Expo, 2003. ICME '03. Proceedings. 2003 International Conference on, 2003, p. II-689-92 vol.2.

Disponível em: http://dx.doi.org/10.1109/ICME.2003.1221710

RaO, K.; NAndi, D.; Koolagudi, S. Film segmentation and indexing using autoassociative neural networks. International Journal of Speech Technology, v. 17, n. 1, p. 65-74, 2014.

Disponível em: http://dx.doi.org/10.1007/s10772-013-9206-4

RaO, M.; RAO, B.; A.Govardhan Content based image retrieval system based on dominant color and texture features. International Journal of Computer Applications, v. 18, n. 6, p. 40- 
46, published by Foundation of Computer Science, 2011.

Disponível em: http://dx.doi.org/10.5120/2285-2961

Raoui, Y.; Bouyakhf, E. H.; Devy, M.; Regragui, F. Global and local image descriptors for content based image retrieval and object recognition. Appl. Math. Sci., Ruse, v. 5, n. 41-44, p. 2109-2136, 2011.

Disponível em: http://www.m-hikari.com/ams/ams-2011/ams-41-44-2011/ raouiAMS 41-44-2011-1.pdf

RAsheED, Z.; SHAh, M. Scene detection in hollywood movies and tv shows. In: Computer Vision and Pattern Recognition, 2003. Proceedings. 2003 IEEE Computer Society Conference on, 2003, p. II-343-8 vol.2.

Disponível em: http://dx.doi.org/10.1109/CVPR.2003.1211489

RASheEd, Z.; SHAh, M. Detection and representation of scenes in videos. Multimedia, IEEE Transactions on, v. 7, n. 6, p. 1097-1105, 2005.

Disponível em: http://dx.doi.org/10.1109/TMM.2005.858392

Renals, S.; Abberley, D.; Kirby, D.; Robinson, T. Indexing and retrieval of broadcast news. Speech Communication, v. 32, p. 5-20, 2000.

Disponível em: http://citeseerx.ist.psu.edu/viewdoc/summary?doi=10. 1.1 .46 .8639

Rijsbergen, C. J. V. Information retrieval. 2nd ed. Newton, MA, USA: ButterworthHeinemann, 1979.

Rodriguez, M.; Ahmed, J.; Shah, M. Action mach a spatio-temporal maximum average correlation height filter for action recognition. In: Computer Vision and Pattern Recognition, 2008. CVPR 2008. IEEE Conference on, 2008, p. 1-8.

Disponível em: http://dx.doi.org/10.1109/CVPR.2008.4587727

RothACKER, L. Learning Bag-of-Features Representations for Handwriting Recognition. Tese de Doutorado, Technische Universität Dortmund, 2011.

Disponível em: http://patrec.cs.tu-dortmund.de/pubs/theses/da_ rothacker.pdf

Rothacker, L.; VAJdA, S.; FInK, G. A. Bag-of-features representations for offline handwriting recognition applied to arabic script. In: Proceedings of the 2012 International Conference on Frontiers in Handwriting Recognition, ICFHR '12, Washington, DC, USA: IEEE Computer Society, 2012, p. 149-154 (ICFHR'12, ).

Disponível em: http://dx.doi.org/10.1109/ICFHR.2012.185 
Rui, Y.; Huang, T.; Mehrotra, S. Exploring video structure beyond the shots. In: Multimedia Computing and Systems, 1998. Proceedings. IEEE International Conference on, 1998, p. 237-240.

Disponível em: http://dx.doi.org/10.1109/MMCS.1998.693648

Rui, Y.; Huang, T. S.; Mehrotra, S. Constructing table-of-content for videos. Multimedia Systems, v. 7, n. 5, p. 359-368, 1999.

Disponível em: http://dx.doi.org/10.1007/s005300050138

SAKARYA, U.; TElatAR, Z. Graph partition based scene boundary detection. In: Image and Signal Processing and Analysis, 2007. ISPA 2007. 5th International Symposium on, 2007, p. 544-549.

Disponível em: http://dx.doi.org/10.1109/ISPA.2007.4383752

SANDEEP, K.; RAJAGOPALAN, A. N. Human face detection in cluttered color images using skin color, edge information. In: ICVGIP'02, 2002, p. -1-1.

Disponível em: http://citeseerx.ist.psu.edu/viewdoc/summary?doi=10. 1.1 .12 .730

Scaiano, M.; InkPen, D.; Laganière, R.; Reinhartz, A. Automatic Text Segmentation for Movie Subtitles. In: FARZINDAR, A.; KEŠELJ, V., eds. Advances in Artificial Intelligence, v. 6085 de Lecture Notes in Computer Science, Springer Berlin Heidelberg, p. 295-298, 2010. Disponível em: http://dx.doi.org/10.1007/978-3-642-13059-5_32

Schabetsberger, C.; Schedl, M. Personalized music recommendation in a mobile environment. In: Proceedings of International Conference on Advances in Mobile Computing \&\#38; Multimedia, MoMM '13, New York, NY, USA: ACM, 2013, p. 63:63-63:67 (MoMM '13, ).

Disponível em: http://doi.acm.org/10.1145/2536853.2536946

Schuldt, C.; LAPTEv, I.; CAPUto, B. Recognizing human actions: a local svm approach. In: Pattern Recognition, 2004. ICPR 2004. Proceedings of the 17th International Conference on, 2004, p. 32-36 Vol.3.

Disponível em: http://dx.doi.org/10.1109/ICPR.2004.1334462

Schwartz, W. R.; Siqueira, F. R.; PEDRini, H. Evaluation of feature descriptors for texture classification. Journal of Electronic Imaging, v. 21, n. 2, p. 023016-1, 2012.

Disponível em: http://spie.org/Publications/Journal/10.1117/1.JEI. 21.2 .023016

Sidiropoulos, P.; Mezaris, V.; Kompatsiaris, I.; Meinedo, H.; Bugalho, M.; TranCOSO, I. Temporal video segmentation to scenes using high-level audiovisual features. IEEE Trans. Cir. and Sys. for Video Technol., v. 21, n. 8, p. 1163-1177, 2011.

Disponível em: http://dx.doi.org/10.1109/TCSVT.2011.2138830 
Sinha, A.; ShuKLA, K. A study of distance metrics in histogram based image retrieval. INTERNATIONAL JOURNAL OF COMPUTERS AND TECHNOLOGY, v. 4, n. 3, 2013.

Disponível em: http://cirworld.com/index.php/ijct/article/view/1181

SIVIC, J.; ZISSERMAN, A. Video google: a text retrieval approach to object matching in videos. In: Computer Vision, 2003. Proceedings. Ninth IEEE International Conference on, 2003, p. 1470-1477 vol.2.

Disponível em: http://dx.doi.org/10.1109/ICCV.2003.1238663

Sivic, J.; Zisserman, A. Video Google: Efficient Visual Search of Videos. In: Ponce, J.; Hebert, M.; Schmid, C.; Zisserman, A., eds. Toward Category-Level Object Recognition, v. 4170 de Lecture Notes in Computer Science, Springer Berlin Heidelberg, p. 127-144, 2006. Disponível em: http://dx.doi.org/10.1007/11957959_7

Smeulders, A. W. M.; Worring, M.; SAntini, S.; Gupta, A.; Jain, R. Content-based image retrieval at the end of the early years. Pattern Analysis and Machine Intelligence, IEEE Transactions on, v. 22, n. 12, p. 1349-1380, 2000.

Disponível em: http://dx.doi.org/10.1109/34.895972

SMith, G.; MURASE, H.; KASHINO, K. Quick audio retrieval using active search. In: Acoustics, Speech and Signal Processing, 1998. Proceedings of the 1998 IEEE International Conference on, 1998, p. 3777-3780 vol.6.

Disponível em: http://dx.doi.org/10.1109/ICASSP.1998.679706

SnOEK, C. G. M.; Worring, M. A review on multimodal video indexing. In: Multimedia and Expo, 2002. ICME '02. Proceedings. 2002 IEEE International Conference on, 2002, p. 21-24 vol.2.

Disponível em: http://dx.doi.org/10.1109/ICME.2002.1035364

Snoek, C. G. M.; Worring, M. Multimodal video indexing: A review of the state-of-the-art. Multimedia Tools Appl., v. 25, n. 1, p. 5-35, 2005.

Disponível em: http://dx.doi.org/10.1023/B:MTAP. $0000046380.27575 . a 5$

Snoek, C. G. M.; Worring, M.; Gemert, J. V.; Geusebroek, J.; Koelma, D.; Nguyen, G. P.; RooiJ, O. D.; SEInstra, F. Mediamill: Exploring news video archives based on learned semantics. In: In ACM Multimedia, 2005, p. 225-226.

Disponível em: http://citeseerx.ist.psu.edu/viewdoc/summary?doi=10. 1.1 .75 .132

Struyf, A.; Hubert, M.; Rousseeuw, P. Clustering in an object-oriented environment. Journal of Statistical Software, v. 1, n. 4, p. 1-30, 1997.

Disponível em: http://www. jstatsoft.org/v01/i 04 
Sugar, C. A.; Gareth; James, M. Finding the number of clusters in a data set: An information theoretic approach. Journal of the American Statistical Association, v. 98, p. 750-763, 2003.

Disponível em: http://citeseerx.ist.psu.edu/viewdoc/summary?doi=10 . 1.1 .107 .9895

Sundaram, H.; Chang, S.-F. Video scene segmentation using video and audio features. In: Multimedia and Expo, 2000. ICME 2000. 2000 IEEE International Conference on, 2000, p. 1145-1148 vol.2.

Disponível em: http://dx.doi.org/10.1109/ICME.2000.871563

Swain, M. J.; Ballard, D. H. Color indexing. Int. J. Comput. Vision, v. 7, n. 1, p. 11-32, 1991.

Disponível em: http://dx.doi.org/10.1007/BF00130487

TAIB, R.; RUIZ, N. Integrating Semantics into Multimodal Interaction Patterns. In: POPESCUBelis, A.; Renals, S.; Bourlard, H., eds. Machine Learning for Multimodal Interaction, v. 4892 de Lecture Notes in Computer Science, Springer Berlin Heidelberg, p. 96-107, 2008.

Disponível em: http://dx.doi.org/10.1007/978-3-540-78155-4_9

TAPU, R.; ZAHARIA, T. Video segmentation and structuring for indexing applications. International Journal of Multimedia Data Engineering and Management (IJMDEM), v. 2, n. 4, p. 38-58, 2012.

Disponível em: http://dx.doi.org/10.4018/jmdem.2011100103

ThaKAR, V.; HADiA, S. An adaptive novel feature based approach for automatic video shot boundary detection. In: Intelligent Systems and Signal Processing (ISSP), 2013 International Conference on, 2013, p. 145-149.

Disponível em: http://dx.doi.org/10.1109/ISSP.2013.6526891

TOFFLER, A. Future shock. Random House, 1970.

Disponível em: http://books.google.com.br/books?id=-BhHAAAAMAAJ

Trojahn, T. H.; Goularte, R. Video scene segmentation by improved visual shot coherence. In: Proceedings of the 19th Brazilian Symposium on Multimedia and the Web, WebMedia '13, New York: ACM, 2013, p. 23-30 (WebMedia'13, ).

Disponível em: http://doi.acm.org/10.1145/2526188.2526206

Truong, B. T.; Venkatesh, S. Video abstraction: A systematic review and classification. ACM Trans. Multimedia Comput. Commun. Appl., v. 3, n. 1, 2007.

Disponível em: http://doi.acm.org/10.1145/1198302.1198305 
Tsiartas, A.; Ghosh, P. K.; Georgiou, P. G.; Narayanan, S. Bilingual audio-subtitle extraction using automatic segmentation of movie audio. In: ICASSP, IEEE, 2011, p. 56245627.

Disponível em: http://dblp.uni-trier.de/db/conf/icassp/icassp2011. html\#TsiartasGGN11

Ullman, S.; Vidal-Naquet, M.; SAli, E. Visual features of intermediate complexity and their use in classification. Nature neuroscience, v. 5, n. 7, p. 682-687, 2002.

Disponível em: http://dx.doi.org/10.1038/nn870

VAlle, E.; CORD, M. Advanced techniques in cbir: Local descriptors, visual dictionaries and bags of features. In: Computer Graphics and Image Processing (SIBGRAPI TUTORIALS), 2009 Tutorials of the XXII Brazilian Symposium on, 2009, p. 72-78.

Disponível em: http://dx.doi.org/10.1109/SIBGRAPI-Tutorials.2009.14

Velivelli, A.; Ngo, C.-W.; Huang, T. Detection of Documentary Scene Changes by AudioVisual Fusion. In: BAKKer, E.; Lew, M.; HuAng, T.; Sebe, N.; Zhou, X., eds. Image and Video Retrieval, v. 2728 de Lecture Notes in Computer Science, Springer Berlin Heidelberg, p. 227-238, 2003.

Disponível em: http://dx.doi.org/10.1007/3-540-45113-7_23

Vogel, J.; Schiele, B. Natural Scene Retrieval Based on a Semantic Modeling Step. In: ENSer, P.; Kompatsiaris, Y.; O’Connor, N.; Smeaton, A.; Smeulders, A., eds. Image and Video Retrieval, v. 3115 de Lecture Notes in Computer Science, Springer Berlin Heidelberg, p. 207-215, 2004.

Disponível em: http://dx.doi.org/10.1007/978-3-540-27814-6_27

WANG, C.; Jing, F.; ZHANG, L.; ZHANG, H.-J. Scalable search-based image annotation. Multimedia Systems, v. 14, n. 4, p. 205-220, 2008.

Disponível em: http://dx.doi.org/10.1007/s00530-008-0128-y

Wang, H.; Klaser, A.; Schmid, C.; LiU, C.-L. Action recognition by dense trajectories. In: Computer Vision and Pattern Recognition (CVPR), 2011 IEEE Conference on, 2011, p. 31693176.

Disponível em: http://dx.doi.org/10.1109/CVPR.2011.5995407

WANG, J.; DUAN, L.; LU, H.; JIN, J.; XU, C. A mid-level scene change representation via audiovisual alignment. In: Acoustics, Speech and Signal Processing, 2006. ICASSP 2006 Proceedings. 2006 IEEE International Conference on, 2006, p. II-II.

Disponível em: http://dx.doi.org/10.1109/ICASSP.2006.1660366 
Wilson, D. R.; Martinez, T. R. Improved heterogeneous distance functions. J. Artif. Int. Res., v. 6, n. 1, p. 1-34, 1997.

Disponível em: http://dl.acm.org/citation.cfm?id=1622767.1622768

Wu, Z.; Ke, Q.; Sun, J.; SHuM, H. A multi-sample, multi-tree approach to bag-of-words image representation for image retrieval. 2009, p. 1992-1999.

Disponível em: http://research.microsoft.com/apps/pubs/default. aspx?id=102131

Xu, C.; Cheng, J.; 0007, Y. Z.; Zhang, Y.; Lu, H. Sports video analysis: Semantics extraction, editorial content creation and adaptation. Journal of Multimedia, v. 4, n. 2, p. 69-79, 2009.

Disponível em: http://dblp.uni-trier.de/db/journals/jmm2/jmm4.html\# XuCZZL09

YAng, F.; Lu, H.; Chen, Y. Bag of features tracking. In: Pattern Recognition (ICPR), 2010 20th International Conference on, 2010, p. 153-156.

Disponível em: http://dx.doi.org/10.1109/ICPR.2010.46

YAnG, M.-H.; Ahuja, N. Detecting human faces in color images. In: Image Processing, 1998. ICIP 98. Proceedings. 1998 International Conference on, 1998, p. 127-130 vol.1.

Disponível em: http://dx.doi.org/10.1109/ICIP.1998.723442

Yeung, M.; YeO, B.-L.; LIU, B. Segmentation of Video by Clustering and Graph Analysis. Computer Vision and Image Understanding, v. 71, n. 1, p. 94-109, 1998.

Disponível em: http://www.sciencedirect.com/science/article/pii/ S1077314297906287

YeunG, M. M.; YeO, B.-L. Video content characterization and compaction for digital library applications. In: Storage and Retrieval for Image and Video Databases (SPIE), 1997, p. 45-58.

Disponível em: http://dblp.uni-trier.de/db/conf/spieSR/spieSR97. html\#YeungY97

YU, C.; ZhANG, H.; SMith, L. B. Learning through Multimodal Interaction. 2006.

Disponível em: http://citeseerx.ist.psu.edu/viewdoc/summary?doi=10 . 1.1 .130 .5404

Yu, H.; Su, B.; Lu, H.; Xue, X. News Video Retrieval by Learning Multimodal Semantic Information. In: QIU, G.; Leung, C.; XUE, X.; LAURINI, R., eds. Advances in Visual Information Systems, v. 4781 de Lecture Notes in Computer Science, Springer Berlin Heidelberg, p. 403-414, 2007.

Disponível em: http://dx.doi.org/10.1007/978-3-540-76414-4_39 
Zagoris, K.; Chatzichristofis, S. A.; Arampatzis, A. Bag-of-visual-words vs global image descriptors on two-stage multimodal retrieval. In: Proceedings of the 34th International ACM SIGIR Conference on Research and Development in Information Retrieval, SIGIR '11, New York, NY, USA: ACM, 2011, p. 1251-1252 (SIGIR'11, ).

Disponível em: http://doi.acm.org/10.1145/2009916.2010144

ZhaI, Y.; SHAh, M. Automatic segmentation of home videos. In: Multimedia and Expo, 2005. ICME 2005. IEEE International Conference on, 2005a, p. 9-12.

Disponível em: http://dx.doi.org/10.1109/ICME.2005.1521347

ZHAI, Y.; SHAH, M. A general framework for temporal video scene segmentation. In: Computer Vision, 2005. ICCV 2005. Tenth IEEE International Conference on, 2005b, p. 1111-1116 Vol. 2.

Disponível em: http://dx.doi.org/10.1109/ICCV.2005.6

ZhaI, Y.; Shah, M. Video scene segmentation using markov chain monte carlo. Multimedia, IEEE Transactions on, v. 8, n. 4, p. 686-697, 2006.

Disponível em: http://dx.doi.org/10.1109/TMM.2006.876299

ZHANG, D.; LU, G. A comparative study of curvature scale space and fourier descriptors for shape-based image retrieval abstract. Journal of Visual Communication and Image Representation, v. 14, n. 1, p. 39-57, 2003.

Disponível em: http://citeseerx.ist.psu.edu/viewdoc/summary?doi=10. 1.1 .68 .9381

ZHANG, T.; KUO, C.-C. J. Audio content analysis for online audiovisual data segmentation and classification. IEEE Transactions on Speech and Audio Processing, v. 9, n. 4, p. 441-457, 2001.

Disponível em: http://dblp.uni-trier.de/db/journals/taslp/taslp9. html\#ZhangK01

ZHANG, Y.; JIN, R.; ZHOU, Z.-H. Understanding bag-of-words model: a statistical framework. International Journal of Machine Learning and Cybernetics, v. 1, n. 1-4, p. 43-52, 2010.

Disponível em: http://dx.doi.org/10.1007/s13042-010-0001-0 